\title{
Baseline Fracture Toughness and CGR Testing of Alloys X-750 and XM-19 (EPRI Phase I)
}

\author{
J. H. Jackson \\ S. P. Teysseyre
}

February 2012

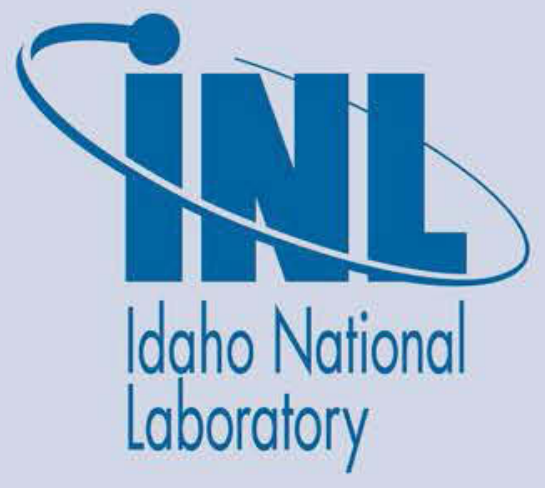

The INL is a U.S. Department of Energy National Laboratory operated by Battelle Energy Alliance 


\section{DISCLAIMER}

This information was prepared as an account of work sponsored by an agency of the U.S. Government. Neither the U.S. Government nor any agency thereof, nor any of their employees, makes any warranty, expressed or implied, or assumes any legal liability or responsibility for the accuracy, completeness, or usefulness, of any information, apparatus, product, or process disclosed, or represents that its use would not infringe privately owned rights. References herein to any specific commercial product, process, or service by trade name, trade mark, manufacturer, or otherwise, does not necessarily constitute or imply its endorsement, recommendation, or favoring by the U.S. Government or any agency thereof. The views and opinions of authors expressed herein do not necessarily state or reflect those of the U.S. Government or any agency thereof. 


\title{
Baseline Fracture Toughness and CGR Testing of Alloys X-750 and XM-19 (EPRI Phase I)
}

\author{
J. H. Jackson \\ S. P. Teysseyre
}

February 2012

\begin{abstract}
Idaho National Laboratory
ATR-NSUF

Idaho Falls, Idaho 83415
\end{abstract}

http://www.inl.gov

Prepared for the

U.S. Department of Energy

Office of Nuclear Energy

Under DOE Idaho Operations Office

Contract DE-AC07-05ID14517 


\section{ATR-NSUF}

\section{Baseline Fracture Toughness and CGR testing of alloys X-750 and XM-19 (Phase I)}

INL/EXT-11-24173

Revision 0

February 2012

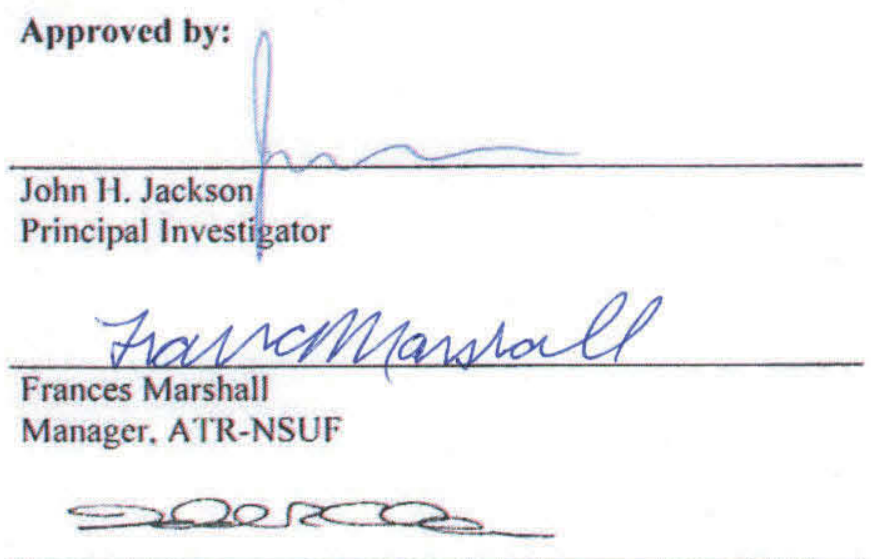

Todd Allen

$\frac{28 \text { Feb } 20 / 2}{\text { Date }}$

ATR-NSUF director

$\frac{2-28-2012}{\text { Date }}$
$\frac{27 \text { Feb 2012 }}{\text { Date }}$




\section{SUMMARY}

The Advanced Test Reactor National Scientific User Facility (ATR NSUF) based at INL and Electric Power Research Institute (EPRI) formed an agreement to test representative alloys used as reactor structural materials as a pilot program toward establishing guidelines for future ATR NSUF research programs. This report contains results from the portion of this program established as Phase I (of three phases) that entails baseline fracture toughness, stress corrosion cracking (SCC), and tensile testing of selected materials. The intent of this Phase I research program is to determine baseline properties for the materials of interest prior to irradiation, and to ensure comparability between laboratories using similar testing techniques, prior to applying these techniques to the same materials after having been irradiated at the Advanced Test Reactor (ATR). The materials chosen for this research are the nickel based super alloy X-750, and nitrogen strengthened austenitic stainless steel XM-19. A spare core shroud upper support bracket of alloy X-750 was purchased by EPRI from Southern Co. and a section of XM-19 plate was purchased by EPRI from GE-Hitachi. These materials were sectioned at GE Global Research and provided to INL. 


\section{CONTENTS}

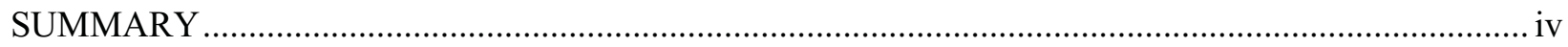

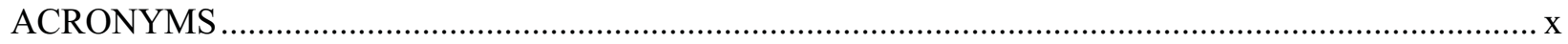

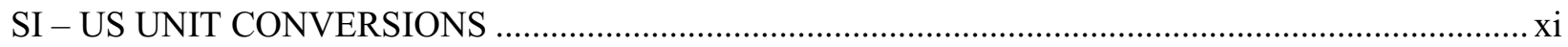

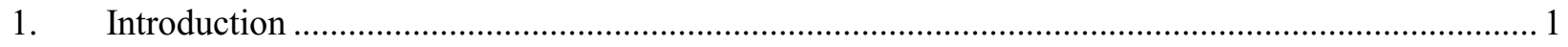

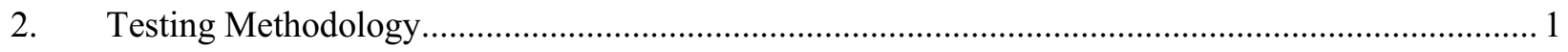

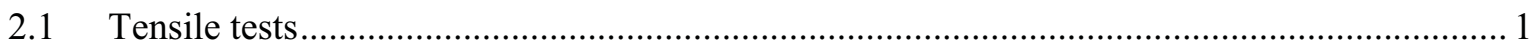

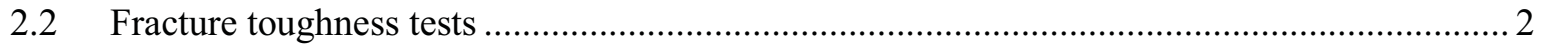

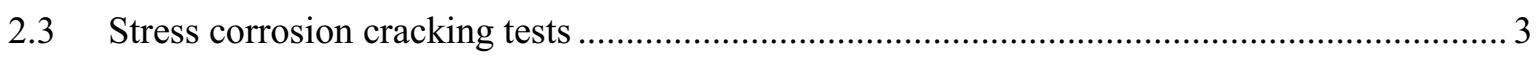

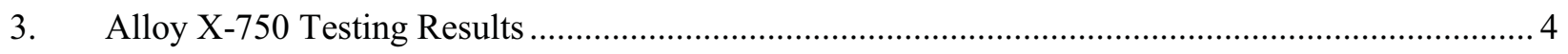

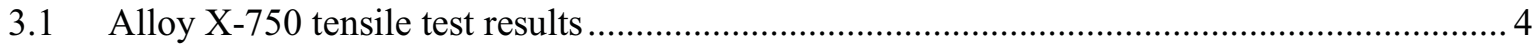

3.2 Alloy X-750 fracture toughness test results ................................................................ 5

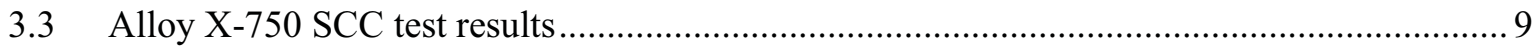

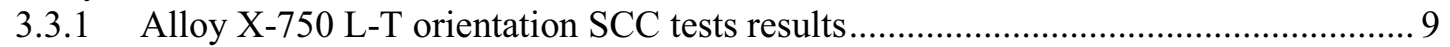

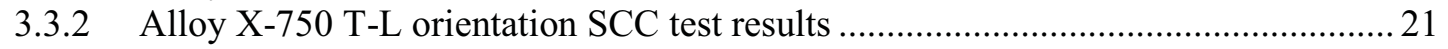

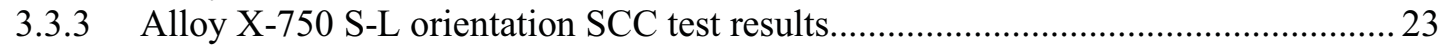

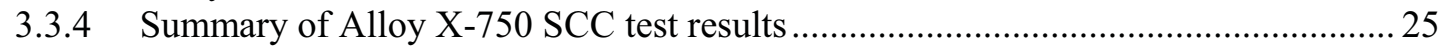

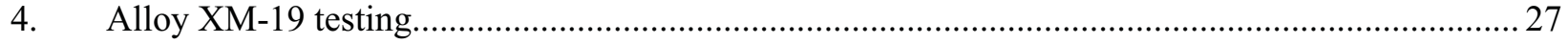

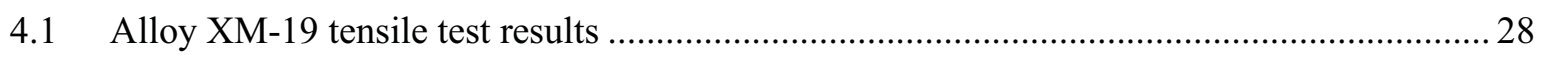

$4.2 \quad 19.3 \%$ CW Alloy XM-19 Fracture toughness test results .................................................. 29

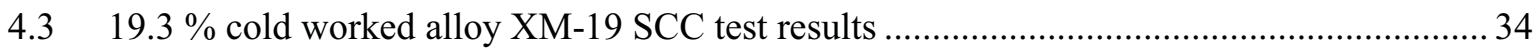

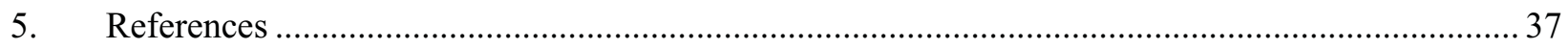

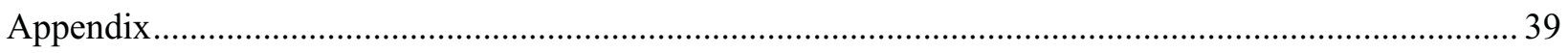

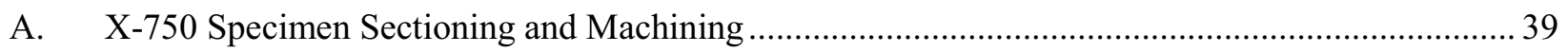

Specimens to be Used for Alloy X-750 Baseline SCC and IASCC Testing ............................. 40

Specimens to be Used for Baseline Alloy X-750 Fracture Toughness Testing ....................... 43

Specimens to be Used for Alloy X-750 Baseline and Irradiated Tensile Testing.................... 44

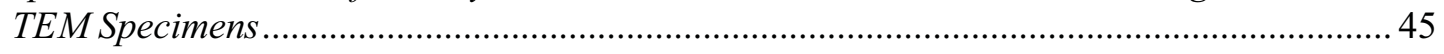

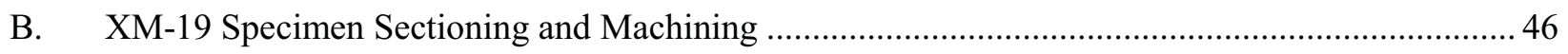

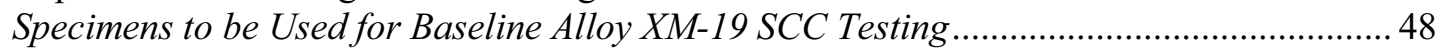

Specimens to be Used for Baseline Alloy XM-19 Fracture Toughness Testing ...................... 49

Specimens to be Used for Baseline Alloy XM-19 Tensile Testing......................................... 50

Specimens to be used for alloy XM-19 IASCC testing and irradiated fracture

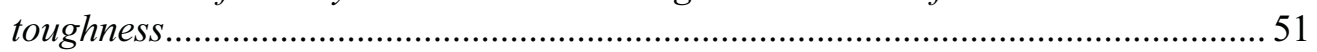

Specimens to be Used for Irradiated Alloy XM-19 Tensile Testing ....................................... 52

Alloy XM-19 TEM Specimens for Irradiation ……............................................................. 53

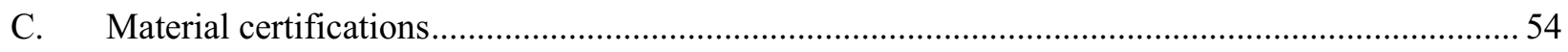




\section{FIGURES}

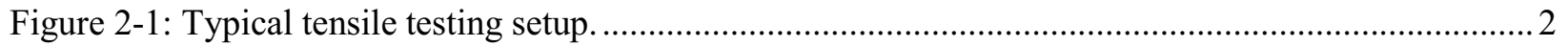

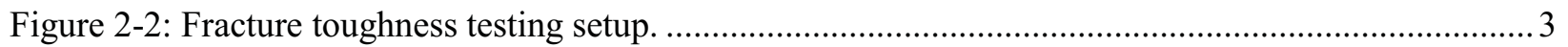

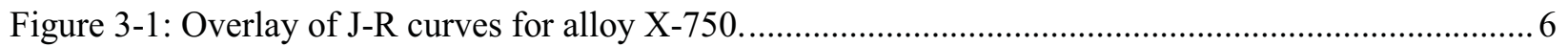

Figure 3-2: Specimen 10A0002 AA $01 \mathrm{~J}-\mathrm{R}$ curve and fracture surface with annotations.......................... 7

Figure 3-3: Specimen 10A0002 AA 02 J-R curve and fracture surface. ................................................. 8

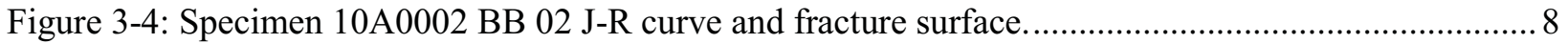

Figure 3-5: SEM fractograph of fracture surface for specimen 10A0002 AA 01 .................................. 9

Figure 3-6: Crack length vs. time obtained with sample ID 10A0002 A01 during cycling in water. ........ 10

Figure 3-7: Crack length vs. time obtained with sample ID 10A0002 A01 in $288^{\circ} \mathrm{C}$ water with sulfate addition.

Figure 3-8: Crack length vs. time obtained with sample ID 10A0002 A01 in $288{ }^{\circ} \mathrm{C}$ water without sulfate addition.

Figure 3-9: Digital fractograph of alloy X750 tested in LT orientation, sample ID 10A0002 A01. The clear area at bottom right part of the fracture surface (near the scale bar) is silver paint used during a Focused Ion Beam milling procedure for additional analysis.

Figure 3-10: Side micrograph of the specimen ID after failure. The top picture shows the crack branching out of plane. The bottom picture illustrates the other side of the specimen showing that, on this side, the crack is aligned with the side grove. The markers A,B,C indicate, respectively, the beginning of initial machined notch, the beginning of the crack and the end of the crack

Figure 3-11: SEM fractograph of sample ID 10A0002 A01. Yellow lines indicate boundaries of the IG cracking region.

Figure 3-12: SEM fractograph of crack path followed in sample ID 10A0002 A01

Figure 3-13: SEM fractographies of secondary cracks in sample ID 10A0002 A01

Figure 3-14: Crack length vs. time obtained with sample ID $10 \mathrm{~A} 0002 \mathrm{~B} 01$ in $288^{\circ} \mathrm{C}$ water with sulfate addition.

Figure 3-15: Length vs. time obtained with sample ID $10 \mathrm{~A} 0002 \mathrm{~B} 01$ in $288^{\circ} \mathrm{C}$ water without sulfate addition.

Figure 3-16: Crack length vs. time obtained at the end of the test with sample ID 10A0002 B01 in $288^{\circ} \mathrm{C}$ water.

Figure 3-17: Digital fractograph of sample ID 10A0002 B01

Figure 3-18: Crack length vs. time obtained with alloy X750 in TL orientation in $288^{\circ} \mathrm{C}$ water with $10 \mathrm{ppb}$ sulfate addition.

Figure 3-19: Crack length vs. time obtained with alloy X750 in TL orientation in $288{ }^{\circ} \mathrm{C}$ water with $0 \mathrm{ppb}$ sulfate addition.

Figure 3-20: Digital fractograph of alloy X750 tested in TL orientation. 
Figure 3-21: SEM fractograph of alloy X750 tested in TL orientation. Yellow lines indicate boundaries of IG crack area.

Figure 3-22: CGR response for alloy X-750 S-L orientation SCC test. ...................................................24

Figure 3-23: Digital fractograph of alloy X-750 tested in SL orientation. .............................................24

Figure 3-24: Closeup of area of interest for CGR response of alloy X-750 S-L orientation SCC

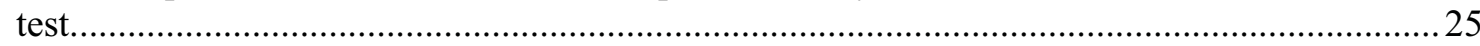

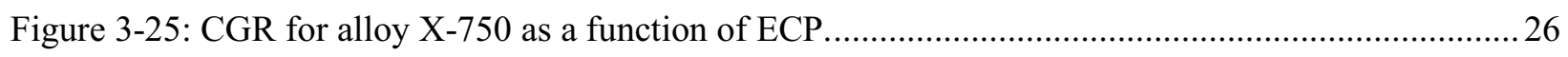

Figure 3-26: Effect of sulfate addition on CGR of alloy X-750 under NWC conditions. .........................26

Figure 3-27: Effect of HWC on CGR compared to NWC for alloy X-750 ............................................ 27

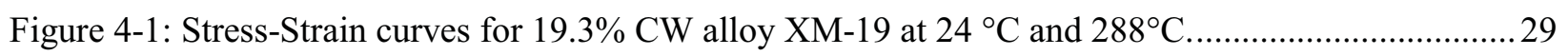

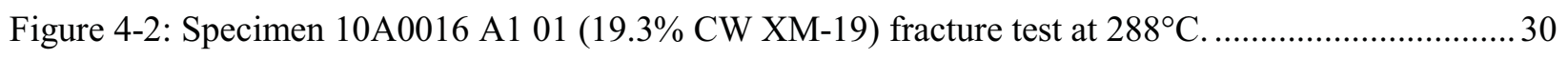

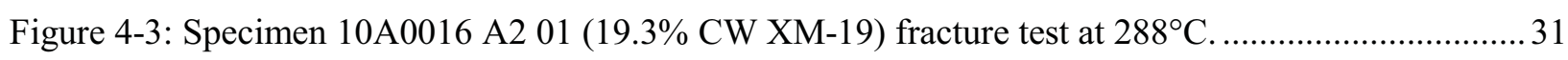

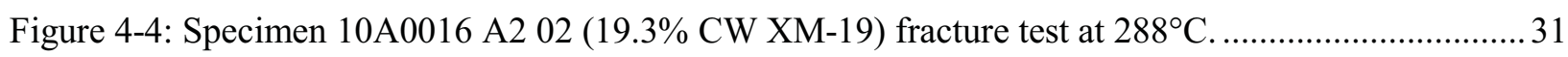

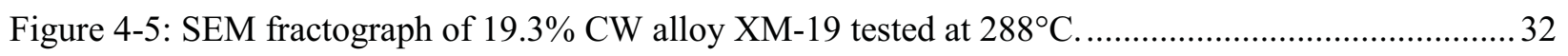

Figure 4-6: SEM image of Mn rich inclusion in fracture surface of 19.3\% CW XM-19 ........................ 33

Figure 4-7: EDAX scan results from Mn rich inclusion in fracture surface of 19.3\% CW XM-19..........33

Figure 4-8: Crack length vs. time obtained with sample ID 10A0016 C3 01, first part of the test. ........... 35

Figure 4-9: Crack length vs. time obtained with sample ID 10A0016 C3 01, last part of the test. ............35

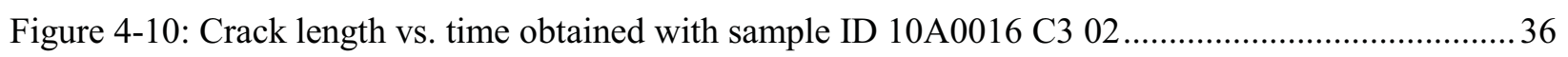

Figure 4-11: Fracture surface of sample ID 10A0016 C3 01, obtained by optical microscopy. .................36

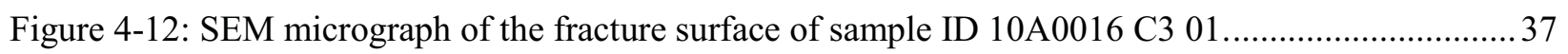

Figure 4-13: Detail of SEM micrograph of the fracture surface of sample ID 10A0016 C3 01................37

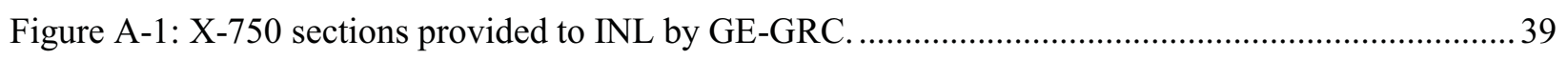

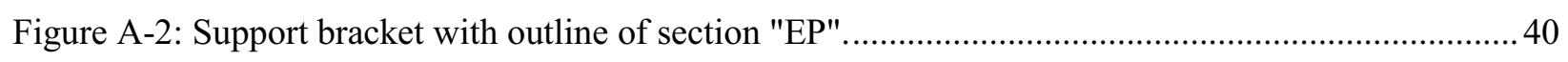

Figure A-3: 0.4T compact tension (CT) specimen used for SCC and IASCC tests (units are inches)

Figure A-4: Initial L-T and T-L orientation specimens and location of S-L specimens.......................... 41

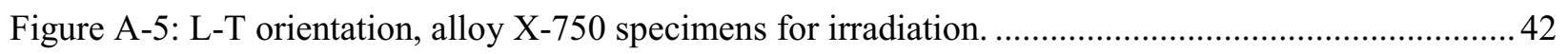

Figure A-6: Machining location for specimens 10A0002 B13 and B14 in T-L orientation...................... 43

Figure A-7: Location of alloy X-750 fracture toughness specimens in section "EP".............................. 44

Figure A-8: Sketch of dogbone tensile specimens (units are inches). .................................................... 44

Figure A-9: Location of tensile blanks in alloy X-750 section "EP"......................................................45

Figure A-10: Fabrication of TEM specimens from CT specimen. ....................................................... 46

Figure B-1: Location of INL XM-19 section from within overall plate. ................................................47

Figure B-2: Rough sectioning of mill annealed alloy XM-19 ............................................................. 47

Figure B-3: Rough sectioning of 19.3\% cold worked alloy XM-19 .................................................... 48 
Figure B-4: Baseline SCC specimen extraction from 19.3\% cold worked alloy XM-19 ....................... 49

Figure B-5: Baseline fracture toughness specimen extraction for 19.3\% cold worked alloy XM-19 ........50

Figure B-6: Baseline tensile specimen extraction for 19.3\% cold worked alloy XM-19 .......................51

Figure B-7: Layout and location of alloy XM-19 IASCC and irradiated fracture specimens ...................52

Figure B-8: Extraction of alloy XM-19 tensile blanks for irradiation ..................................................53

Figure C-1: Page 1 of alloy X-750 material certification report (excluding fax cover)........................... 54

Figure C-2: Page 2 of alloy X-750 material certification report............................................................ 55

Figure C-3: Page 3 of alloy X-750 material certification report............................................................56

Figure C-4: Page 4 of alloy X-750 material certification report.............................................................5

Figure C-5: Alloy XM-19 material certification report. ....................................................................... 58 


\section{TABLES}

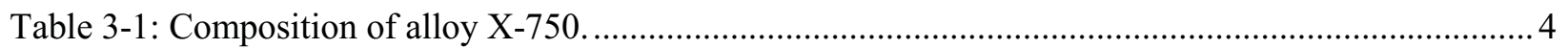

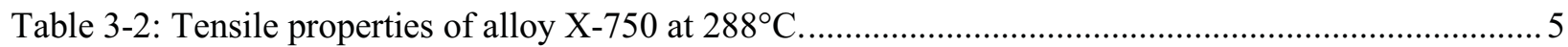

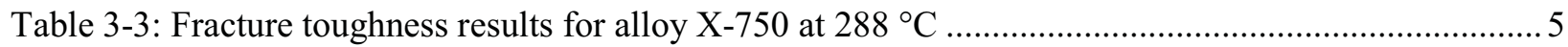

Table 3-4: Summary of alloy X-750 SCC tests with measured errors....................................................27

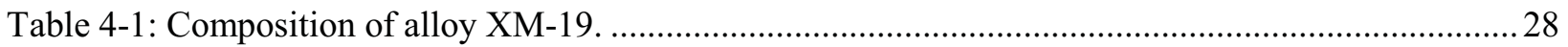

Table 4-2: Tensile properties of $19.3 \% \mathrm{CW}$ alloy XM-19 at $24{ }^{\circ} \mathrm{C}$ and $288^{\circ} \mathrm{C}$. ...................................28

Table 4-3: Fracture toughness results for $19.3 \% \mathrm{CW}$ alloy XM-19 at $288^{\circ} \mathrm{C}$. .......................................30 


\section{ACRONYMS}

$\begin{array}{ll}\text { ASTM } & \text { American Society for Testing of Materials } \\ \text { BWR } & \text { Boiling Water Reactor } \\ \text { CGR } & \text { Crack Growth Rate } \\ \text { COD } & \text { Crack Opening Displacement } \\ \text { CT } & \text { Compact Tension } \\ \text { CW } & \text { Cold Worked } \\ \text { DCPD } & \text { Direct Current Potential Drop } \\ \text { ECP } & \text { Electrochemical Corrosion Potential } \\ \text { EPRI } & \text { Electric Power Research Institute } \\ \text { HWC } & \text { Hydrogen Water Chemistry } \\ \text { INL } & \text { Idaho National Laboratory } \\ \text { LLD } & \text { Load Line Displacement } \\ \text { MTS } & \text { Material Test Systems } \\ \text { NWC } & \text { Normal Water Chemistry } \\ \text { PIE } & \text { Post Irradiation Examination } \\ \text { SCC } & \text { Stress Corrosion Cracking } \\ \text { SEM } & \text { Scanning Electron Microscope } \\ \text { TEM } & \text { Transmission Electron Microscope }\end{array}$




\section{SI - US UNIT CONVERSIONS}

$1 \mathrm{~mm}=0.0394$ in

$1 \mathrm{MPa}=0.145 \mathrm{ksi}$

$1 \mathrm{~kJ} / \mathrm{m}^{2}(\mathrm{kPa}-\mathrm{m})=5.71$ psi-in

$1 \mathrm{MPa} \sqrt{\mathrm{m}}=0.910 \mathrm{ksi} \sqrt{ }$ in

$288^{\circ} \mathrm{C}=550^{\circ} \mathrm{F}$ 


\section{Baseline Fracture Toughness and CGR testing of alloys X-750 and XM-19 (Phase I)}

\section{Introduction}

This report describes the testing and analysis that was performed during phase one of a three phase pilot project, a collaboration between the Electric Power Research Institute (EPRI) and INL to characterize the response of alloys X-750 and XM-19 to irradiation at three different exposure levels of interest. The objectives of this initial phase were to obtain materials of interest; machine specimens for tensile, fracture toughness, and stress corrosion cracking (SCC) testing; and characterize the baseline (unirradiated) material properties including tensile strength and fracture toughness at boiling water reactor (BWR) temperatures of $288^{\circ} \mathrm{C}$ as well as SCC crack growth rates (CGR) under BWR hydrogen water chemistry (HWC) and normal water chemistry (NWC) conditions. These material property characterizations serve two purposes; to ensure validity of INL data in comparison to well established laboratories and to provide baseline materials properties for eventual comparison to material properties that are expected to change as a function of their exposure to neutron fluences. Careful attention was paid to location of extraction of all specimens from the alloy sections that were provided by EPRI in order to ensure a valid comparison between un-irradiated and irradiated material properties at the end of the pilot project.

Detailed descriptions of testing methodology and equipment used for testing are included. The report also contains descriptions of analysis techniques used and results of testing. The appendix discusses the specimen naming conventions and identifies locations and orientations of all specimens that were prepared for this phase one testing as well as the specimens to be used for irradiation and post irradiation examination (PIE) studies.

\section{Testing Methodology}

\section{$2.1 \quad$ Tensile tests}

Tensile tests for this project were completed using an Instron model 8501, $100 \mathrm{KN}$ capacity servohydraulic test system outfitted with a $50 \mathrm{KN}$ load cell, an MTS model 652.02A, dual zone, high temperature box furnace, and an Epsilon Technologies model 3448, high temperature extensometer with a $25.4 \mathrm{~mm}$ gage length and 50\% strain capacity. A typical test setup is shown in Figure 2-1. All tests were performed according to the American Society for Testing of Materials (ASTM) Standard E8 "Standard Test Methods for Tension Testing of Metallic Materials" (1). The nominal gage cross section was 6.35 $\mathrm{mm}$ and the gage length was $25.4 \mathrm{~mm}$. The specimen geometry is shown in the appendix of this report. All specimens were tested in displacement control at a displacement rate of $0.279 \mathrm{~mm} / \mathrm{min}$ (strain rate $0.11 \%-S^{-1}$ ) at a nominal temperature within the gage section of $288^{\circ} \mathrm{C}$. Two, type $\mathrm{K}$ thermocouples were attached via spot weld to the specimen shoulder just outside the gage section on both ends in order to monitor gage section temperature. Force and extensometer readings were recorded using Labview ${ }^{\circledR}$ software. 


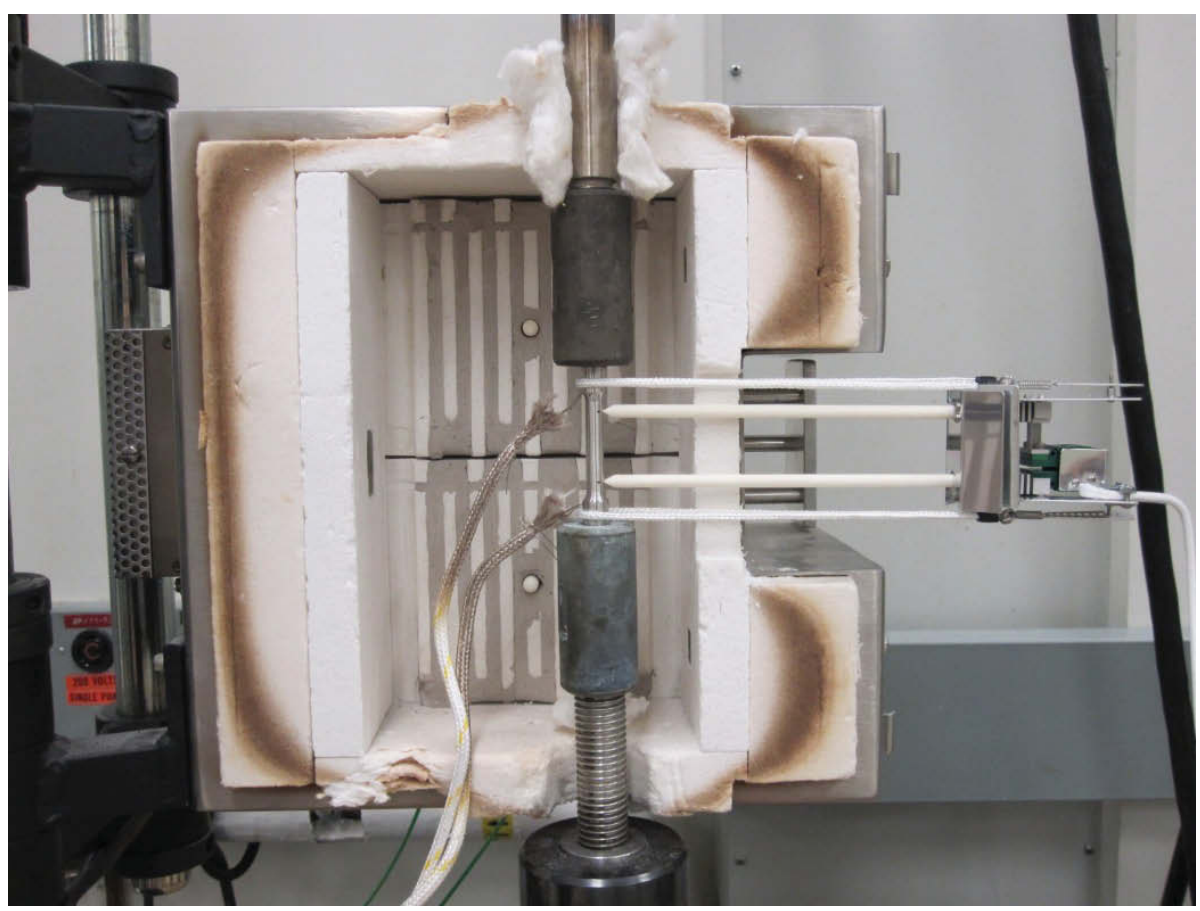

Figure 2-1: Typical tensile testing setup.

\subsection{Fracture toughness tests}

Fracture toughness tests for this project were all performed using an Instron model 8501, $100 \mathrm{KN}$ capacity servo-hydraulic test system outfitted with a $50 \mathrm{KN}$ load cell, a Material Test Systems (MTS) model 652.02A, dual zone, high temperature box furnace, an FTA, reversing DC Potential Drop (DCPD) system, and an MTS, model 652.65E-03, high temperature crack opening displacement (COD) gage. All data was collected using LabView ${ }^{\circledR}$ data acquisition software. The crack tip temperature was monitored during testing for all specimens by welding a type $\mathrm{K}$ thermocouple spanning the crack path and approximately $5 \mathrm{~mm}$ ahead of the notch tip as well as an additional type $\mathrm{K}$ thermocouple welded to the top edge of the specimen to ensure negligible temperature gradient within the specimen. A picture of the typical fracture toughness test setup is shown here in Figure 2-2. All tests were performed according to ASTM Standard E1820-09 "Standard Test Method for Measurement of Fracture Toughness" (2). 


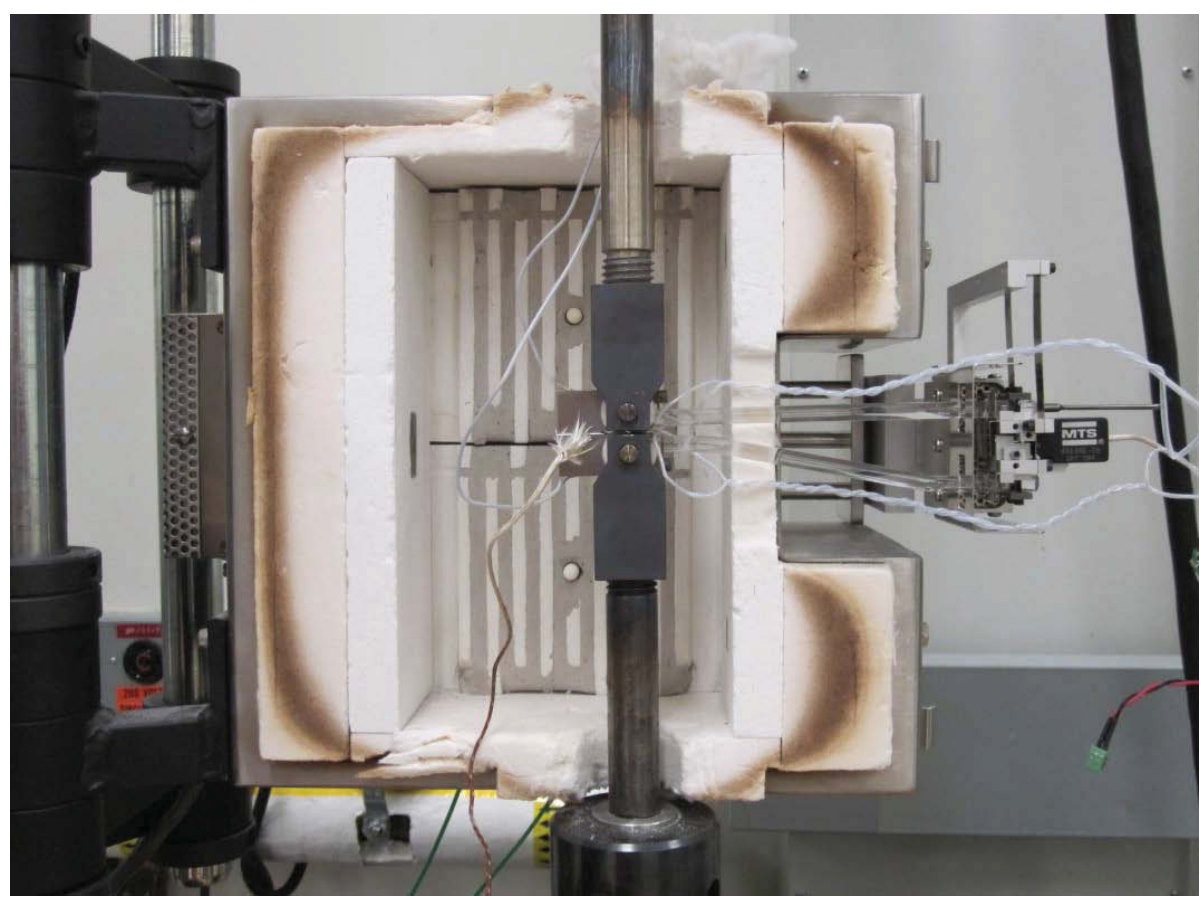

Figure 2-2: Fracture toughness testing setup.

Data collected during all fracture toughness tests included force, COD, actuator displacement, and two separate DCPD potential signals. Since the COD gage was attached to the front face of the specimen, a geometrical factor was applied to correct the measurement to load line displacement (LLD). Real time crack length was calculated as a function of DCPD readings. All fracture toughness tests were conducted using displacement control with a constant displacement rate of $0.2 \mathrm{~mm}$ per minute with the exception of specimen 10A0016-A2-01, which was tested at a displacement rate of $0.13 \mathrm{~mm}$ per minute in an attempt to capture extra data following crack initiation.

\subsection{Stress corrosion cracking tests}

The stress corrosion cracking tests were performed in two testing loops. The water was continuously refreshed with a flow rate of approximately $200 \mathrm{ml} / \mathrm{min}$ for a 4 liter autoclave and the water chemistry was continuously monitored and controlled. Dissolved gas concentration was controlled by applying an overpressure of mixed gas at room temperature before the water flowed to the high pressure high temperature part of the loop. The ion content in the water was controlled by flowing water through an ion exchanger to remove corrosion products and by adding a controlled amount of sulfate $\left(\mathrm{SO}_{4}\right)$ when desired. Typically the tests were performed in normal water chemistry (NWC) with 2 ppm dissolved oxygen in pure water and hydrogen water chemistry (HWC) with about $63 \mathrm{ppb}$ dissolved hydrogen in pure water ${ }^{\mathrm{a}}$. However, in order to facilitate crack engagement and to remain consistent with methodology employed in other laboratories, sulfate addition (up to $30 \mathrm{ppb}$ ) was sometimes used. The loop designs are identical and only differ in construction material. In one loop, the tubing and the autoclave were made of 316 SS while the other was comprised of commercially pure titanium. For crack growth monitoring, the AT5 software provided by the GE Global Research Center (GE-GRC) was used.

The overall tests were performed in 4 steps: 1) pre-cracking in air, 2) fatigue in the environment, 3 ) stress corrosion cracking in the various environments and conditions of interest, 4) post test fatigue. Typically, the crack was initiated and extended in air to $1.4 \mathrm{~mm}$ from the machined notch by a three step

\footnotetext{
${ }^{a}$ Although the statement of work for this project calls for dissolved hydrogen at 120-200 ppb levels, 63 ppb was used to correspond to the level used by the laboratory (GE-GRC) used by EPRI for concurrent testing.
} 
fatigue program. After several days in the environment to assure stabilization of the corrosion potential, crack extension was continued in the environment with a frequency that decreased from 0.1 to $0.001 \mathrm{~Hz}$ followed by introduction of a hold time of $9000 \mathrm{~s}$ at $\mathrm{K}_{\max }$ to transition the fatigue transgranular crack to an intergranular stress corrosion crack. The experiment was then performed with a fully constant $\mathrm{K}$ step targeted to $27.5 \mathrm{Mpa} \sqrt{ } \mathrm{m}(25 \mathrm{ksi} \sqrt{ } \mathrm{in})$. The targeted constant $\mathrm{K}$ was maintained while the specimen was immersed in various environments of interest. At the end of the test the specimen was ruptured by fatigue and the fracture surface was analyzed using optical and scanning electron microscopy. For crack path analysis, the specimen was cross-sectioned and analyzed before it was ruptured for fractography. Since the crack front was not always flat, the minimum, maximum and averaged actual crack propagation depth is reported. The average depth is determined using the "area averaging method": (the area of the propagated crack is measured and average crack depth is computed as if the crack front were straight). The percentage difference (error) between the propagated crack as determined with the DCPD technique and the actual measured crack propagation (the average value) is determined as (actual DCPD)/actual*100. This post test computed error is used as a basis to compensate for the commonly observed discrepancy between DCPD measured crack lengths and the actual physically measured crack length.

\section{Alloy X-750 Testing Results}

Several sections of Inconel alloy X-750 were provided to INL by GE-GRC. These sections were removed by GE-GRC from a spare upper support bracket that was purchased from Southern Co. by EPRI. A decision was made by INL to fabricate all fracture toughness and Stress Corrosion Cracking (SCC) specimens required for the pilot program from a single section, labeled "EP". Details of the sectioning of this piece and the machining of specimens may be found in the appendix of this report. The material was delivered in the HTH condition which consists of a $35 \%$ minimum reduction hot roll ${ }^{\text {b }}$; solution anneal at $1107{ }^{\circ} \mathrm{C}$ for 1 hour and rapid cool; aging at $704{ }^{\circ} \mathrm{C}$ for 20 hours and air cool. The composition for this material is given in Table 3-1 and additional microstructural details may be found in (3). Note that one element is unreadable on the material test report and is shown here as a question mark.

Table 3-1: Composition of alloy X-750.

\begin{tabular}{|c|c|c|c|c|c|c|c|c|c|c|c|c|c|c|}
\hline $\mathrm{Al}$ & $\mathrm{C}$ & $\begin{array}{c}\mathrm{Nb}+ \\
\mathrm{Ta}\end{array}$ & $\mathrm{Co}$ & $\mathrm{Cr}$ & $\mathrm{Cu}$ & $\mathrm{Fe}$ & $\mathrm{Mg}$ & $\mathrm{Ni}$ & $\mathrm{P}$ & $\mathrm{S}$ & $\mathrm{Si}$ & $\mathrm{Ti}$ & $\mathrm{Ta}$ & $?$ \\
\hline $\mathbf{0 . 7 7}$ & $\mathbf{0 . 0 4}$ & $\mathbf{0 . 9 9}$ & $\mathbf{0 . 7 2 6}$ & $\mathbf{1 4 . 9 9}$ & $\mathbf{0 . 0 1 5 1}$ & $\mathbf{7 . 8}$ & $\mathbf{0 . 1 9 7}$ & $\mathbf{7 0 . 8}$ & $<\mathbf{0 . 0 0 5}$ & $\mathbf{0 . 0 0 2}$ & $\mathbf{0 . 2 5}$ & $\mathbf{2 . 4 2}$ & $<0.01$ & $\mathbf{0 . 9 7}$ \\
\hline
\end{tabular}

\subsection{Alloy $X-750$ tensile test results}

Only two tensile tests were conducted for this project since the results were very repeatable and were essentially identical to those obtained by M. Morra at GE-GRC (3). Tensile tests were not part of the scope of this project but were performed to ensure lab to lab comparability. The results of the tensile tests are shown in Table $3-2$. The average $0.2 \%$ offset yield strength $\left(\sigma_{\mathrm{y}}\right)$ for alloy X-750 tested at $288^{\circ} \mathrm{C}$ was $713.5 \mathrm{MPa}$, the average tensile strength $\left(\sigma_{\text {ult }}\right)$ was $1079 \mathrm{MPa}$, and the average strain to failure $\left(\varepsilon_{\mathrm{f}}\right)$ was $31.1 \%$. Both specimens were oriented along the L, or rolling direction to coincide with the L-T orientation of the CT specimens to be used in fracture testing and SCC testing.

\footnotetext{
${ }^{b}$ Note that this step is typical of the HTH heat treatment but was not documented in the material certification for the material used in this project.
} 
Table 3-2: Tensile properties of alloy $\mathrm{X}-750$ at $288^{\circ} \mathrm{C}$.

\begin{tabular}{l|c|c|c|}
\cline { 2 - 4 } & (MPa) & (MPa) & (\%) \\
\hline EP1-L5 & 712 & 1076 & 31.8 \\
\hline \multirow{2}{*}{ EP1-L6 } & 715 & 1082 & 30.4 \\
\cline { 2 - 4 }
\end{tabular}

\subsection{Alloy $X-750$ fracture toughness test results}

Three, 0.5T-CT specimens machined in the L-T orientation were used to measure $J$ resistance $(J-R)$ for the supplied alloy X-750 in air at a nominal temperature of $288^{\circ} \mathrm{C}$. These specimens are identified as $10 \mathrm{~A} 0002 \mathrm{AA} 01,10 \mathrm{~A} 0002 \mathrm{AA} 02$, and 10A0002 BB 02. All were machined with side grooves of 5\% per side ( $10 \%$ total side groove) to control tunneling of the crack front. The specimens were fatigue precracked at room temperature in air to an initial normalized crack length, $a_{0} / W$ target between 0.55 and 0.6. Fatigue pre-cracking was performed at room temperature with an $R$ ratio (ratio of minimum to maximum force) of 0.1 and with a $K_{\max }<50 \mathrm{MPa} \sqrt{ }$ m; the maximum allowable $K_{\max }$ for pre fatigue per ASTM E1820-09 (2) is $60 \%$ of $K_{\mathrm{JQ}}$.

Following each $J-R$ test, the specimens were fatigued completely in half and cracking regimes were measured using a Nikon model 6C-2 Profile Projector at 10X magnification. Each successive crack front (notch, pre-fatigue, and post fatigue) was measured in 9 locations across the crack front in order to determine the level of tunneling and in order to correct the DCPD measured crack lengths for the approximate 3-5\% expected error. Figures 3-2 through 3-4 contain 20X magnification photographs of the fracture surfaces of all of the specimens.

Figure 3-1 is an overlay graph of all three $J-R$ curves of the alloy X-750 tested in this project. The $J_{\text {IC }}$ values ranged from a low of $132.6 \mathrm{~kJ} / \mathrm{m}^{2}$ for specimen $10 \mathrm{~A} 0002 \mathrm{BB} 02$ to a high of $163.5 \mathrm{~kJ} / \mathrm{m}^{2}$ for specimen 10A0002 AA 01. The variance in $J_{\text {IC }}$ values is an artifact of the local curve fit at a point representative of crack tip blunting as described in (2). Tearing modulus, which is indicative of a material's resistance to stable tearing, ranges from 70 to 81 . A previous study (4) reported $J_{\text {IC }}$ to be 130 $\mathrm{kJ} / \mathrm{m}^{2}$ at a test temperature of $427^{\circ} \mathrm{C}$ and $102 \mathrm{~kJ} / \mathrm{m}^{2}$ at $24{ }^{\circ} \mathrm{C}$ for an Inconel X-750 heat treated in the AH condition which tends to have higher tensile and yield strengths and thus an implied lower toughness than material in the HTH condition as tested in the current project.

Table 3-3: Fracture toughness results for alloy $\mathrm{X}-750$ at $288^{\circ} \mathrm{C}$

\begin{tabular}{c|c|c|c|}
\cline { 2 - 4 } & $a_{0} / \mathrm{W}$ & Jic $\left(\mathbf{k J} / \mathbf{m}^{2}\right)$ & - \\
\hline 10A0002 AA 01 & 0.584 & 163.5 & 78 \\
\hline 10A0002 AA 02 & 0.595 & 160.8 & 70 \\
\hline 10A0002 BB 02 & 0.592 & 132.6 & 81 \\
\cline { 2 - 4 } & & &
\end{tabular}




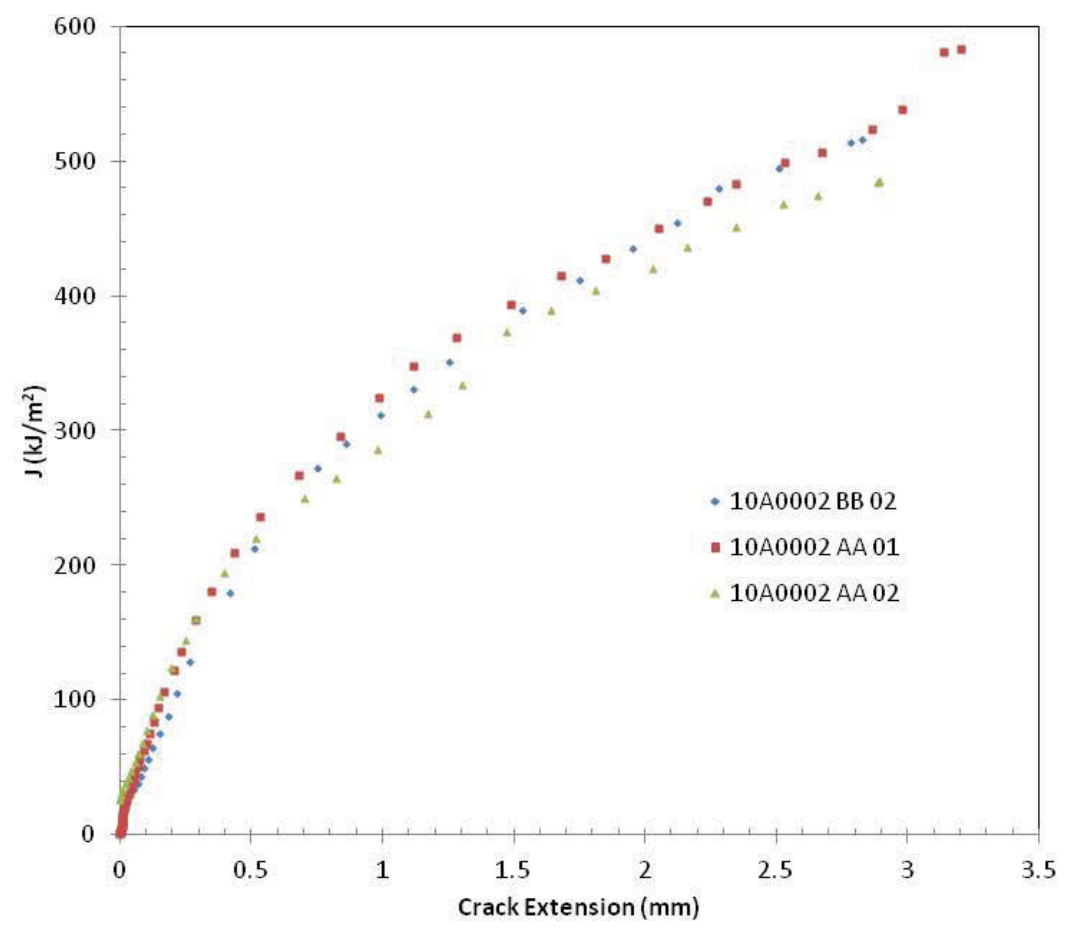

Figure 3-1: Overlay of J-R curves for alloy X-750.

For all alloy X-750 specimens tested, the formulation outlined in ASTM E1820-09 (2) was used to calculate a value of $J$ for all values of $\Delta a$ (crack growth). This formulation utilizes measured force, load line displacement, and crack length to calculate $J$ - $\Delta a$ pairs to form the $J$-R curve. Blunting lines were formed using a slope, $M \sigma_{\mathrm{f}}$, where $M=2.0$ as suggested in the standard and $\sigma_{\mathrm{f}}$ is the flow stress, or average of $0.2 \%$ offset yield strength $\left(\sigma_{\mathrm{y}}\right)$ and the ultimate tensile strength, $\sigma_{\mathrm{ult}} . J_{\mathrm{Q}}$ is calculated as the intercept of a $0.2 \mathrm{~mm}$ offset blunting line and a power law regression fit of all of the $J-\Delta a$ data located between $\Delta a=$ $0.15 \mathrm{~mm}$ and $1.5 \mathrm{~mm}$ exclusion blunting lines. Since the value of $J_{\mathrm{Q}}$ is very dependent on the value of the initial crack length, an initial $J-R$ curve was produced using the original $J-\Delta a$ pairs; these data were then fit to a third order polynomial in the form of Equation 1 and an offset for $\Delta a$ is calculated as the difference between $a_{0}$ and $a_{0 q}$. A revised $J-R$ curve was plotted after $\Delta a$ was adjusted. This effectively accounts for any minor perturbations in the crack initiation regime of the fracture toughness test that can have a very large effect on the value of $J_{\mathrm{Q}}$. It should be noted that this procedure is typically used within the context of the compliance method for measurement of crack growth to correct the initial crack length estimated using compliance to that measured optically. Since the DCPD method was used for this study, there was technically no reason to do this since initial crack length was defined based on post-test measured initial crack length. However, due to the sensitivity of the DCPD method, there are commonly small perturbations in measured crack length due primarily to crack tip plasticity and this method provides a reasonable approach to compensating for the perturbations that can have a large effect on the value of $J_{\mathrm{Q}}$.

\section{Equation 1}

For all of the alloy X-750 specimens, $J_{\mathrm{Q}}$ was qualified as $J_{\mathrm{IC}}$, a geometry independent fracture toughness because all specimens met the requirements for this qualification. According to ASTM E1820- 
09 (2), it is required that the specimen thickness and net ligament be greater than 10 times the ratio of $J_{\mathrm{Q}}$ to the flow stress $\left(\sigma_{\mathrm{f}}\right)$ and it is required that the slope of the power law regression at $J_{\mathrm{Q}}, a_{\mathrm{Q}}$ also be less than the value of the flow stress.

Figures 3-2 through 3-4 are the individual $J-R$ curves for the three alloy $\mathrm{X}-750$ specimens fracture tested for this project.

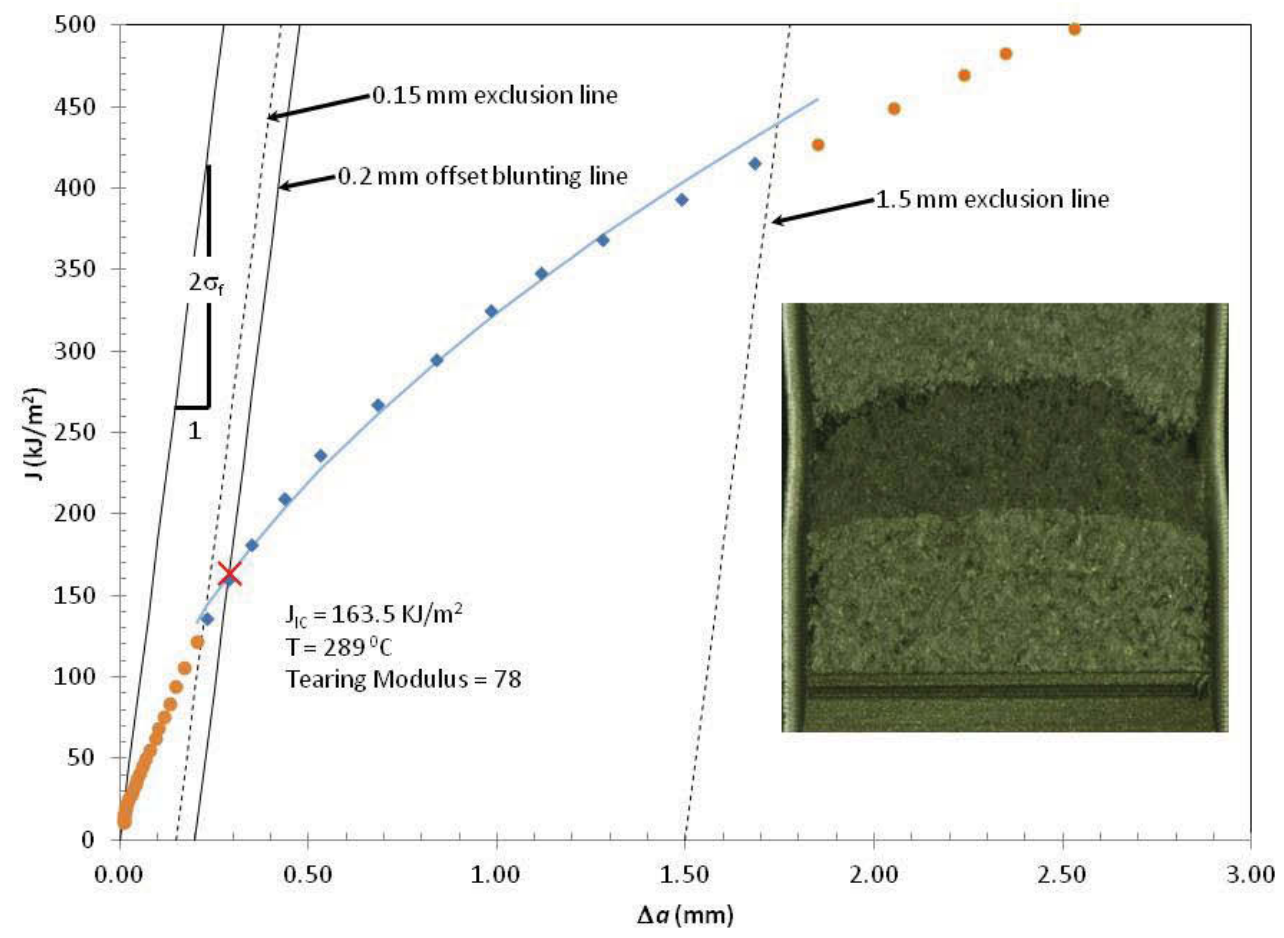

Figure 3-2: Specimen 10A0002 AA $01 \mathrm{~J}-\mathrm{R}$ curve and fracture surface with annotations. 


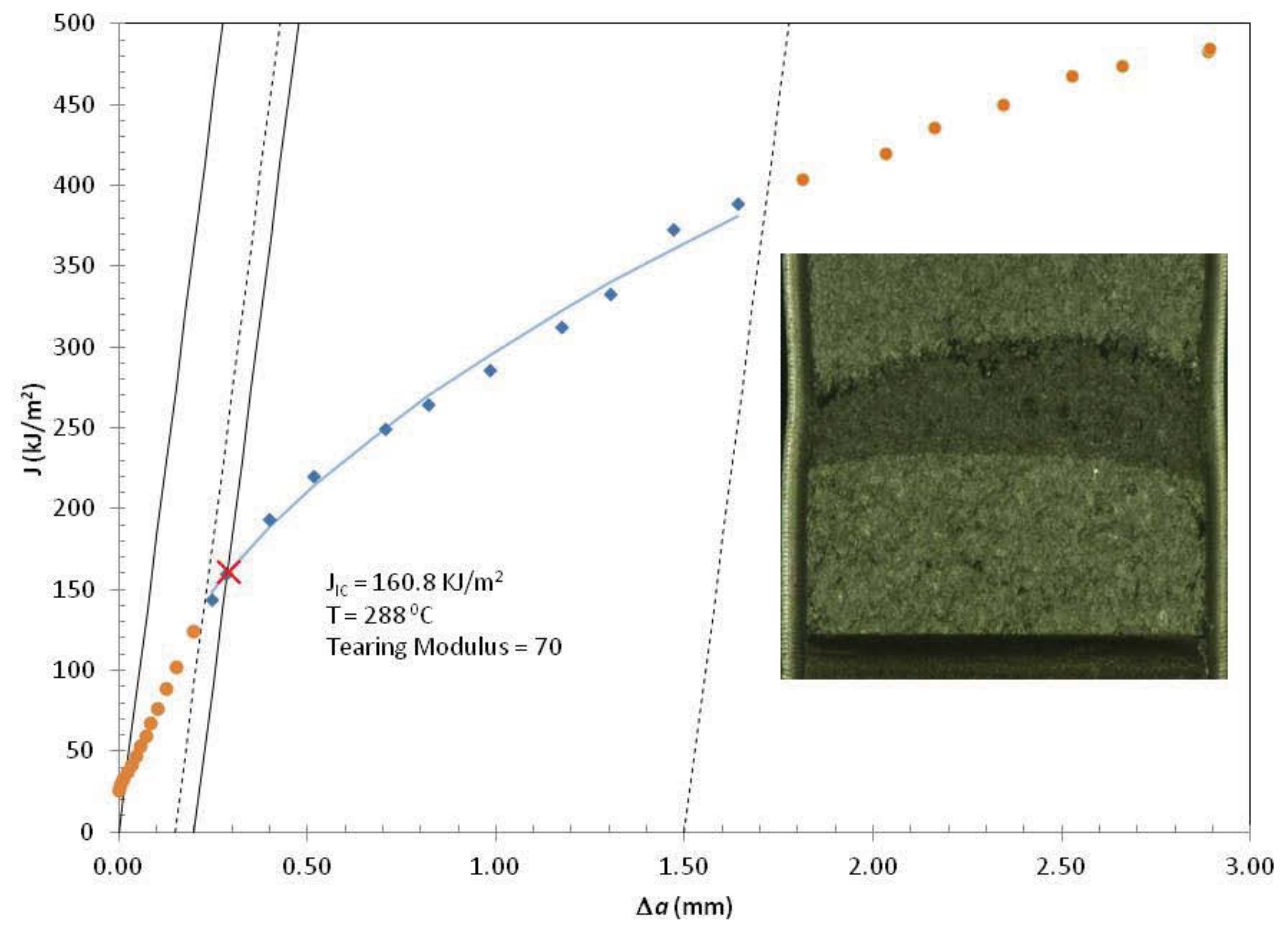

Figure 3-3: Specimen 10A0002 AA 02 J-R curve and fracture surface.

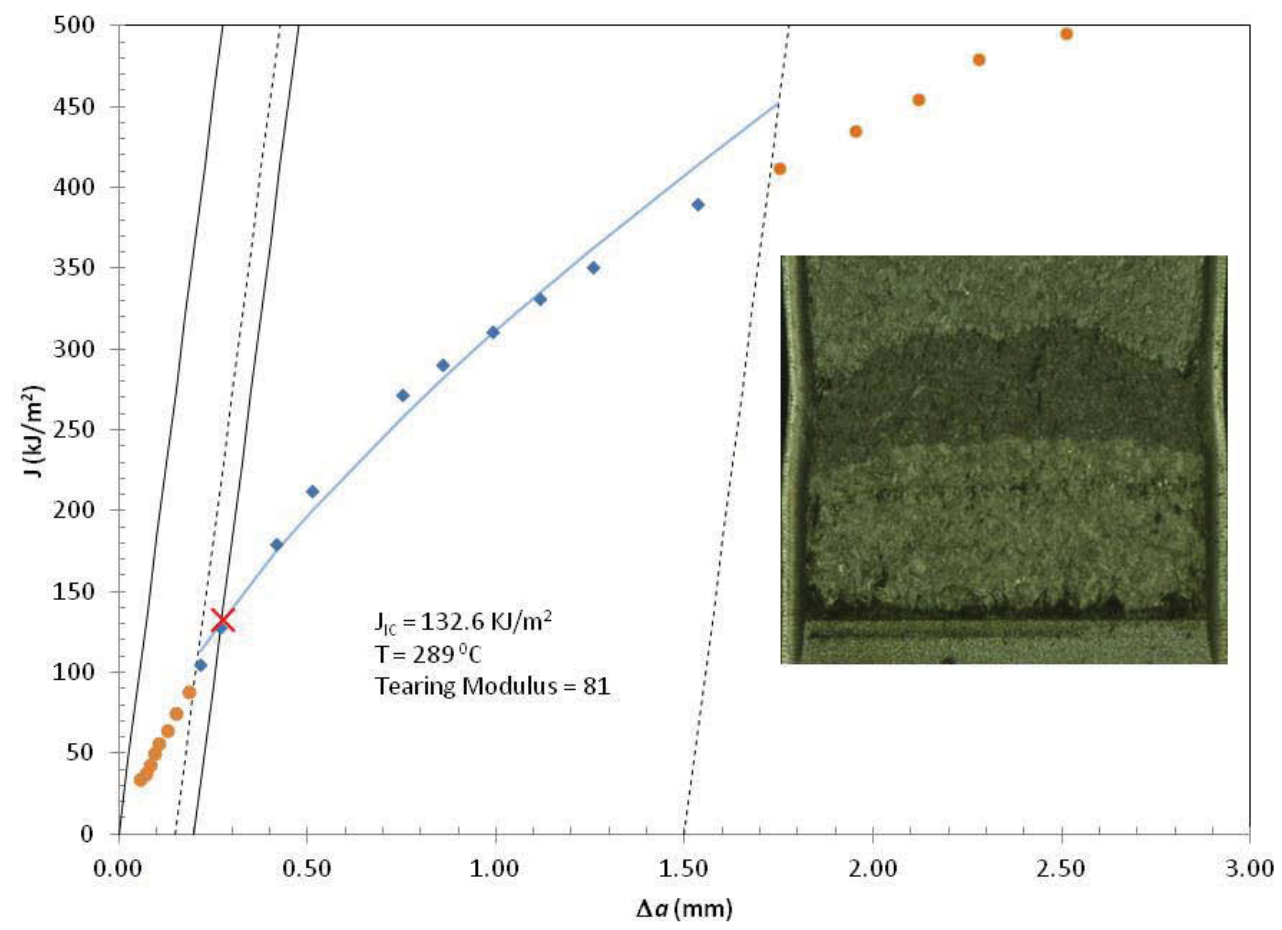

Figure 3-4: Specimen 10A0002 BB 02 J-R curve and fracture surface. 
Following fracture testing and post fatigue, the fracture surface of specimen 10A0002 AA 01 was examined in a Scanning Electron Microscope (SEM) as a representative fracture surface. The fracture surface appears to be primarily a mixture of transgranular morphology along with dimple rupture networks and occasional inclusions thought to be primary $\mathrm{Ti}, \mathrm{Nb}(\mathrm{C}, \mathrm{N})$ carbonitrides as identified in (3). This is consistent with observations made in (4) for alloy X-750 tested at $427{ }^{\circ} \mathrm{C}$.

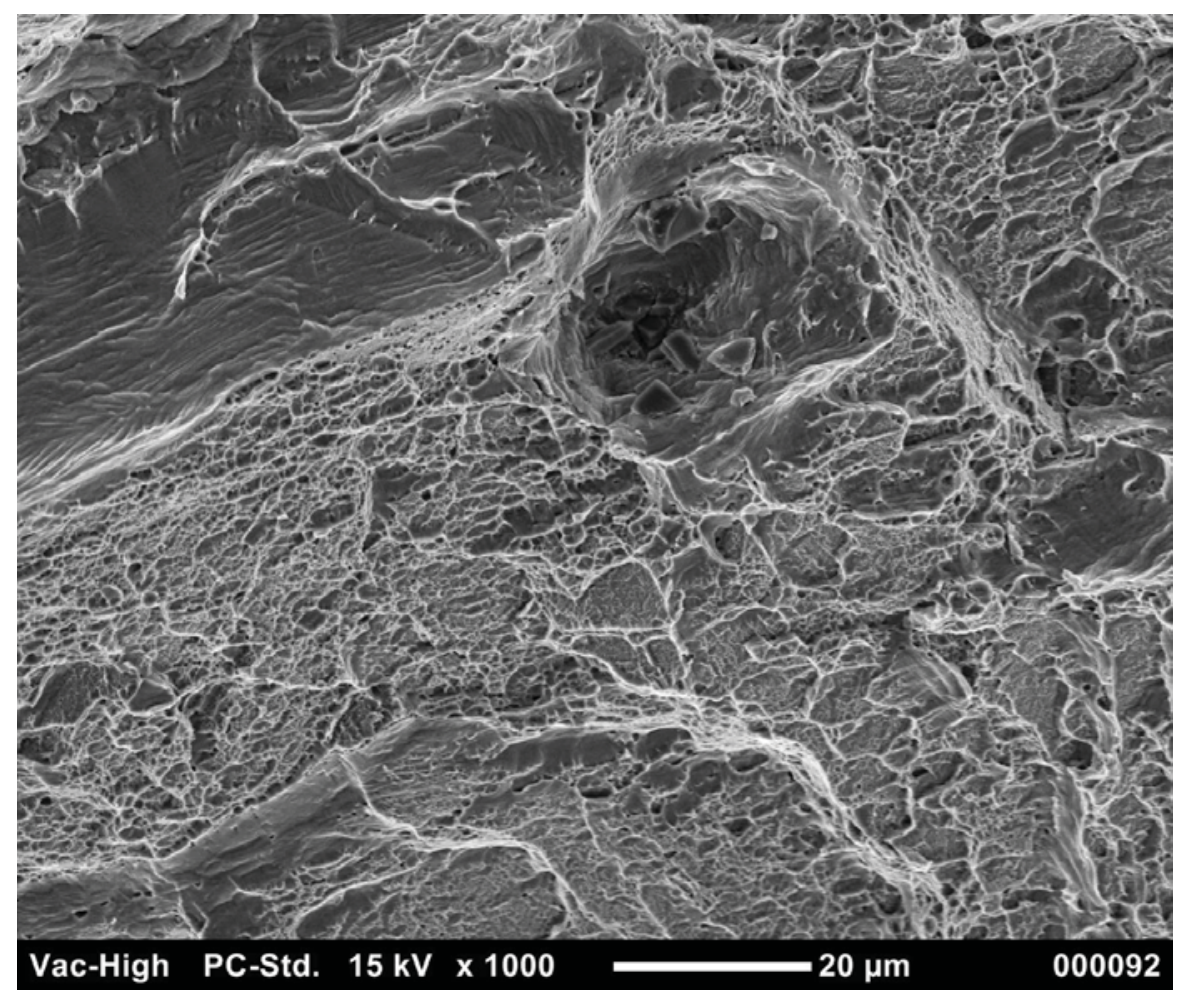

Figure 3-5: SEM fractograph of fracture surface for specimen 10A0002 AA 01.

\subsection{Alloy X-750 SCC test results}

The primary goal of the alloy X-750 SCC testing for this project was to determine CGRs for material in the L-T orientation under both NWC and HWC conditions. In addition to the two L-T orientation SCC tests under the proposed scope of work, one SCC test was completed for an alloy X-750 specimen in the $\mathrm{T}$-L orientation, and one SCC test was completed on a specimen in the S-L orientation. These additional tests were confirmatory and were completed in order to allow comparison of results to those of a well known laboratory (GE-GRC) by EPRI.

\subsubsection{Alloy X-750 L-T orientation SCC tests results}

Two experiments were performed in $288^{\circ} \mathrm{C}$ water. For the first one (specimen ID 10A0002 A01) no anticipatory online correction to DCPD measured crack length was used. The error between the post test measured average crack length and the DCPD predicted crack length was $46.4 \%$ and the appropriate post test correction was applied to the data presented. This discrepancy led to a maximum K applied of 40.1 $\mathrm{Mpa} \sqrt{ } \mathrm{m}$ while the target was $27.5 \mathrm{Mpa} \sqrt{ } \mathrm{m}$. For the second test (specimen ID 10A0002 B01), although a $50 \%$ anticipatory correction of DCPD measured crack length was enforced, the error between the post test measured crack length and the DCPD predicted crack length was $37.5 \%$ and additional post test 
correction was necessary. This discrepancy led to a maximum $\mathrm{K}$ applied of $28.8 \mathrm{Mpa} \sqrt{\mathrm{m}}$ while the target was $27.5 \mathrm{Mpa} \sqrt{ } \mathrm{m}$.

Figure 3-6 shows the various steps of cycling in environment before the test was switched to constant $\mathrm{K}$ mode for the first test. In this figure, " $\mathrm{F}$ " is cycling frequency in hertz and " $\mathrm{R}$ " is the ratio of maximum to minimum applied force. The effect of holding time is apparent and leads to a crack rate increase. This area corresponds to the transition from transgranular to intergranular cracking as observed on the fracture surface.

The first part of the test for the first specimen (ID 10A0002 A01) consisted of growing a crack in water with $10 \mathrm{ppb}$ of sulfate added to the initial NWC condition ( $2 \mathrm{ppm}$ dissolved oxygen) then in HWC conditions (63 ppb dissolved hydrogen) before returning to NWC in order to demonstrate the effect of corrosion potential on CGR. The CGRs measured were between $1.1 \times 10^{-6} \mathrm{~mm} / \mathrm{s}$ and $1.5 \times 10^{-6} \mathrm{~mm} / \mathrm{s}$ for NWC condition and $5.3 \times 10^{-8} \mathrm{~mm} / \mathrm{s}$ in the HWC condition. These steps are presented in Figure 3-7. In the second part of the test no sulfate was added to the water, and the water chemistry was switched from NWC condition to HWC several times. Under these conditions, CGR was between $2.8 \times 10^{-7} \mathrm{~mm} / \mathrm{s}$ and $6.1 \times 10^{-7} \mathrm{~mm} / \mathrm{s}$ in the NWC environment and between $3.2 \times 10^{-8} \mathrm{~mm} / \mathrm{s}$ and $4.1 \times 10^{-8} \mathrm{~mm} / \mathrm{s}$ in the HWC environment. These steps are presented in Figure 3-8.

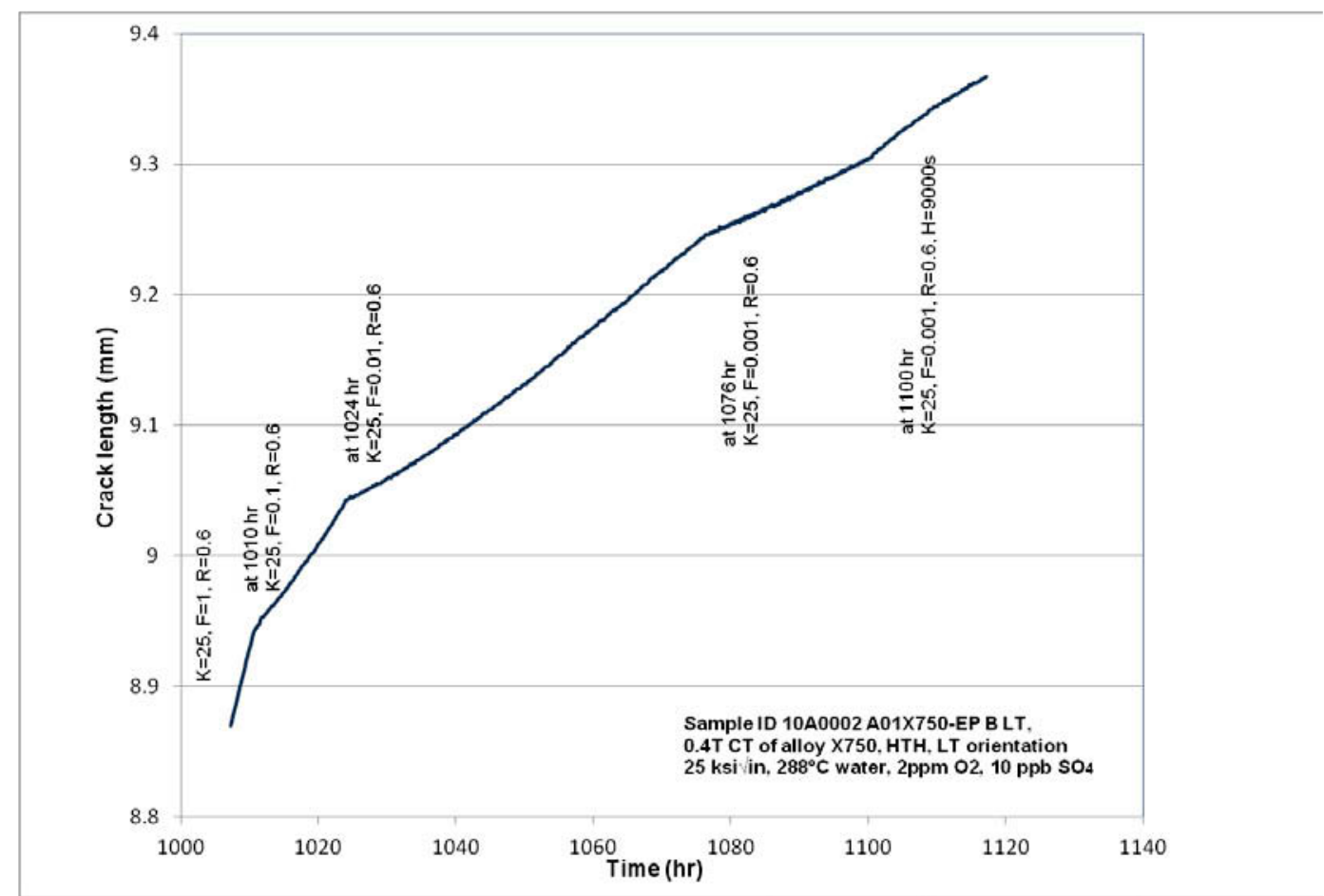

Figure 3-6: Crack length vs. time obtained with sample ID $10 \mathrm{A0002}$ A01 during cycling in water. 


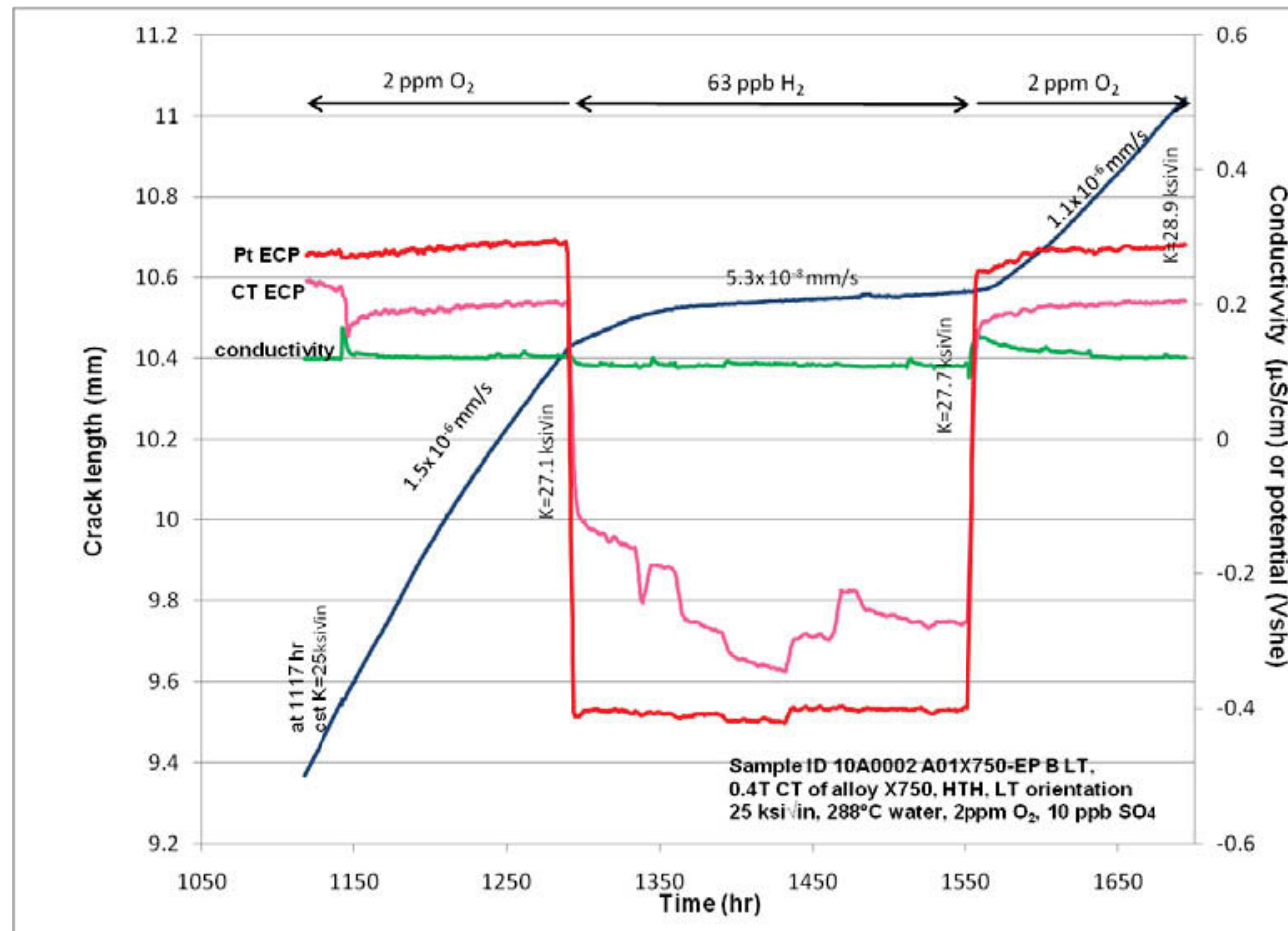

Figure 3-7: Crack length vs. time obtained with sample ID $10 \mathrm{A0002} \mathrm{A01}$ in $288{ }^{\circ} \mathrm{C}$ water with sulfate addition.

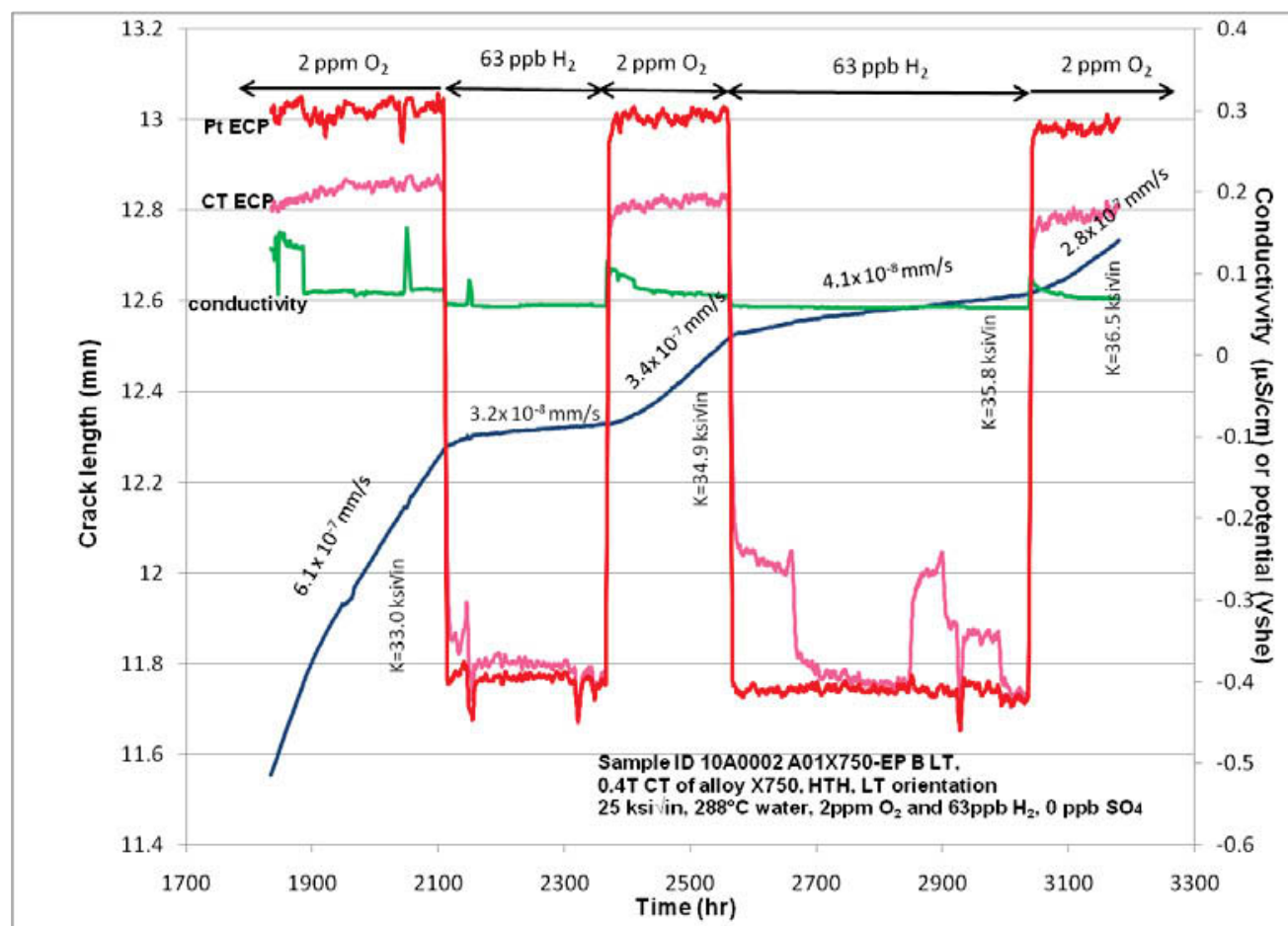

Figure 3-8: Crack length vs. time obtained with sample ID $10 \mathrm{A0002} \mathrm{A01}$ in $288^{\circ} \mathrm{C}$ water without sulfate addition. 
Optical fracture surface analysis of specimen ID 10A002 A01 (Figure 3-9) showed a fully engaged crack but with less crack growth on one side of the specimen. The minimum crack depth is $3.257 \mathrm{~mm}$, the maximum $6.955 \mathrm{~mm}$ (including a finger that is $1.821 \mathrm{~mm}$ deep) and the average $4.632 \mathrm{~mm}$. A single narrow crack can be seen ahead of the overall crack. In addition, micrographs of the sides of the specimen (views of the side grooves) illustrate the fact that the fracture surface observed is not planar and not fully contained between the side grooves. The top image of Figure 3-10 shows the crack branching that initiated this unexpected cracking. One crack propagated along the side groove while the other propagated at an approximate 45 degree angle upward. The crack angled at approximately 45 degrees ended up being part of the main propagating crack although this area didn't propagate further. This explains why, as seen in Figure 3-9, the left side of the specimen exhibits a shorter crack and why the side groove is not apparent in the photograph. SEM fracture surface analysis showed that the crack propagated intergranularly (Figure 3-11). Crack path analysis showed that the crack propagation was modified while crossing specific features in the material such as bands of small grains where significant branching is observed. Figure 3-12 is an SEM image illustrating this observed branching in areas of small grains. Higher magnification shows that the intergranular cracks can be either rugged or straight (Figure 3-13). A closer look shows that the rugged cracks are found on grain boundaries pinned by carbides. 


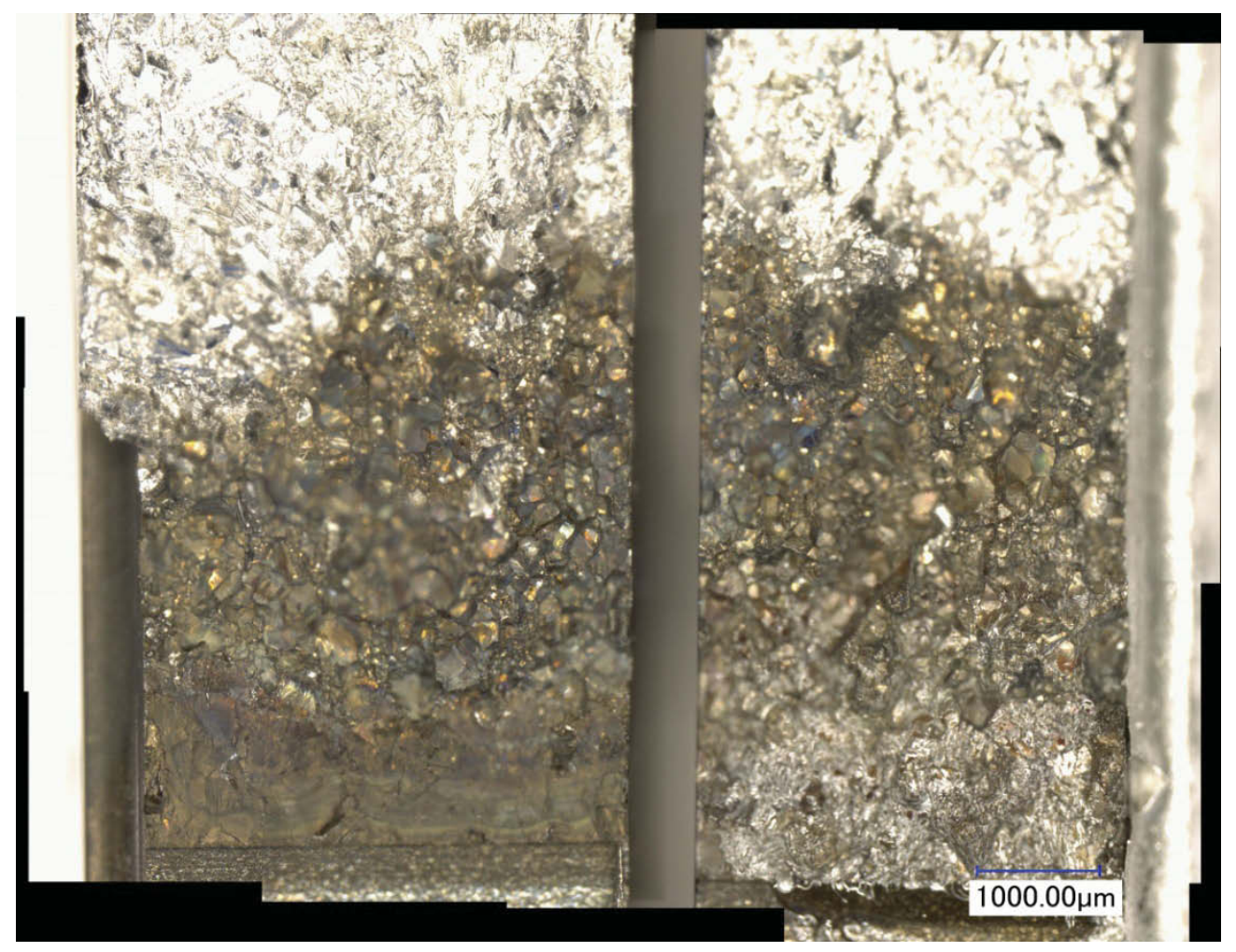

Figure 3-9: Digital fractograph of alloy X750 tested in LT orientation, sample ID 10A0002 A01. The clear area at bottom right part of the fracture surface (near the scale bar) is silver paint used during a Focused Ion Beam milling ${ }^{c}$ procedure for additional analysis.

${ }^{\mathrm{c}}$ Focused Ion Beam (FIB) milling was used to extract a small section of this material for an atom probe analysis as a separate study. 

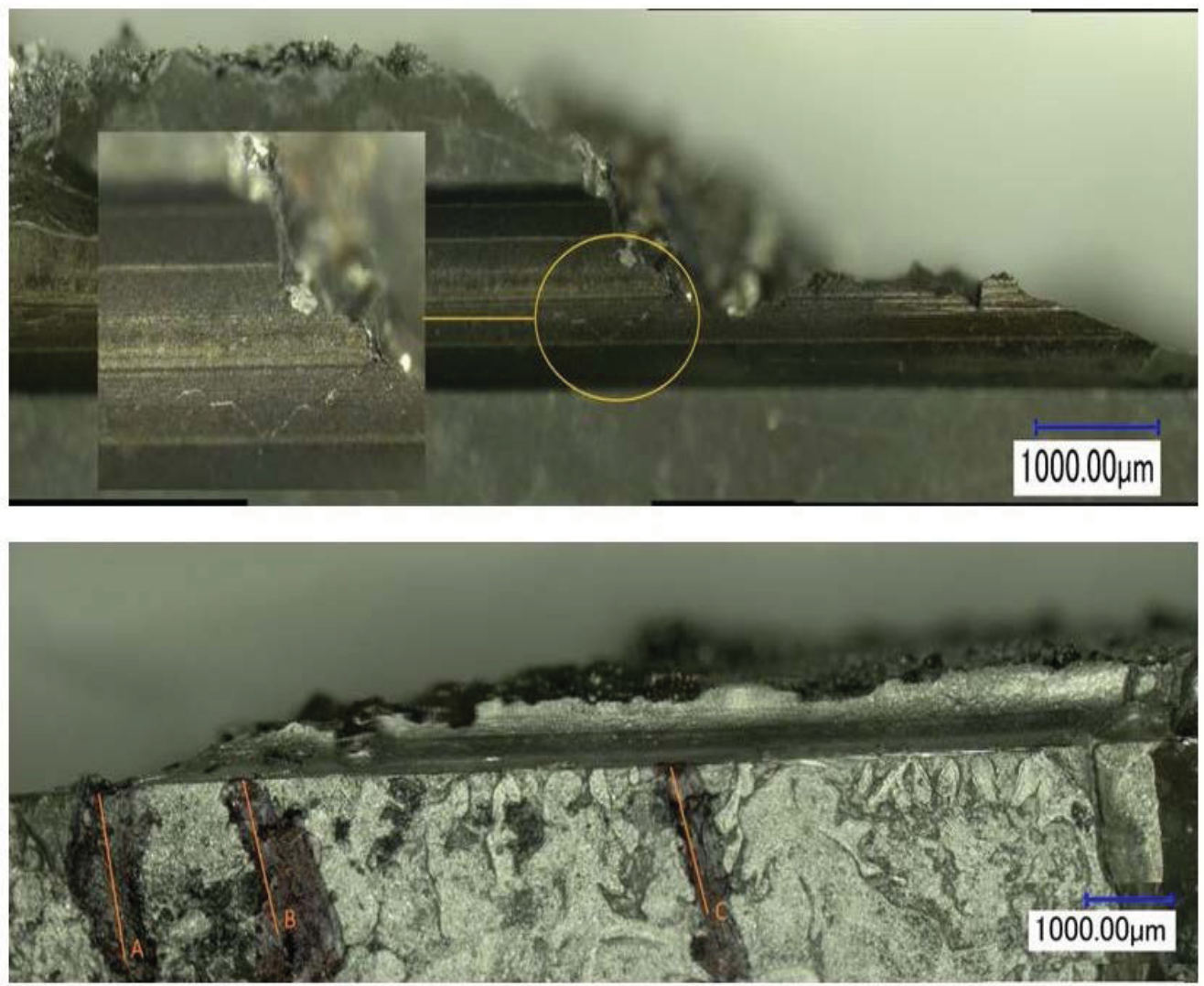

Figure 3-10: Side micrograph of the specimen ID after failure. The top picture shows the crack branching out of plane. The bottom picture illustrates the other side of the specimen showing that, on this side, the crack is aligned with the side grove. The markers $A, B, C$ indicate, respectively, the beginning of initial machined notch, the beginning of the crack and the end of the crack. 


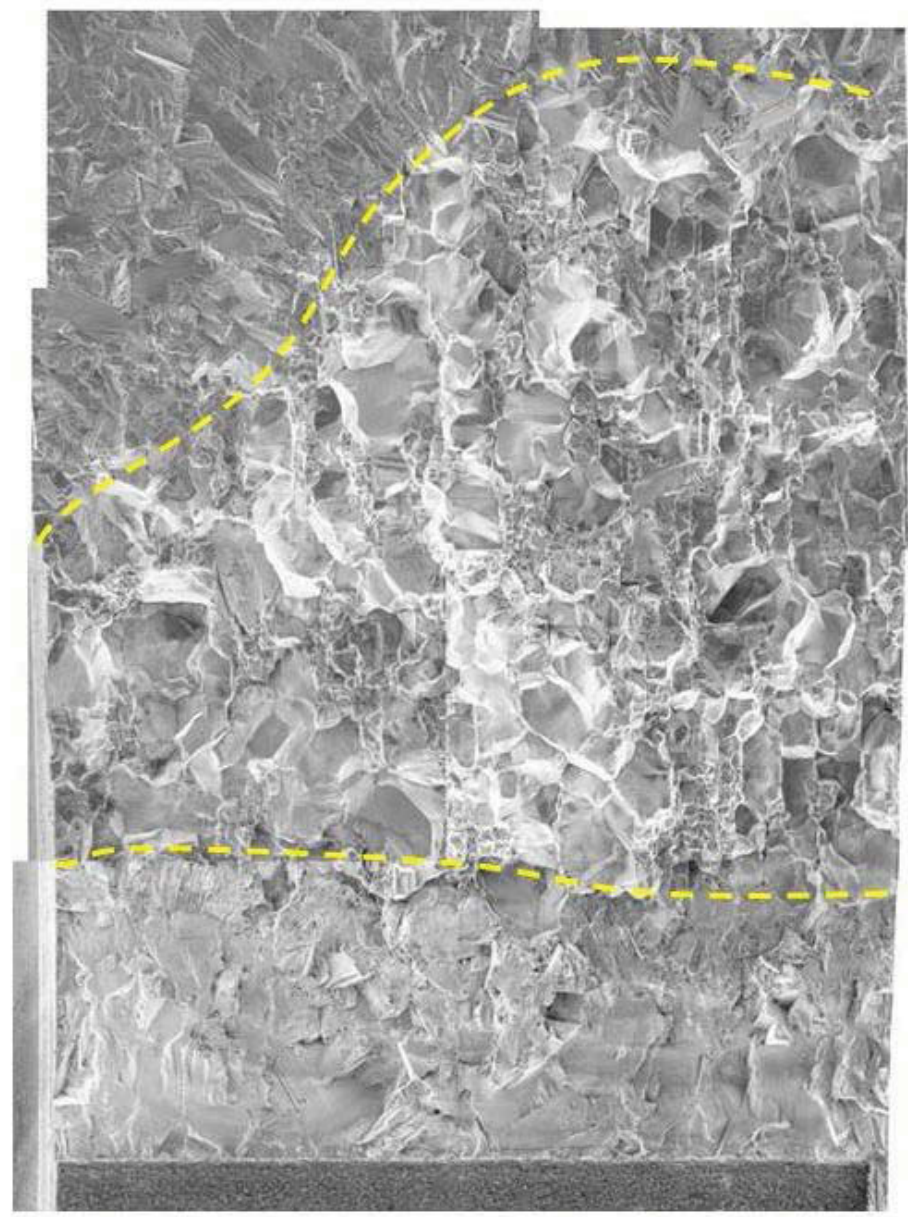

Figure 3-11: SEM fractograph of sample ID $10 \mathrm{A0002}$ A01. Yellow lines indicate boundaries of the IG cracking region. 


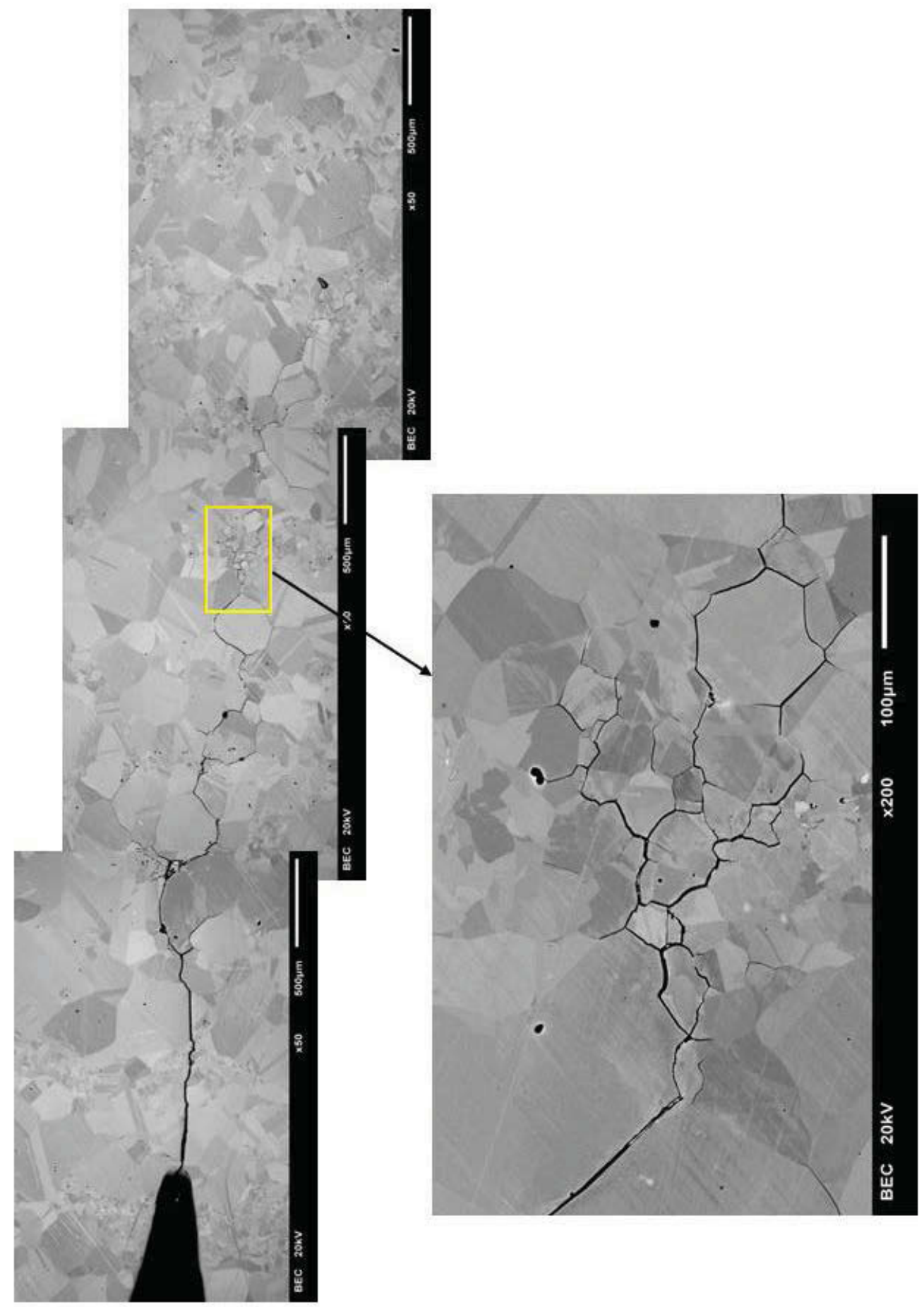

Figure 3-12: SEM fractograph of crack path followed in sample ID 10A0002 A01. 

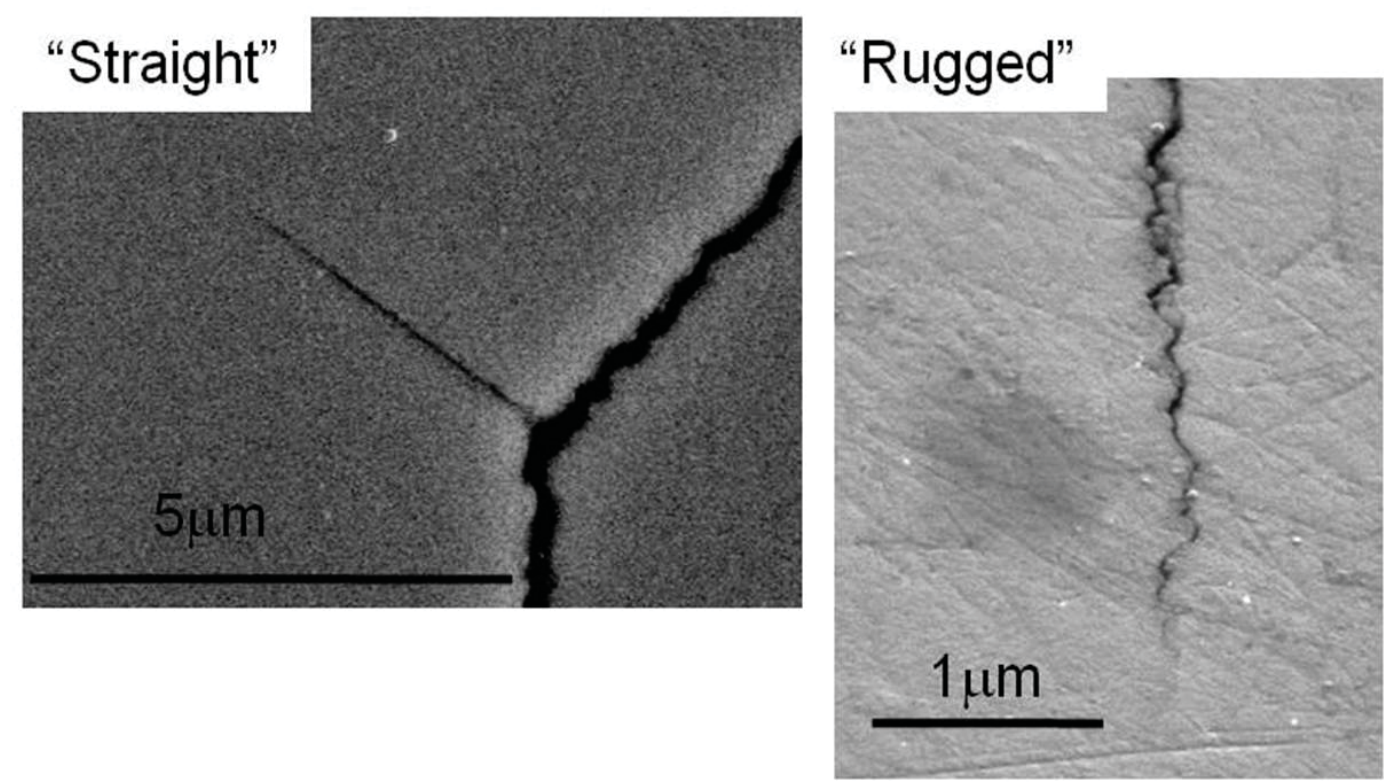

Figure 3-13: SEM fractographies of secondary cracks in sample ID 10A0002 A01.

During the second L-T orientation alloy X-750 test (specimen ID 10A0002 B01) the crack was propagated under both NWC and HWC conditions with $10 \mathrm{ppb}$ sulfate addition and subsequently without sulfate addition. Due to time constraints, it was decided not to spend a lot of time running the experiment with sulfate addition. While the crack was growing, changes in water chemistry responded well to water chemistry change (various DO and DH content) and it was decided to transition to testing without sulfate addition. Although the time under these conditions was short, a maximum crack propagation rate of $8.8 \mathrm{x}$ $10^{-7} \mathrm{~mm} / \mathrm{s}$ in NWC and $4.2 \times 10^{-8} \mathrm{~mm} / \mathrm{s}$ in the HWC environment may be observed. The crack length vs. time behavior with sulfate addition is presented in Figure 3-14. Figure 3-15 shows the crack length vs. time behavior without sulfate addition. The CGR was between $1.1 \times 10^{-7} \mathrm{~mm} / \mathrm{s}$ and $1.9 \times 10^{-7} \mathrm{~mm} / \mathrm{s}$ in the NWC environment and between $1.3 \times 10^{-8} \mathrm{~mm} / \mathrm{s}$ and $2.5 \times 10^{-8} \mathrm{~mm} / \mathrm{s}$ in the HWC environment. After 2600 hours the CGR decreased and it appears that the crack was stopping. The lower CGR observed in this region is not considered valid for this reason. Several attempts were made to reactivate the crack. Figure 3-16 shows this final part of the test. The only observation of note during this stage is the propagation of the crack by steps when cycling plus hold is applied. Here, the time between the steps corresponds to the holding time, and it can be seen that the crack propagates as the load increases. In this figure changes in the "noise" are due to the modification of the sampling rate. Two successive, unplanned, interruptions precipitated the final interruption of the test.

Optical fracture surface analysis of sample ID 10A002 B01 (Figure 3-17) showed a fully engaged crack but with a non uniform crack front. The minimum crack depth is $2.178 \mathrm{~mm}$, the maximum is 3.668 $\mathrm{mm}$ and the average $2.960 \mathrm{~mm}$. Ahead of the crack can be seems " dark areas" that may be oxidized areas, which may indicate that finger like cracking occurred outside the plane of the crack. The maximum crack depth given does not include those features as their connection to the main crack, although likely, is not evident on the picture. 


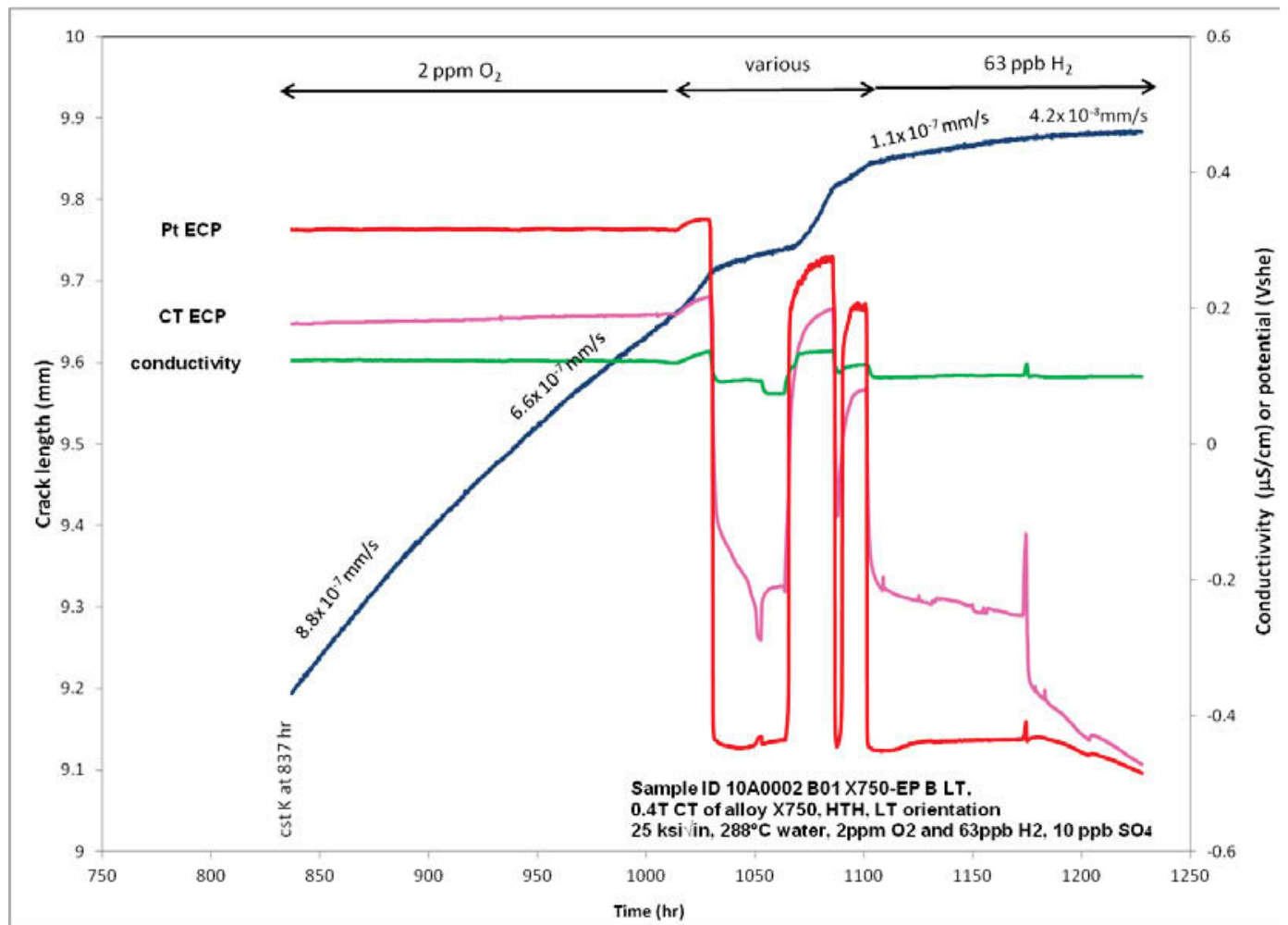

Figure 3-14: Crack length vs. time obtained with sample ID $10 \mathrm{A0002} \mathrm{B} 01$ in $288^{\circ} \mathrm{C}$ water with sulfate addition. 


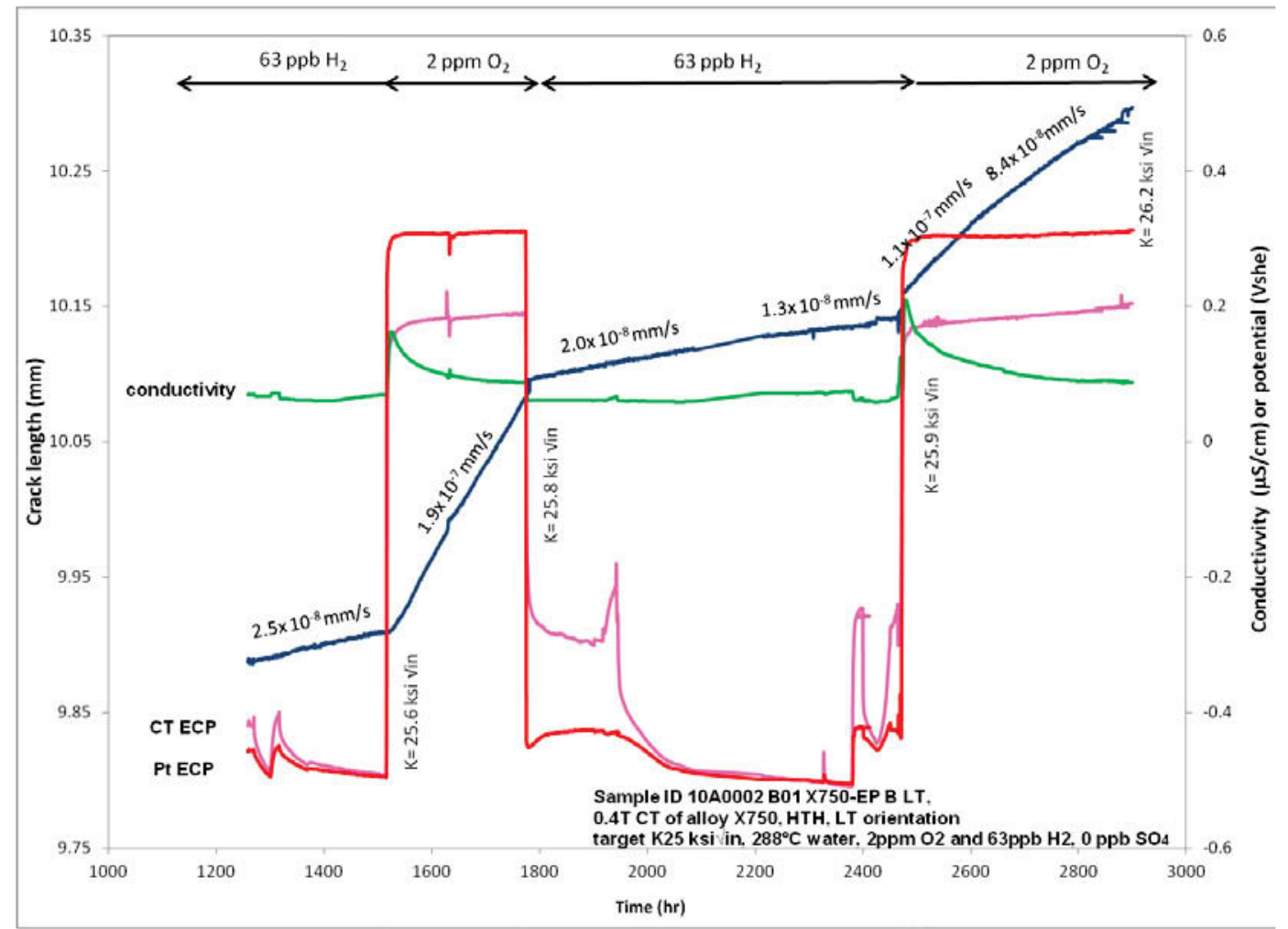

Figure 3-15: Length vs. time obtained with sample ID $10 \mathrm{A0002} \mathrm{B} 01$ in $288{ }^{\circ} \mathrm{C}$ water without sulfate addition. 


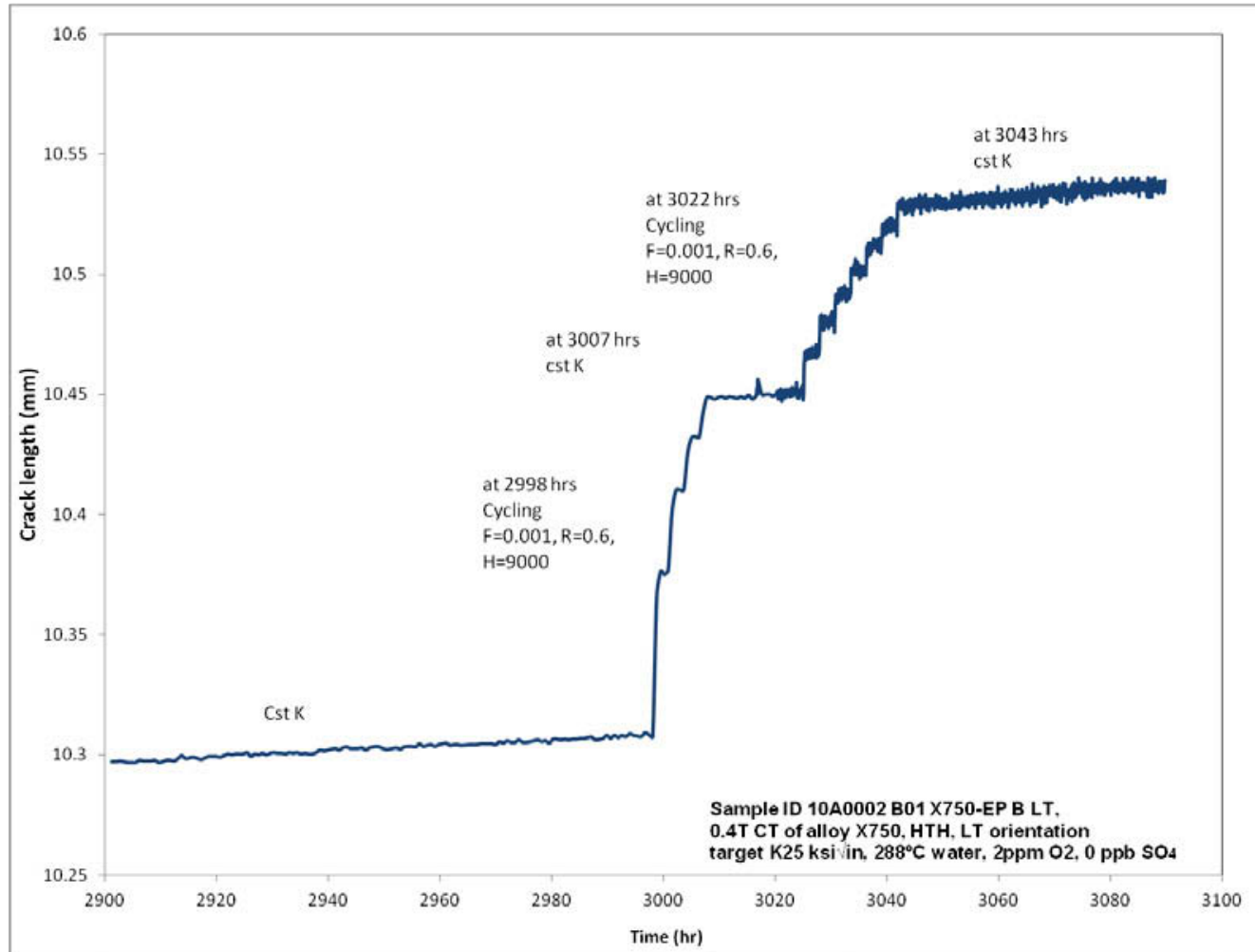

Figure 3-16: Crack length vs. time obtained at the end of the test with sample ID $10 \mathrm{A0002}$ B01 in $\mathbf{2 8 8}^{\circ} \mathrm{C}$ water.

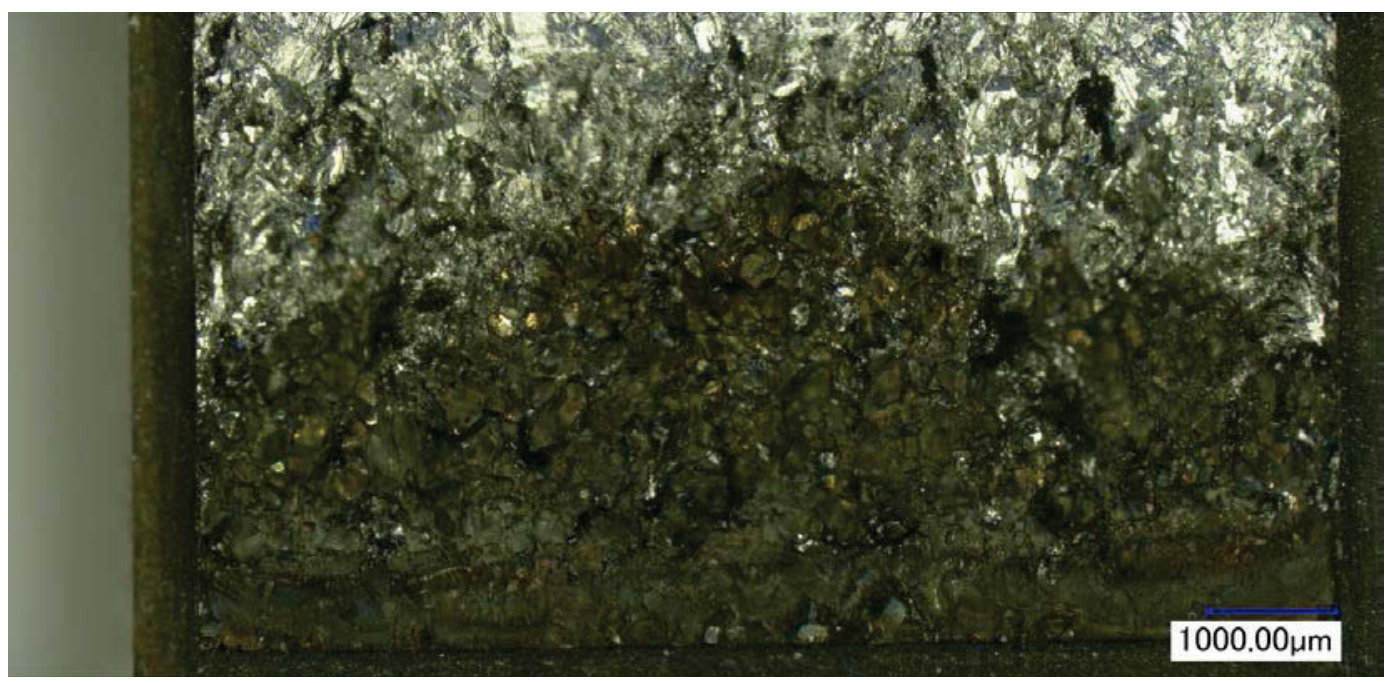

Figure 3-17: Digital fractograph of sample ID 10A0002 B01. 


\subsubsection{Alloy X-750 T-L orientation SCC test results}

One experiment on an alloy X-750 specimen oriented in the T-L orientation (specimen ID 10A0002B13) was performed in $288^{\circ} \mathrm{C}$ water both in NWC and $\mathrm{HWC}$ conditions. For the first 600 hours of the test which was held at constant $\mathrm{K}, 10 \mathrm{ppb}$ sulfate was added to the water. For the remainder of the test no sulfate was added. Post test analysis showed the error between the post test measured average crack length and that measured with the DCPD technique was $43.5 \%$. The data presented and discussed in this report are corrected to compensate for this error. The maximum $\mathrm{K}$ reached was $34.25 \mathrm{MPa} \sqrt{ } \mathrm{m}$. At about 700 hours, a power outage occurred causing the applied load to drop and the test was subsequently restarted using a "gentle" cycling with a load ratio, $\mathrm{R}=0.6$ with 9000 second hold time to re-transition to IG cracking. At approximately 1700 hours, the crack length began to increase in steps and the test was subsequently stopped.

Figures 3-18 and 3-19 show the crack length as a function of time. With $10 \mathrm{ppb}$ sulfate addition, CGR was measured between $1.2 \times 10^{-6} \mathrm{~mm} / \mathrm{s}$ and $1.8 \times 10^{-6} \mathrm{~mm} / \mathrm{s}$ in NWC and $1.3 \times 10^{-7} \mathrm{~mm} / \mathrm{s}$ in HWC. Without sulfate addition, the CGR measured in NWC was $4.1 \times 10^{-7} \mathrm{~mm} / \mathrm{s}$, about one third of the CGR obtained with $10 \mathrm{ppb}$ sulfate addition. In HWC, the highest CGR obtained was $1.0 \times 10^{-7} \mathrm{~mm} / \mathrm{s}$, slightly less than the CGR obtained with $10 \mathrm{ppb}$ sulfate addition. At about 1700 hours the crack propagated "in steps" with a constant CGR period of about $4.1 \times 10^{-8} \mathrm{~mm} / \mathrm{s}$.

Optical fracture surface analysis showed a generally straight crack front throughout the crack advance but also reveals 4 thin oxidized fingers ahead of the crack front (Figure 3-20) as long as $1.3 \mathrm{~mm}$. The minimum crack depth is $2.637 \mathrm{~mm}$; the maximum is 5.022 (including a narrow "finger" crack that is $1.355 \mathrm{~mm}$ deep) and the average $3.679 \mathrm{~mm}$.

SEM fractography showed that the crack propagated intergranularly (Figure 3-21) but there is not a perfect match between the intergranular area and the oxidized area, which may suggest that the burst of crack increase observed toward the end of the test may be due to transgranular propagation.

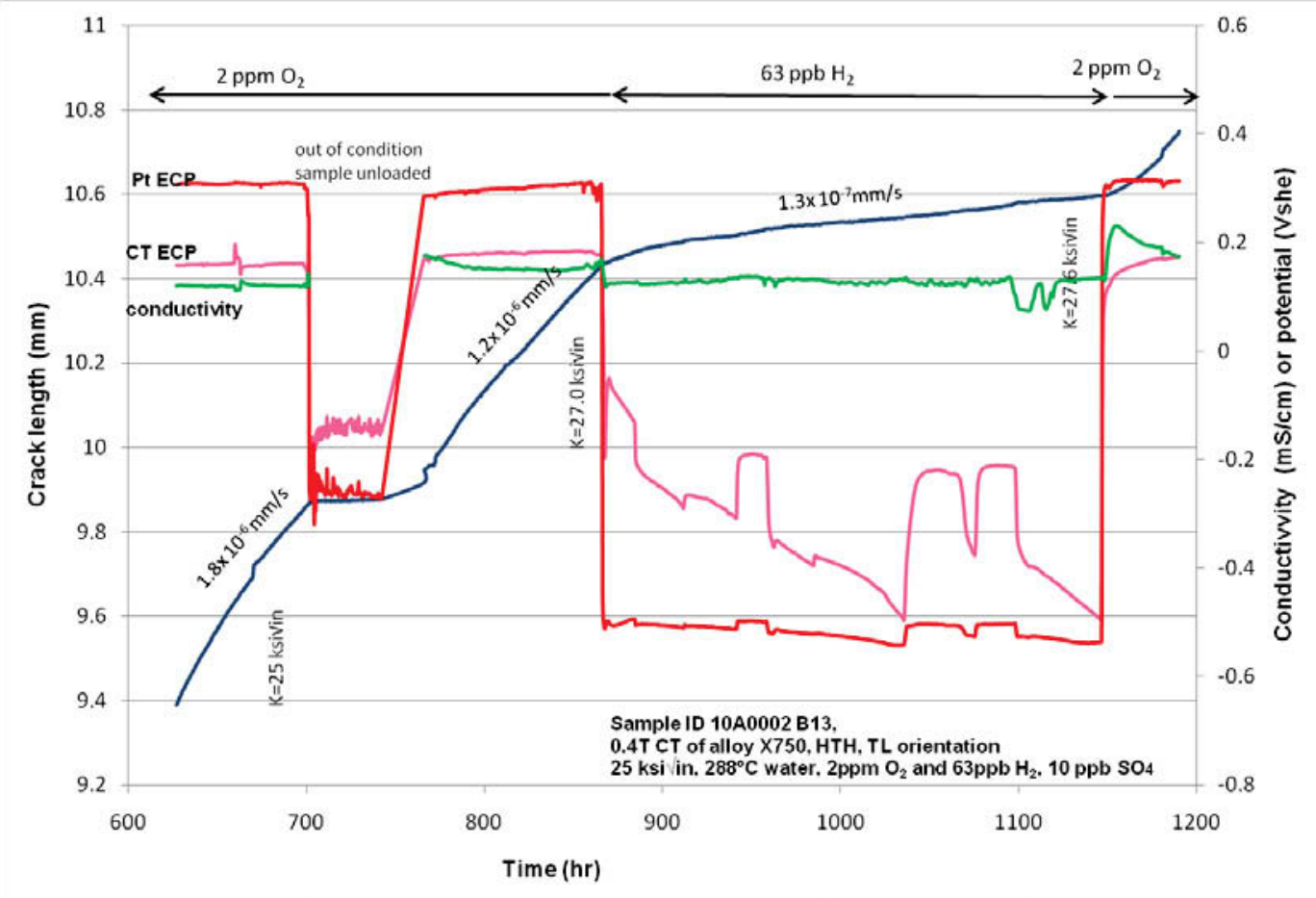

Figure 3-18: Crack length vs. time obtained with alloy X750 in TL orientation in $288{ }^{\circ} \mathrm{C}$ water with $10 \mathrm{ppb}$ sulfate addition. 


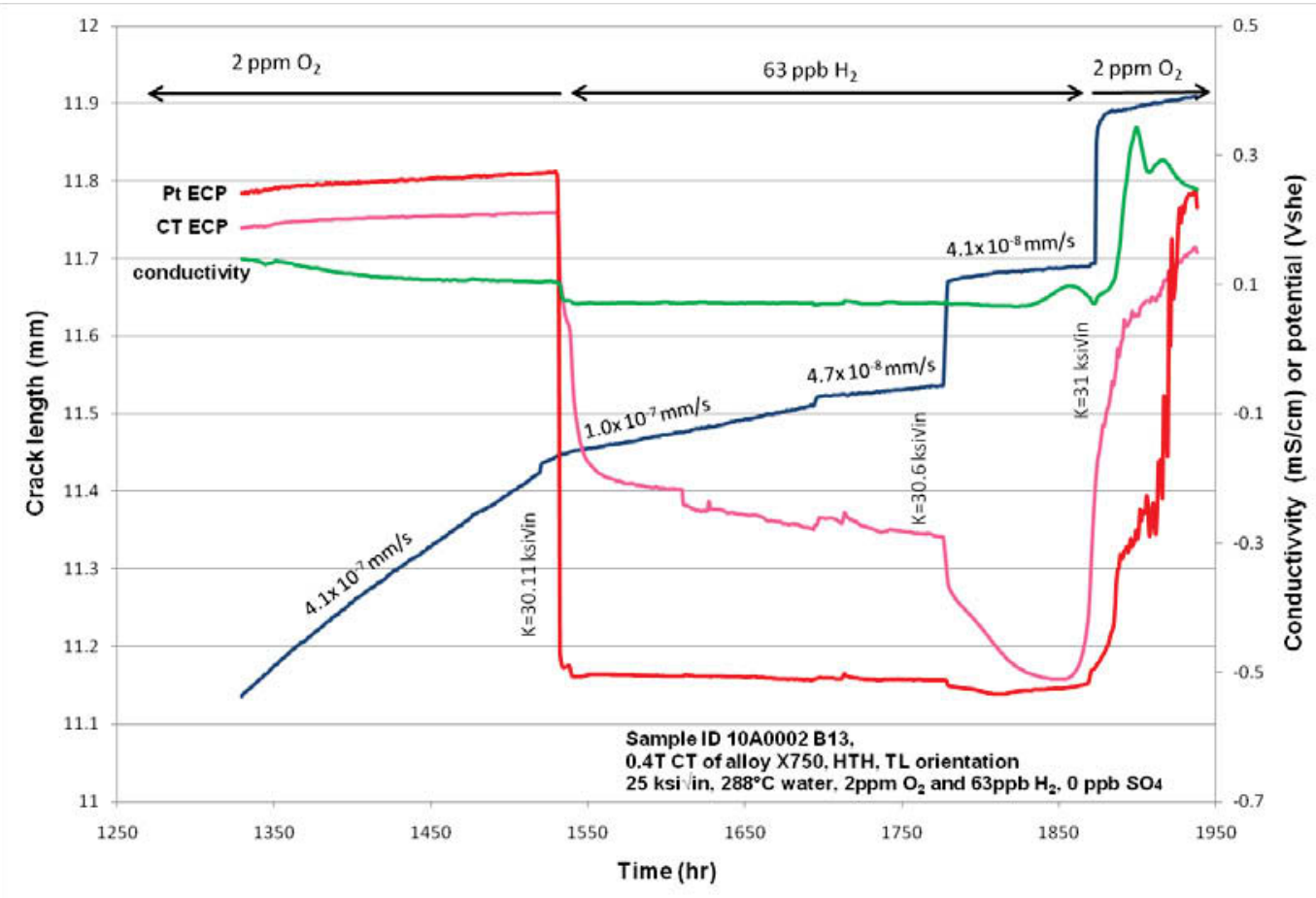

Figure 3-19: Crack length vs. time obtained with alloy X750 in TL orientation in $288{ }^{\circ} \mathrm{C}$ water with 0 ppb sulfate addition.

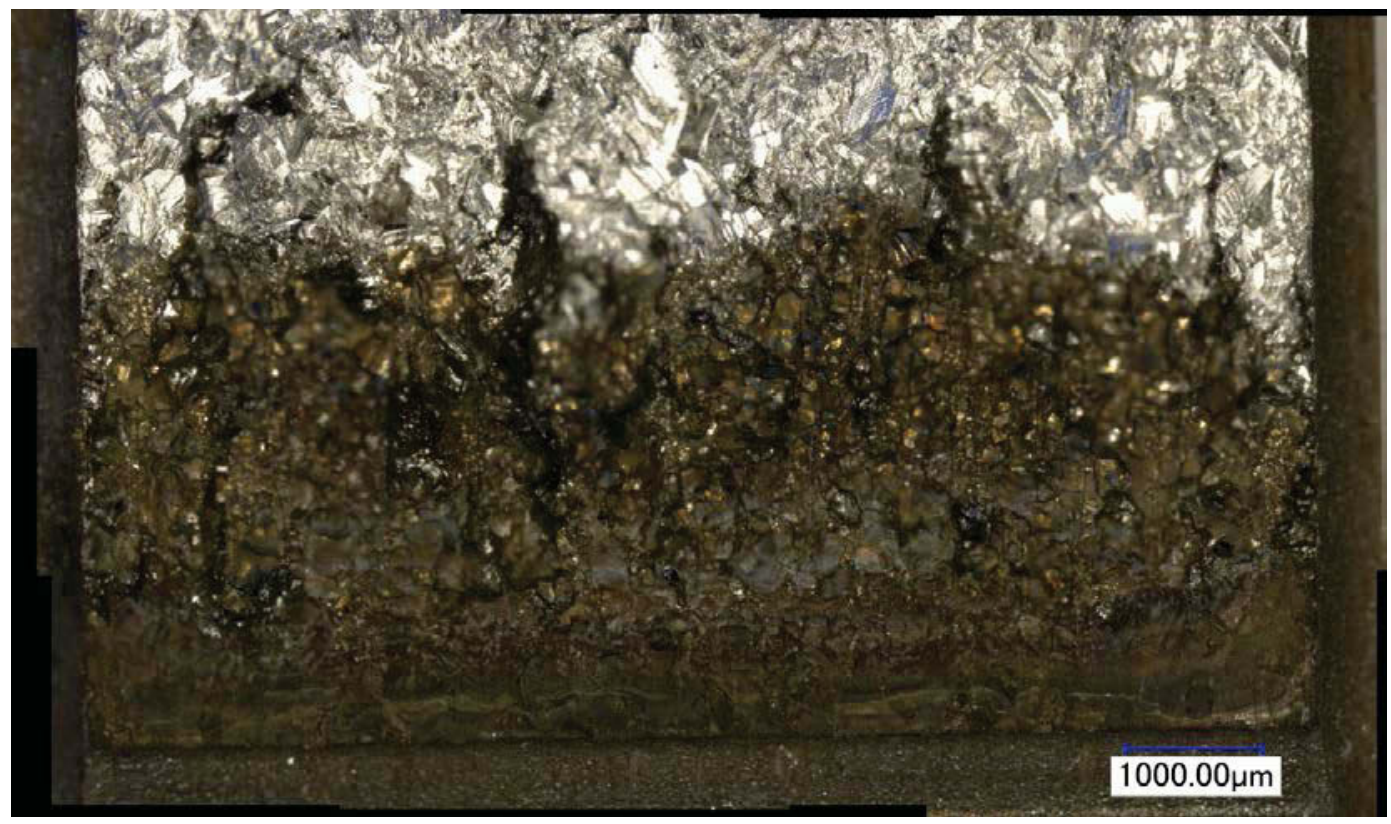

Figure 3-20: Digital fractograph of alloy X750 tested in TL orientation. 


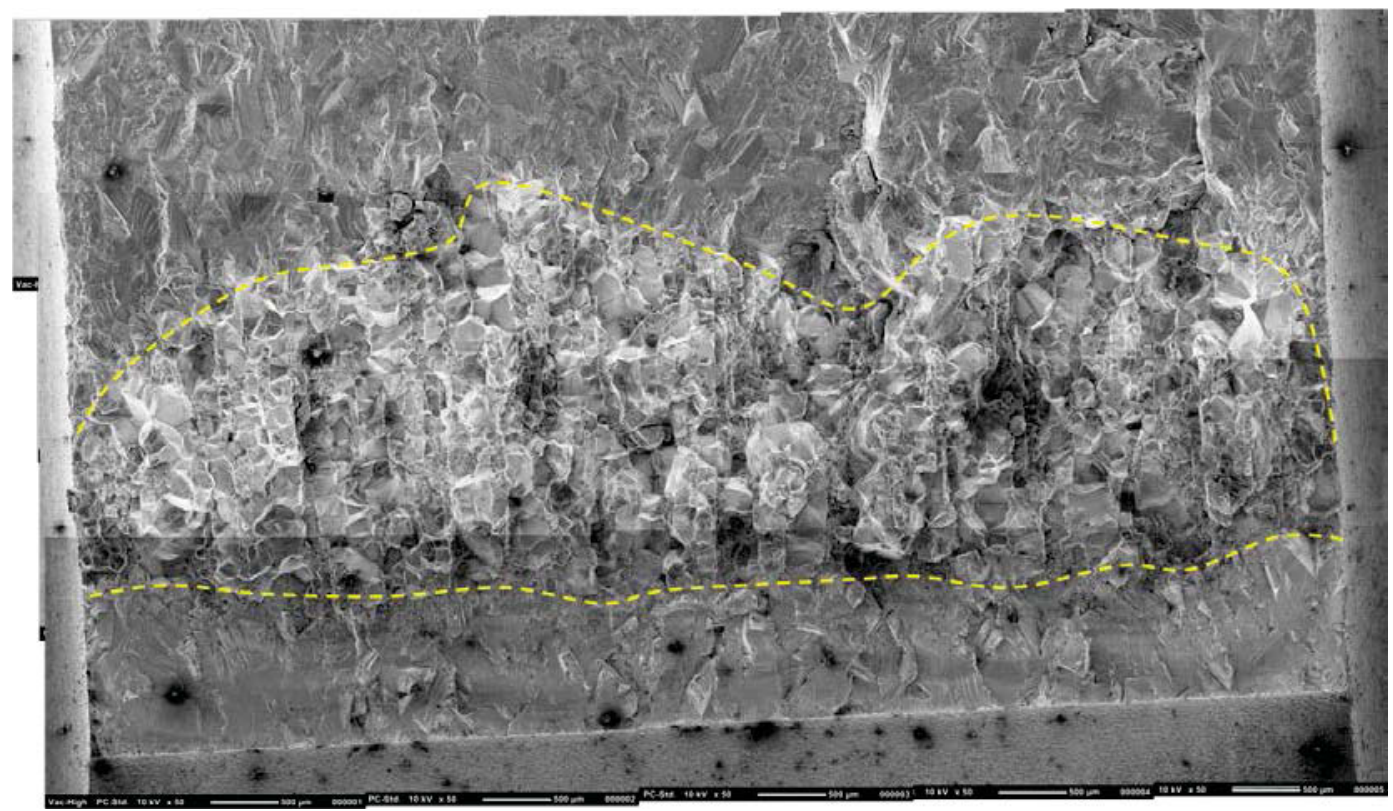

Figure 3-21: SEM fractograph of alloy X750 tested in TL orientation. Yellow lines indicate boundaries of IG crack area.

\subsubsection{Alloy X-750 S-L orientation SCC test results}

One alloy X-750 specimen ( specimen ID10A0002 EP R) was tested in the S-L orientation under constant $\mathrm{K}$ in $288^{\circ} \mathrm{C}$ water with 0,5 and $10 \mathrm{ppb}$ of sulfate addition in pure water and the CGR was recorded under these conditions. However, the outlet conductivity control was a concern during sulfate addition and was not as well controlled as expected for this part of the test; therefore most of the test was performed with $0 \mathrm{ppb}$ sulfate addition. For this test, no ECP was measured because the test equipment was new and an ECP reference probe had not been obtained. During this test a $50 \%$ anticipatory online correction was used. The error measured following the test between the post test measured average crack length and that measured with the DCPD technique was $42.0 \%$. The data presented and discussed are corrected to compensate for this error. The maximum $\mathrm{K}$ reached during this test was $32.7 \mathrm{MPa} \sqrt{ } \mathrm{m}$.

Figure 3-22 shows the crack length as a function of time for this test. Although the data did show an influence of sulfate addition to CGR, only the CGRs with $0 \mathrm{ppb}$ sulfate addition are presented. CGR was measured between $5.2 \times 10^{-7} \mathrm{~mm} / \mathrm{s}$ and $7.3 \times 10^{-7} \mathrm{~mm} / \mathrm{s}$ under NWC conditions and $1.3 \times 10^{-7} \mathrm{~mm} / \mathrm{s}$ in HWC condition. 


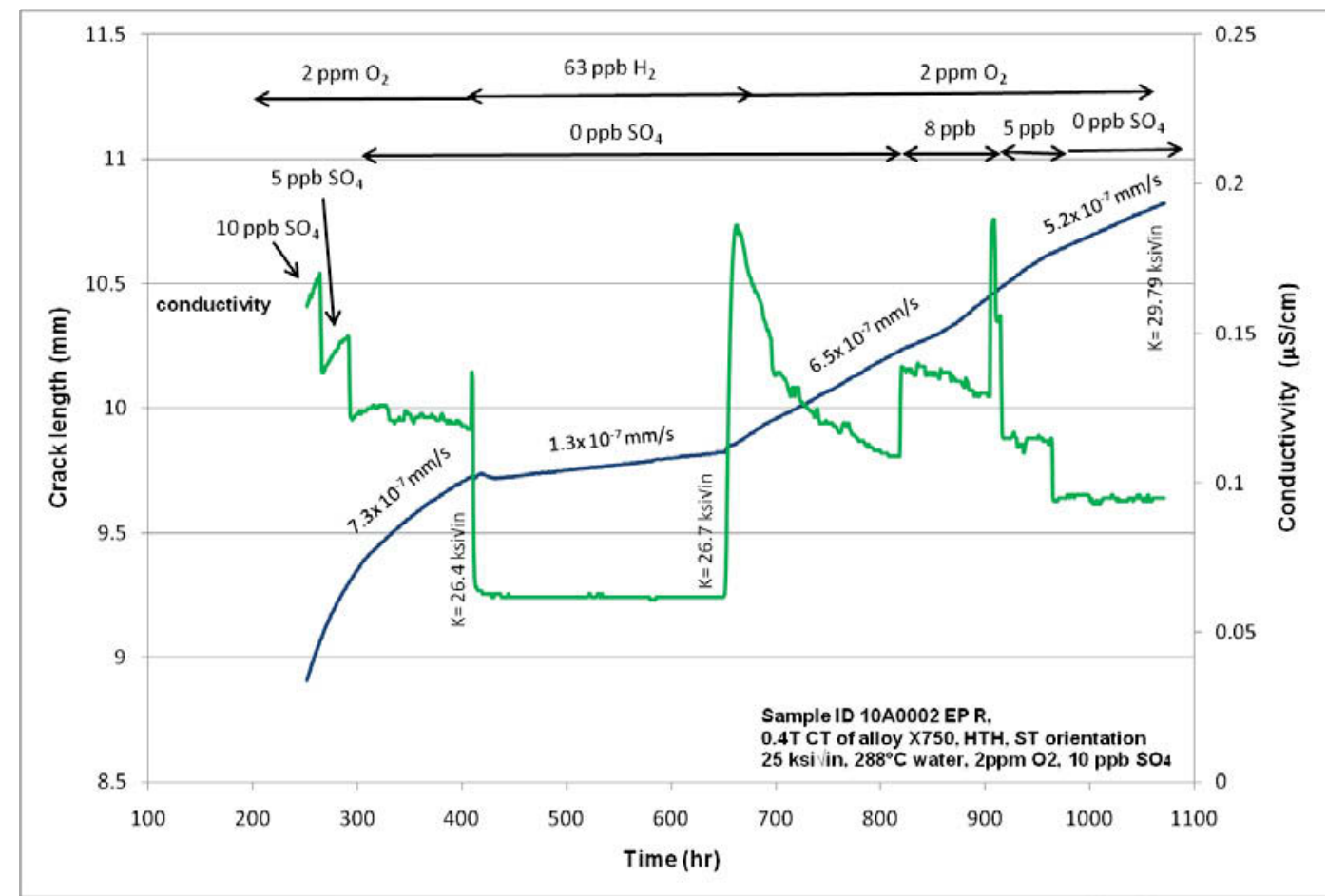

Figure 3-22: CGR response for alloy X-750 S-L orientation SCC test.

Optical fractography (Figure 3-23) showed that the crack front has a slight thumb nail shape which is confirmed by SEM fractography (Figure 3-24). The shortest crack length is $1.327 \mathrm{~mm}$, while the deepest is close to $3.818 \mathrm{~mm}$, the average crack depth is $2.981 \mathrm{~mm}$. There are also indications of narrow cracks ahead of the main crack front although they are less obvious than those observed in specimens of other orientations. The applied correction mentioned above was based on an average crack length estimated using the optically measured cracked area as described previously.

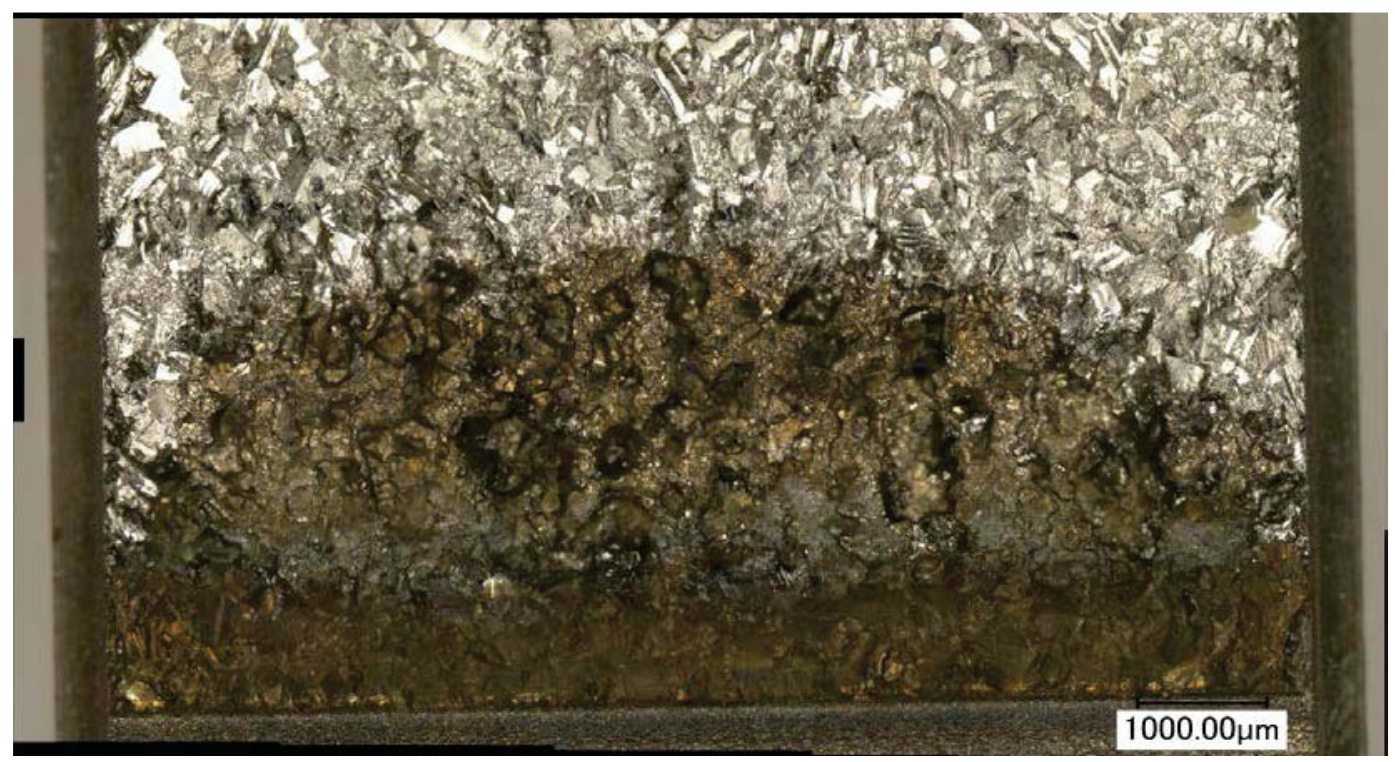

Figure 3-23: Digital fractograph of alloy X-750 tested in SL orientation. 


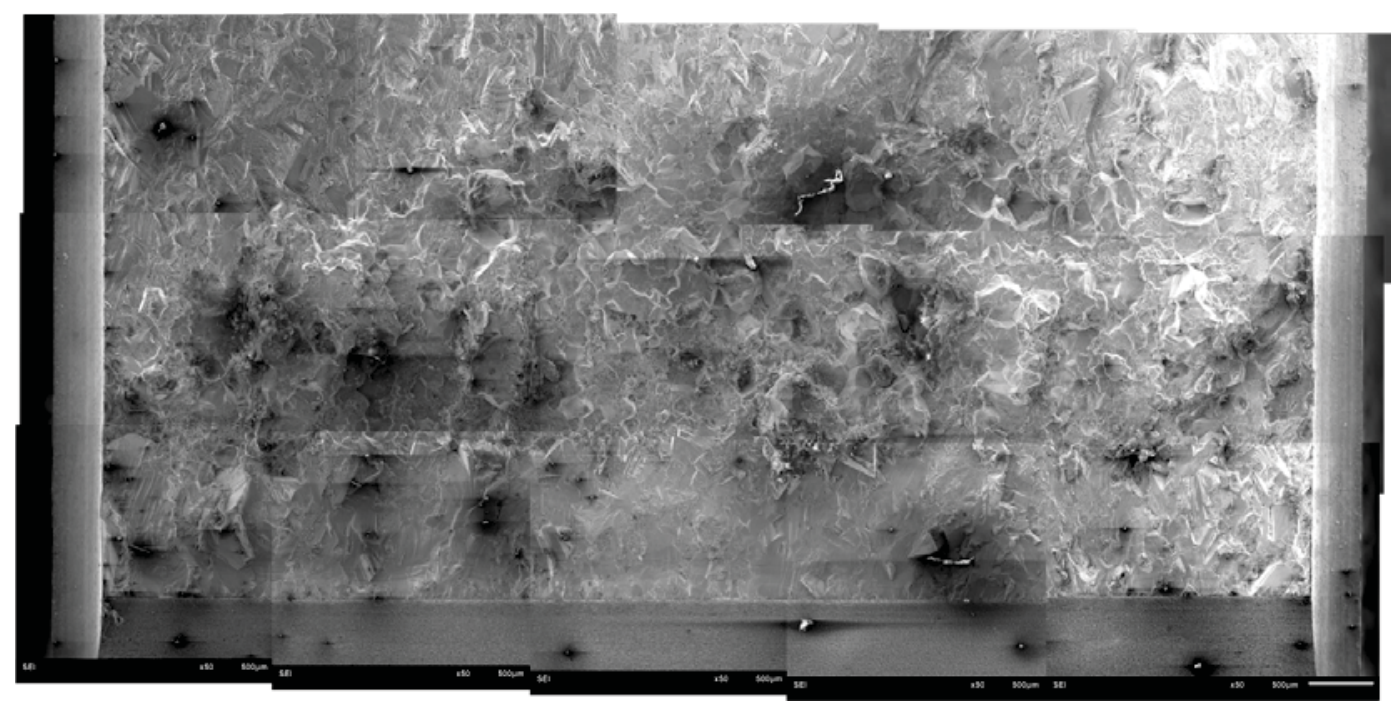

Figure 3-24: Closeup of area of interest for CGR response of alloy X-750 S-L orientation SCC test.

\subsubsection{Summary of Alloy X-750 SCC test results}

Alloy X-750 was of primary interest in this study for comparison to external (GE-GRC) lab results as well as determination of any effect of orientation on CGR. As such, there were tests conducted on three different orientations (T-L, L-T, and S-L) with, and without sulfate addition to aid crack initiation and propagation similar to the practice employed by GE-GRC for tests on the same material. Results from GE-GRC SCC tests on this same material may be found in (5) for comparison. It is assumed that the data shown in (5) is collected from multiple locations within the same plate but comparison should still be relevant since it is the identical alloy X-750 heat that was provided to INL for this testing. Table 3-4 shows the total DCPD measurement error associated with the results presented. Most fracture surfaces showed indications of narrow cracks ahead of the main crack front that are not necessarily in the main crack propagation plane. Such cracking behavior decreases the accuracy of the online measurements of the crack propagation. Figure 3-25 summarizes the various CGR measured for all specimens at the various water chemistries tested. When compared to CGR under NWC conditions, the effect of HWC on CGR without the addition of sulfate is noted to reduce CGR by a maximum of approximately one order of magnitude (10X) in the L-T orientation (Figure 3-26) and appears to have a smaller effect of an approximate $4 \mathrm{X}$ reduction in the other cases. Additionally, there appears to be only a subtle difference in CGR between orientations with the S-L orientation appearing slightly more prone to cracking. In all cases, the addition of $10 \mathrm{ppb}$ sulfate served to increase CGR by a factor 3 to 5 (Figure 3-27). In comparison to results for this alloy presented in (5), the measured CGR for respective chemistries is within reason although the effect of HWC is not quite as strong here. This difference may be at least partially due to testing at higher constant K levels; it is noted in (5) that there is a CGR K dependency of approximately $\mathrm{K}^{1.5}$. Location dependence within the plate may also play some role. 


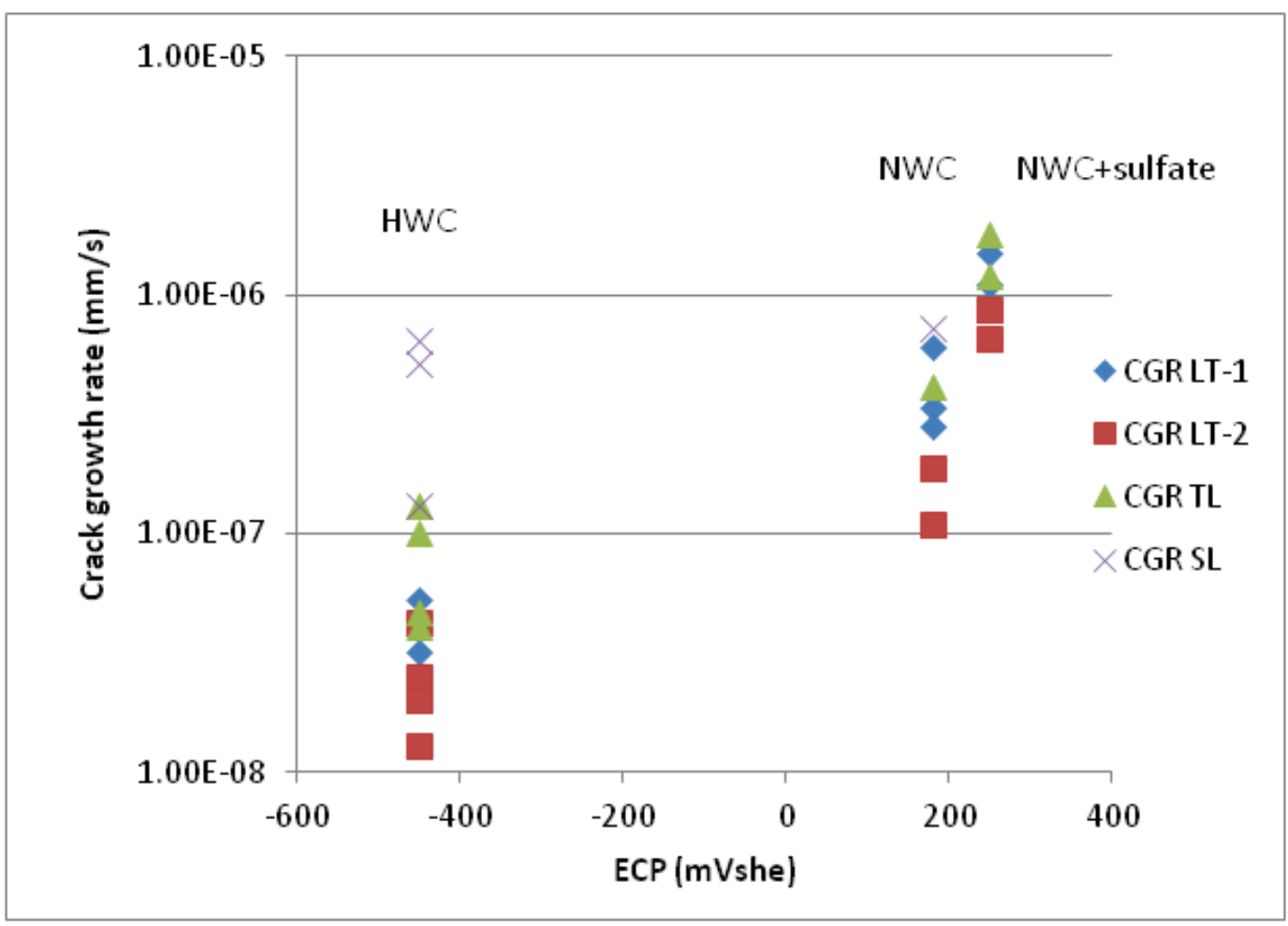

Figure 3-25: CGR for alloy X-750 as a function of ECP.



Figure 3-26: Effect of sulfate addition on CGR of alloy X-750 under NWC conditions. 


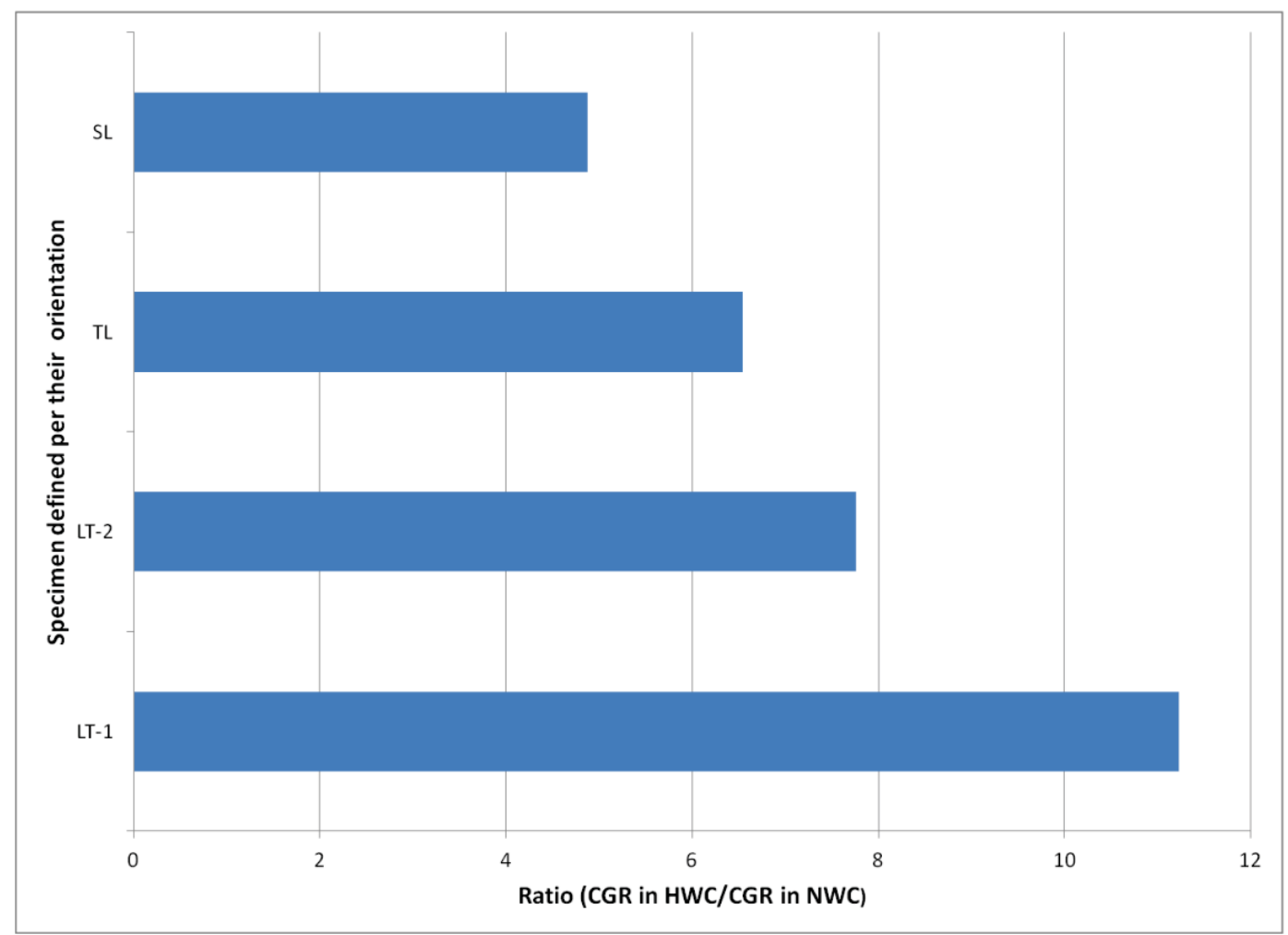

Figure 3-27: Effect of HWC on CGR compared to NWC for alloy X-750.

Table 3-4: Summary of alloy X-750 SCC tests with measured errors.

\begin{tabular}{c|c|c|c|}
\cline { 2 - 4 } Specimen ID & Orientation & $\begin{array}{c}\text { Measurement error } \\
(\%)\end{array}$ & Maximum K $(\mathrm{MPa} \sqrt{\mathrm{m}})$ \\
\hline 10A0002 A01 & L-T & 46.4 & 40.1 \\
\hline 10A0002 B01 & L-T & 37.5 & 28.8 \\
\hline 10A0002 B13 & T-L & 43.5 & 34.2 \\
\hline \multirow{2}{*}{ ID10A0002 EP R } & S-L & 42.0 & 32.7 \\
\cline { 2 - 4 } & & &
\end{tabular}

\section{Alloy XM-19 testing}

Two sections of alloy XM-19 (Heat \#A17509-BD3) were provided to INL by GE Global Research Company. One of the sections was provided in the annealed condition and the other was cold rolled in a large rolling mill at GE Global Research to induce a total of $19.3 \%$ cold work in only 2 passes. It was decided by the project team to use the $19.3 \%$ cold worked material for the baseline testing performed under this phase I project to allow comparison to the effect of neutron embrittlement on the annealed material under phase III of this project. It is expected that both cold work and neutron embrittlement will serve to increase the yield strength of the material and reduce its fracture toughness. The material 
composition is shown here in table 4-1; further details on the microstructure of the annealed alloy XM-19 may be found in (3).

Table 4-1: Composition of alloy XM-19.

\begin{tabular}{|c|c|c|c|c|c|c|c|c|c|c|c|c|c|}
\hline Mo & $\mathrm{C}$ & $\mathrm{Nb}$ & $\mathrm{Co}$ & $\mathrm{Cr}$ & $\mathrm{Cu}$ & $\mathrm{Fe}$ & $\mathrm{Mn}$ & $\mathrm{Ni}$ & $\mathrm{P}$ & $\mathrm{S}$ & $\mathrm{Si}$ & $\mathrm{Ti}$ & $\mathrm{W}$ \\
\hline 2.17 & 0.027 & 0.20 & 0.016 & 20.76 & 0.06 & $\mathrm{Bal}$ & 4.59 & 12.82 & $\mathbf{0 . 0 1 4}$ & $\mathbf{0 . 0 0 6}$ & 0.39 & 0.001 & 0.02 \\
\hline
\end{tabular}

\subsection{Alloy $\mathrm{XM}-19$ tensile test results}

Three tensile tests on $19.3 \%$ cold worked alloy XM-19 oriented in the L (rolling) direction were completed for this project. Two were performed in air at a temperature of $288^{\circ} \mathrm{C}$ and one was completed in air at room temperature $\left(24^{\circ} \mathrm{C}\right)$. Tensile tests were not conducted for the annealed XM-19 as they were outside the scope of this work and these tensile results are provided in (3). The results are listed in Table 4-2 and shown graphically in Figure $4-1$. Average $0.2 \%$ offset yield strength $\left(\sigma_{\mathrm{y} 0.2 \%}\right)$ at $288{ }^{\circ} \mathrm{C}$ was 689 $\mathrm{MPa}$, the average tensile strength $\left(\sigma_{\mathrm{ult}}\right)$ at $288^{\circ} \mathrm{C}$ was $789 \mathrm{MPa}$, and the average strain to failure $\left(\varepsilon_{\mathrm{f}}\right)$ at $288{ }^{\circ} \mathrm{C}$ was $14.5 \%$. When tested at room temperature, the $0.2 \%$ offset yield strength, tensile strength, and strain to failure increased to $891 \mathrm{MPa}, 993 \mathrm{MPa}$, and $22.1 \%$, respectively. The strength of the $19.3 \%$ cold worked material is significantly higher and the ductility is significantly lower than that of the annealed material as reported in (3). At a temperature of $288^{\circ} \mathrm{C}$, the average $0.2 \%$ offset yield strength is approximately 2.75 times that of the annealed material, while the tensile strength is increased by approximately 1.27 times and the strain to failure is reduced by 2.2 to 3.2 times. Room temperature yield strength was increased by approximately 2.2 times, tensile strength increased approximately 1.3 times and strain to failure was reduced by 2.3 to 2.7 times when compared to that of the annealed material.

Table 4-2: Tensile properties of $19.3 \% \mathrm{CW}$ alloy $\mathrm{XM}-19$ at $24^{\circ} \mathrm{C}$ and $288^{\circ} \mathrm{C}$.

\begin{tabular}{l|c|c|c|c|}
\cline { 2 - 5 } & $\mathbf{T ~}\left({ }^{\circ} \mathbf{C}\right)$ & (MPa) & (MPa) & (\%) \\
\hline XM-19 CW 01 & 288 & 678 & 786 & 14.5 \\
\hline XM-19 CW 03 & 288 & 701 & 793 & 14.6 \\
\hline XM-19 CW 02 & 24 & 891 & 993 & 22.1 \\
\cline { 2 - 5 }
\end{tabular}




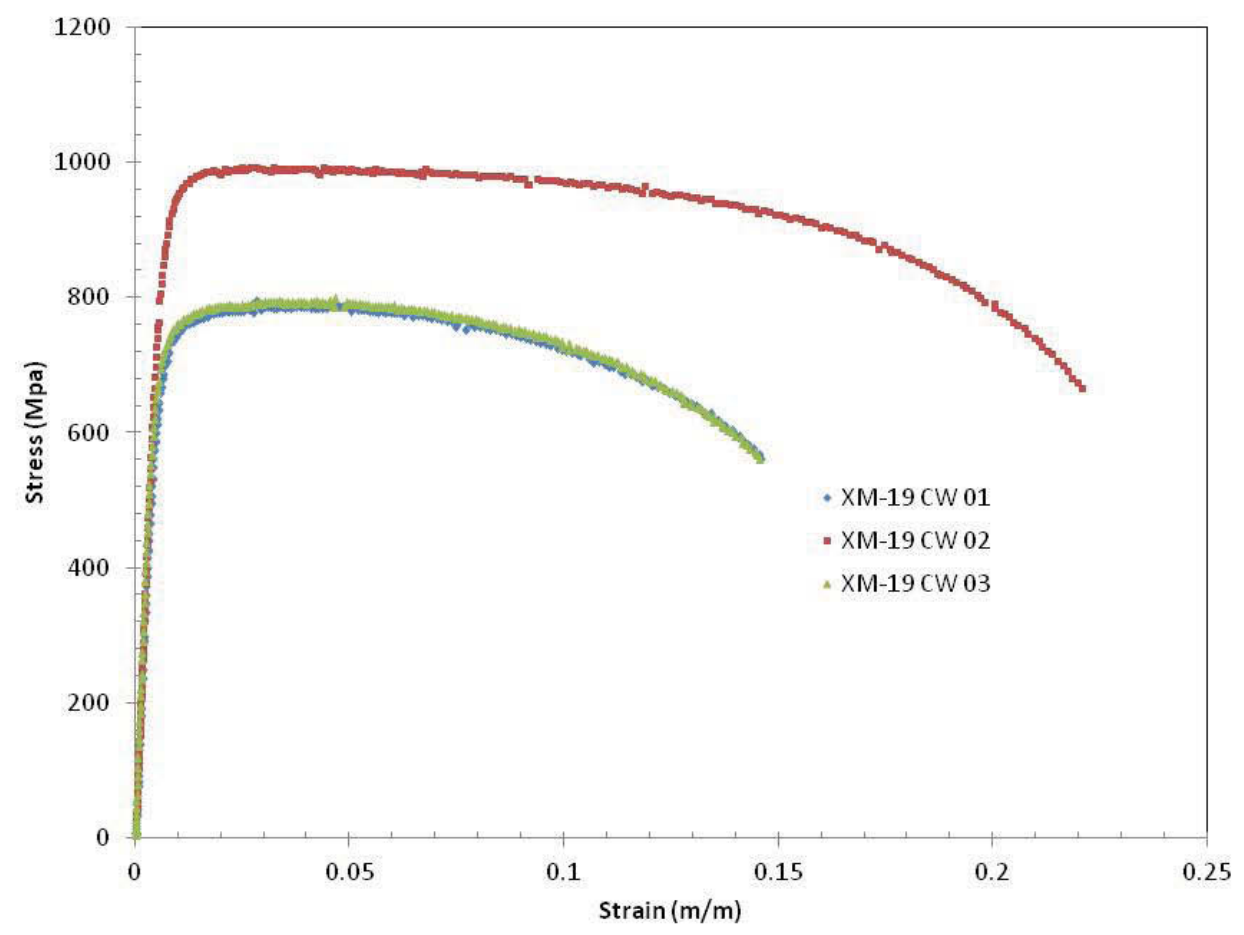

Figure 4-1: Stress-Strain curves for $19.3 \% \mathrm{CW}$ alloy $\mathrm{XM}-19$ at $24^{\circ} \mathrm{C}$ and $288^{\circ} \mathrm{C}$.

\section{$4.2 \quad 19.3 \%$ CW Alloy XM-19 Fracture toughness test results}

Three, $0.5 \mathrm{~T}-\mathrm{CT}$ specimens machined in the L-T orientation were used to measure $J$ resistance $(J-R)$ for the supplied $19.3 \%$ cold worked alloy XM-19 in air at a nominal temperature of $288^{\circ} \mathrm{C}$. These specimens are identified as 10A0016 A1 01, 10A0016 A2 01, and 10A0016 A2 02. Specimen 10A0016 A1-01 was machined with side grooves of 5\% per side (10\% total side groove) and specimens $10 \mathrm{~A} 0016$ A2 01 and 10A0016 A2 02 had their side grooves deepened to $10 \%$ per side (20\% total) in order to control the extensive tunneling observed while testing specimen 10A0016 A1 01. The specimens were fatigue pre-cracked at room temperature in air to an initial normalized crack length, $a_{0} / W$ target between 0.50 and 0.60 . Fatigue pre-cracking was performed with an $R$ ratio (ratio of minimum to maximum force) of 0.1 and with a $K_{\max }<50 \mathrm{MPa} \sqrt{ }$ m, the maximum allowable $K_{\max }$ for pre fatigue of this material per ASTM E1820-09 (2).

The response of the $19.3 \%$ cold worked alloy XM-19 specimens precludes them from being considered for determination of a $J-R$ curve, and elastic-plastic fracture toughness $J_{\text {IC }}$. This is primarily because at the point of failure, the magnitude of the tearing modulus $(\mathrm{dJ} / \mathrm{d} a)$ is reduced to essentially zero and rapid crack growth occurs with little, if any additional driving force. Stable crack growth is defined as that during which the resistance curve ( $J-R$ curve) has a positive slope. When the resistance curve becomes tangent to the driving force curve, fracture instability has occurred (6). For the material tested here, this occurred concurrent with crack initiation; thus, no stable crack propagation occurred and $J_{\text {IC }}$ cannot be defined per ASTM E1820-09 (2). Additionally, the severe tunneling observed in these specimens is associated with a large variation of stress triaxiality through the material thickness, making an estimation of generalized strain energy release rate ( $J$-integral) dependent on location within the thickness of the specimen. 
The fracture toughness for the $19.3 \%$ cold worked alloy XM-19 was determined using the $95 \%$ secant method outlined in (2). Here, the slope of the linear portion of the force vs. COD is determined and a straight line is plotted over the curve at $95 \%$ of this value. The intersection of this $95 \%$ secant line and the force vs. $C O D$ curve is defined as $P_{\mathrm{Q}}$; this value of force is used to calculate $K_{\mathrm{Q}}$ at the current crack length, $a$. These specimens met all requirements for qualifying $K_{\mathrm{Q}}$ as $K_{\mathrm{IC}}$, except that the ratio of maximum load $\left(P_{\max }\right)$ to $P_{\mathrm{Q}}$ was greater than 1.10; a requirement defined in ASTM E1820-09 (2) for qualification of $K_{\mathrm{Q}}$ as $K_{\mathrm{IC}}$. The implication is that the toughness values reported here are specimen size dependent because of the implied ductility associated with the difference between $P_{\max }$ and $P_{\mathrm{Q}}$. The value of 1.10 is somewhat arbitrary and in all cases for the specimens tested under this project this ratio was not appreciably higher. Therefore, it is the opinion of the author that the values of $K_{\mathrm{Q}}$ calculated here may be considered valid.

Table 4-3: Fracture toughness results for $19.3 \% \mathrm{CW}$ alloy $\mathrm{XM}-19$ at $288^{\circ} \mathrm{C}$.

\begin{tabular}{c|c|c|}
\cline { 2 - 3 } & $a_{0} / W$ & $K_{Q}(-)$ \\
\hline 10A0016 A1 01 & 0.574 & 81.3 \\
\hline 10A0016 A2 01 & 0.534 & 71.5 \\
\hline 10A0016 A2 02 & 0.566 & 83.5 \\
\cline { 2 - 3 }
\end{tabular}

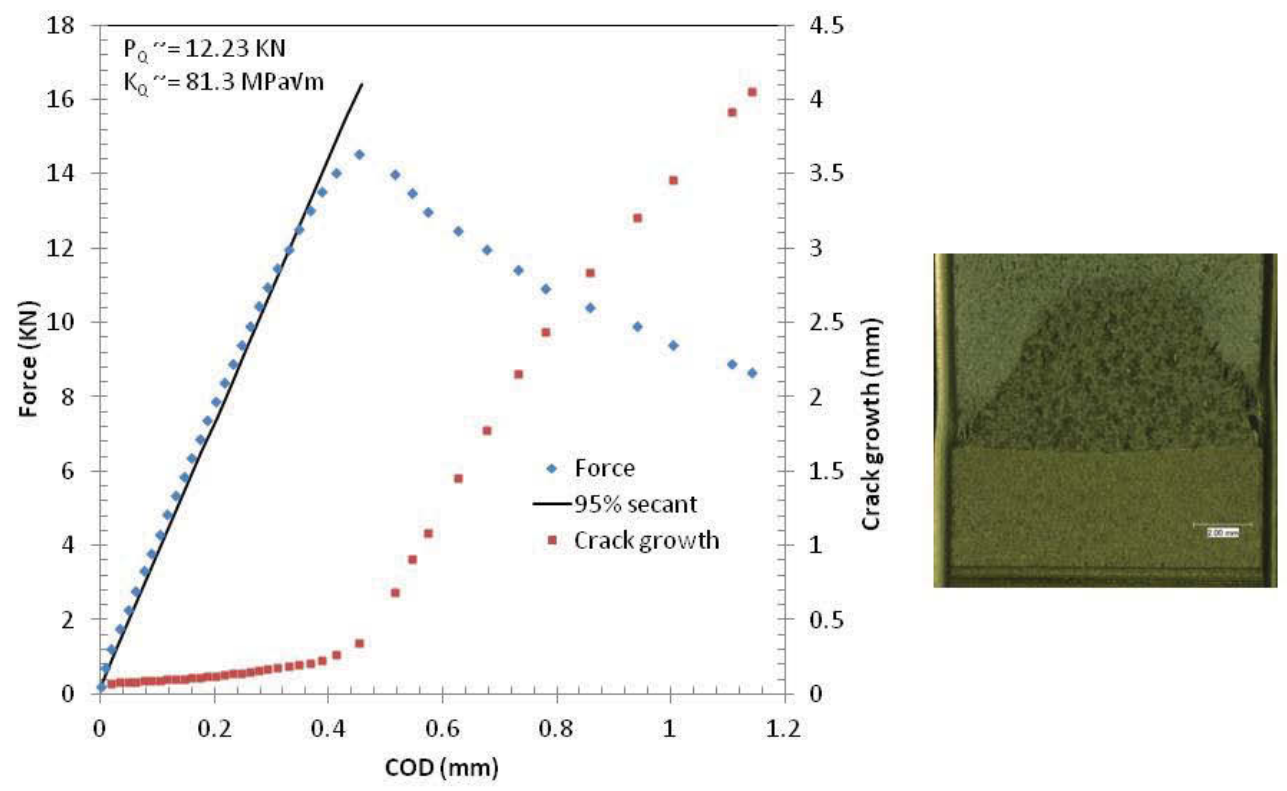

Figure 4-2: Specimen $10 \mathrm{A0016}$ A1 01 (19.3\% CW XM-19) fracture test at $288^{\circ} \mathrm{C}$. 


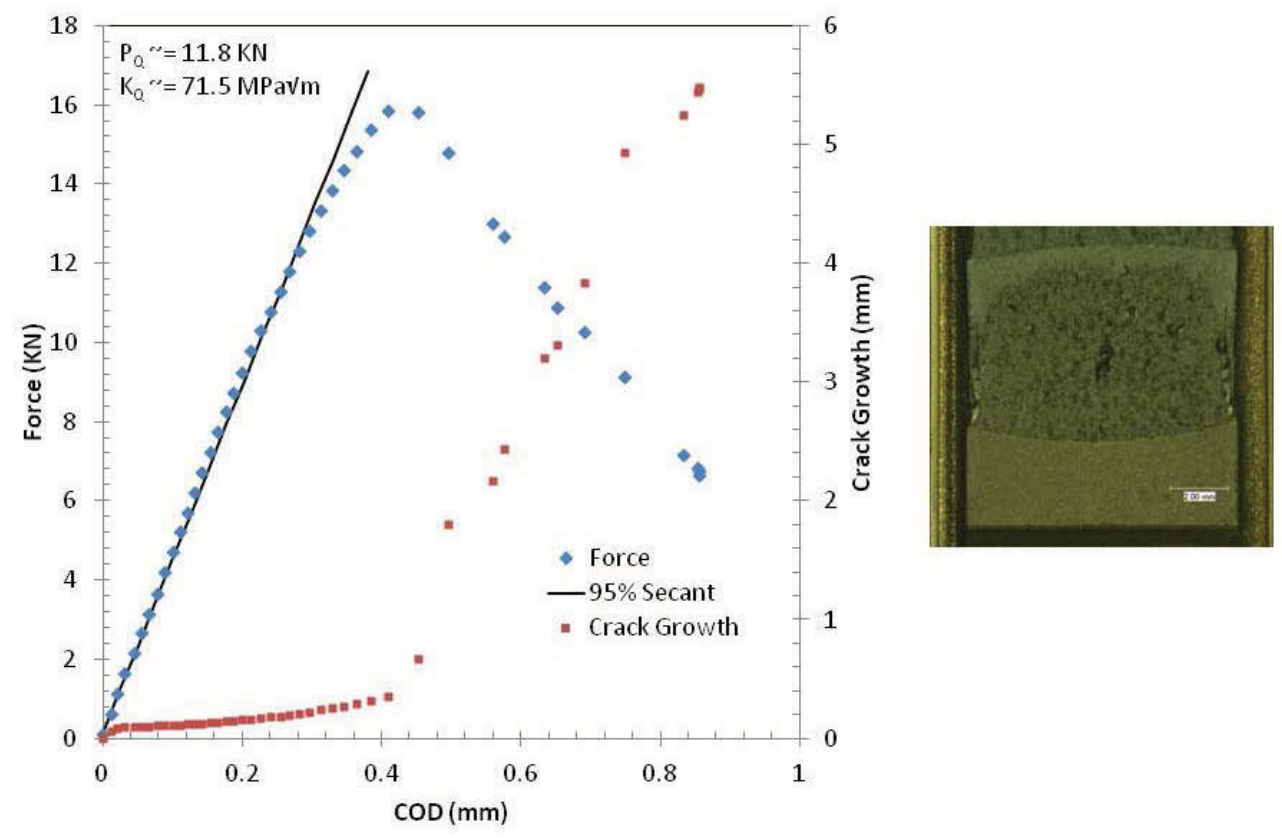

Figure 4-3: Specimen 10A0016 A2 01 (19.3\% CW XM-19) fracture test at $288^{\circ} \mathrm{C}$.

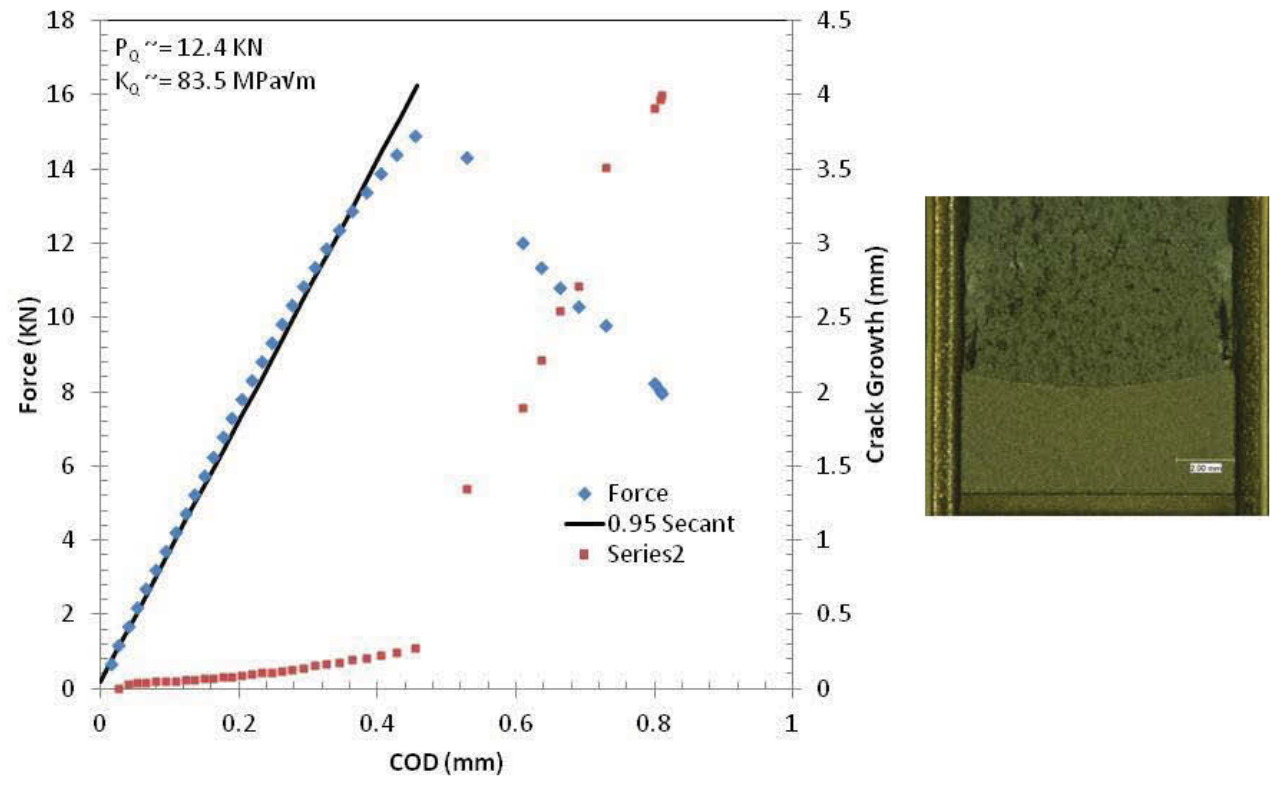

Figure 4-4: Specimen 10A0016 A2 $02\left(19.3 \%\right.$ CW XM-19) fracture test at $288^{\circ} \mathrm{C}$. 
Following fracture testing, the fracture surface of specimen 10A0016 A1 01 was examined in an SEM to determine the primary mode of failure. Figure 4-5 is an SEM fractograph showing typical fracture surface features of the $19.3 \%$ cold worked alloy XM-19. The growth mechanism appears to be almost exclusively microvoid growth and coalescence with interspersed large inclusions. This is consistent with the extensive tunneling and the nonlinearity between $P_{\max }$ and $P_{\mathrm{Q}}$ observed during fracture testing. Figure 4-6 is a 500X SEM image focused on an inclusion and Figure 4-7 is an EDAX scan result for this inclusion showing that it is a manganese rich particle. It is noted that $\mathrm{MnS}$ inclusions were identified in this material in (3) but the absence of sulfur in the EDAX scan precludes definition as a sulfide particle in this particular case.

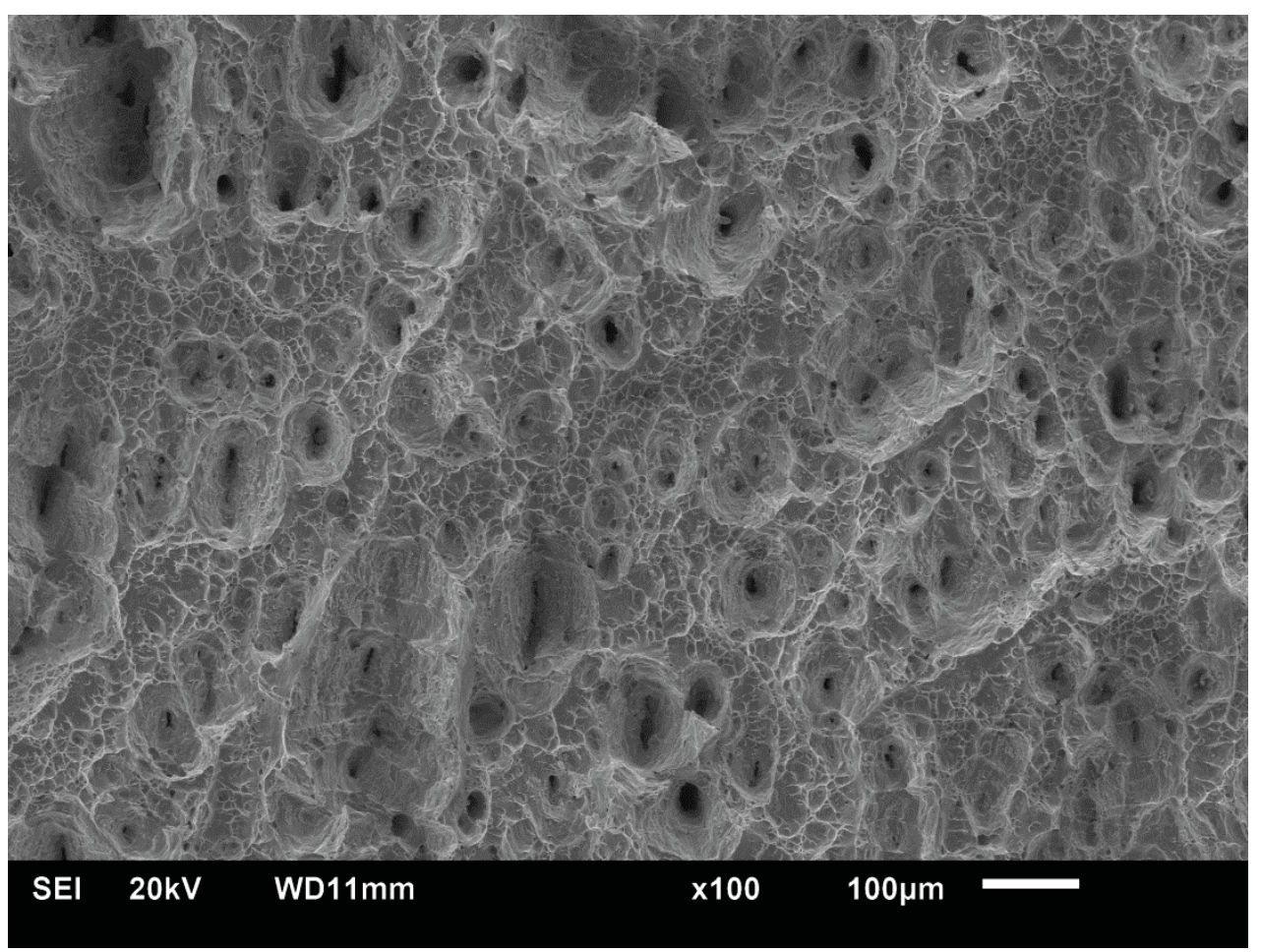

Figure 4-5: SEM fractograph of $19.3 \% \mathrm{CW}$ alloy XM-19 tested at $288^{\circ} \mathrm{C}$. 


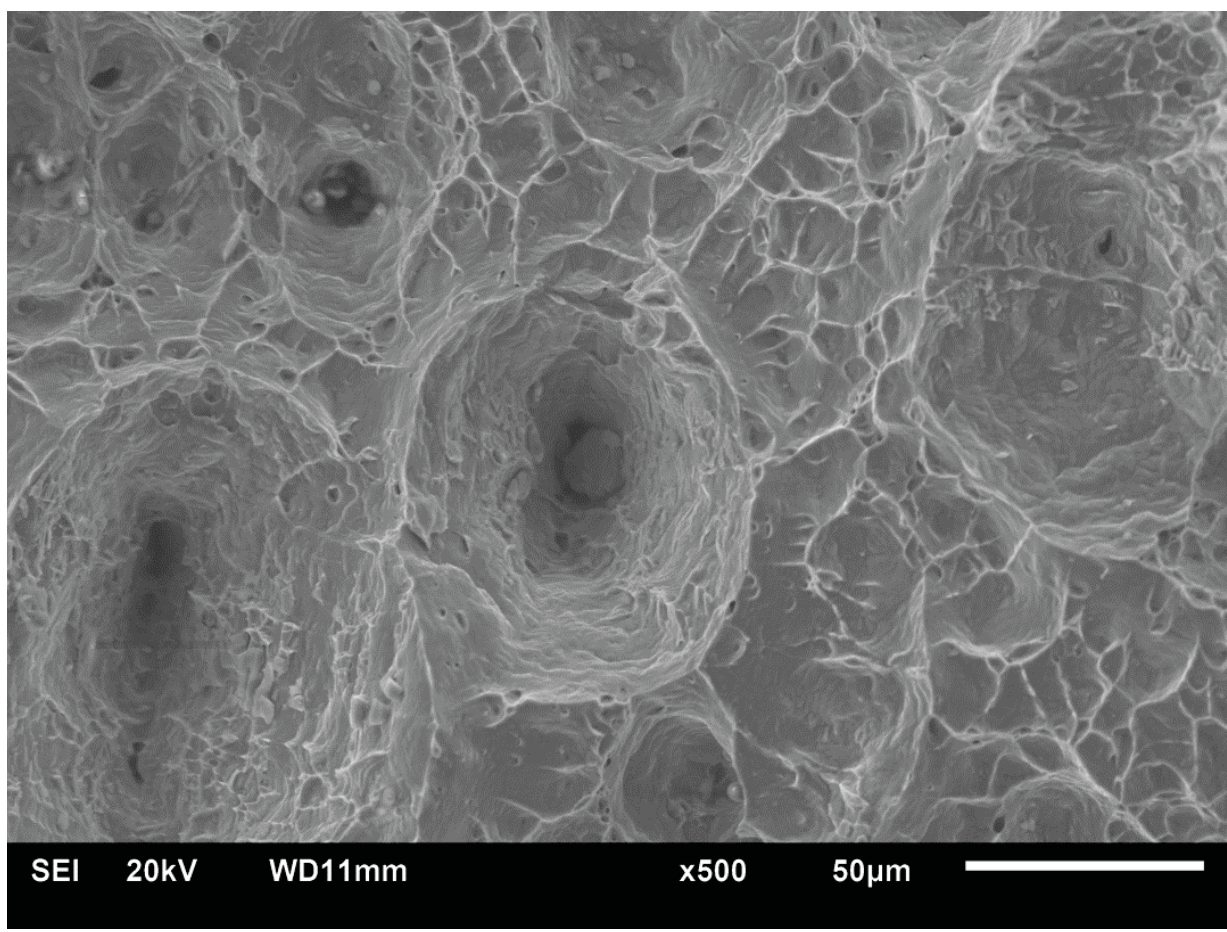

Figure 4-6: SEM image of Mn rich inclusion in fracture surface of 19.3\% CW XM-19.

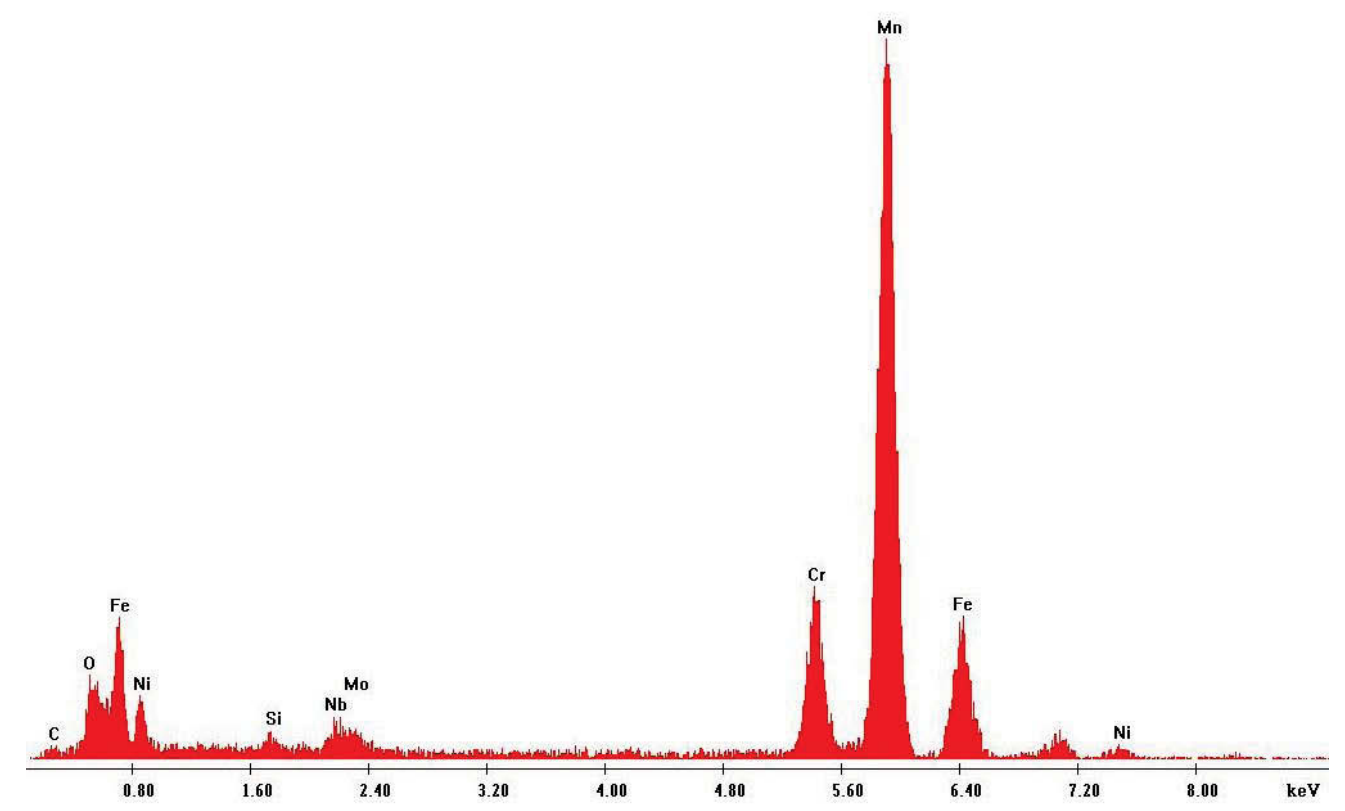

Figure 4-7: EDAX scan results from Mn rich inclusion in fracture surface of $19.3 \% \mathrm{CW}$ XM-19. 


\section{3 $19.3 \%$ cold worked alloy XM-19 SCC test results}

The first SCC experiment on 19.3\% cold worked alloy XM-19 ( specimen ID 10A0016C3-01) was performed in $288^{\circ} \mathrm{C}$ water with no sulfate added. No online correction of DCPD for crack length estimation was used. Post test analysis showed the error between the post test measured average crack length and that measured with the DCPD technique was $13 \%$. The data presented were corrected to compensate for this error. For the second, ongoing confirmatory test (specimen ID 10A0016C3-02), an anticipatory online correction $(20 \%)$ is being used and the data are presented without any correction.

The first CGR was measured under NWC conditions. The crack propagated at a stable rate of $3.1 \mathrm{x}$ $10^{-7} \mathrm{~mm} / \mathrm{s}$ for about 170 hours. When the water chemistry was switched to HWC, the CGR dropped to 4.3 $\mathrm{x} 10^{-10} \mathrm{~mm} / \mathrm{s}$ and stayed constant for 150 hours. When the water chemistry was then changed back to NWC, the CGR stayed very low for about 70 hours before resuming at a $2.6 \times 10^{-7} \mathrm{~mm} / \mathrm{s}$ rate that was maintained for 130 hours. These steps are presented in Figure 4-8. It was then decided to return to HWC in small, incremental steps in an effort to prevent crack arrest and to reproduce the average ECP between the transition between HWC and NWC at 800 hours. The environment was first de-aerated by bubbling argon. In this condition, the CGR decreased but stayed significantly higher than the CGR obtained at 800 hours. As there was no indication that the CGR would decrease at this point, the water chemistry was switched fully to HWC where a stable CGR of $1.2 \times 10^{-9} \mathrm{~mm} / \mathrm{s}$ was maintained for about 200 hours. At that point, the water flow rate was decreased to let the conductivity increase with the expectation that water conductivity similar to that in NWC would accelerate CGR. No additives were used at this point. After a quick excursion to high conductivity $(0.138 \mu \mathrm{S} / \mathrm{cm})$ the CGR increased and maintained a constant value even after the conductivity was brought to about $0.063 \mu \mathrm{S} / \mathrm{cm}$. The CGR was stable for 200 hours at $6.6 \times 10^{-9} \mathrm{~mm} / \mathrm{s}$. The water chemistry was returned to NWC condition where a CGR of $2.7 \times 10^{-7} \mathrm{~mm} / \mathrm{s}$ was obtained. Similar to the previous transition, it took about 55 hours for the CGR to start increasing after the transition. These last steps of the test are presented in Figure 4-9.

Figure 4-10 shows the crack propagating in specimen 10A0016C3-02 in NWC conditions. After propagating at a stable rate of $3.6 \times 10^{-7} \mathrm{~mm} / \mathrm{s}$ for 75 hours, a lower rate of $1.2 \times 10^{-7} \mathrm{~mm} / \mathrm{s}$ was measured for the next 125 hours. To this point the measured CGR is consistent with the results obtained for specimen 10A0016C3-01. Final results for this test will be added to this report as an addendum when the CGR test is completed. Based on the stable behavior of this material observed in the first test (10A0016C3-01), it is anticipated that final results will be very similar. 


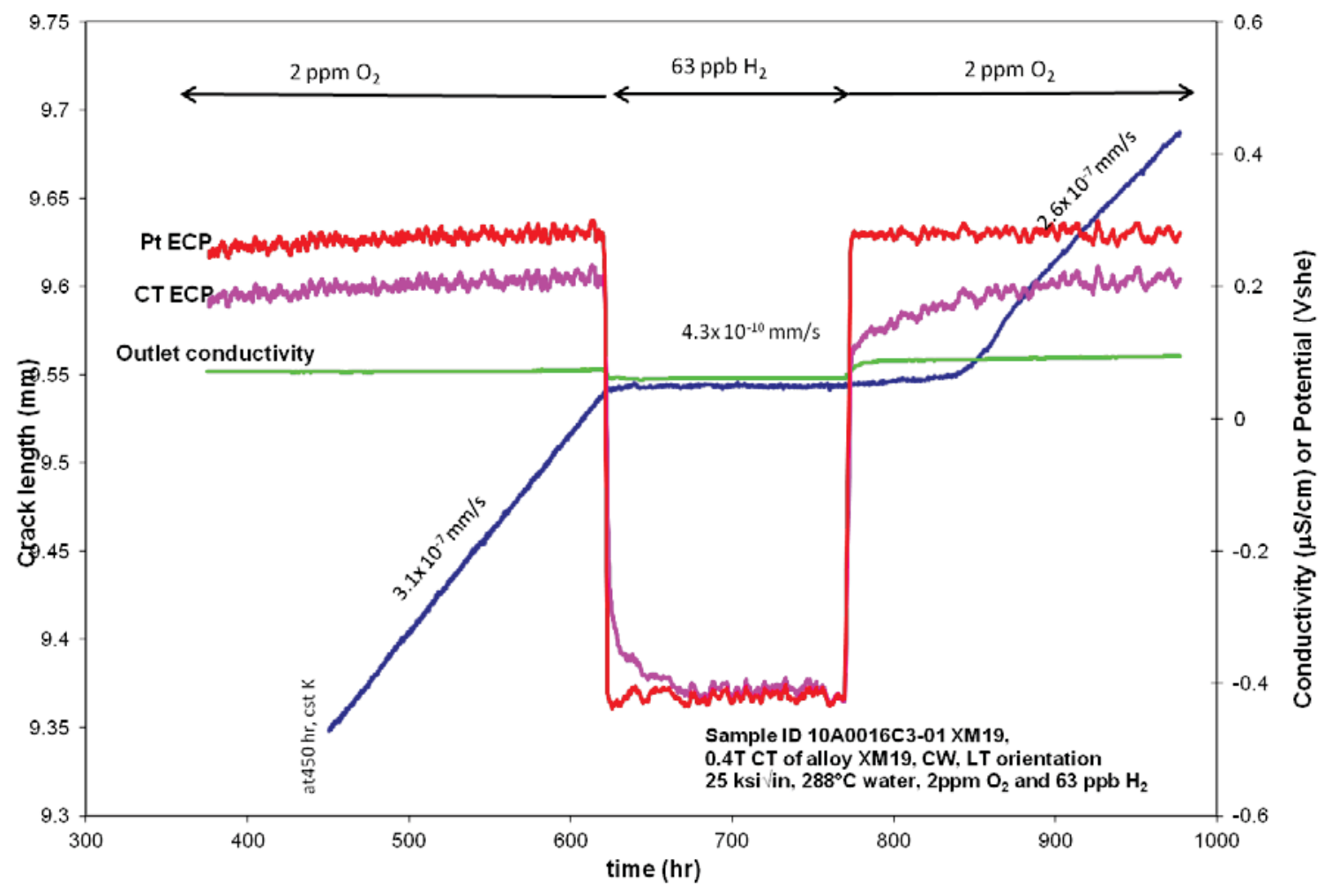

Figure 4-8: Crack length vs. time obtained with sample ID $10 \mathrm{A0016}$ C3 01, first part of the test.

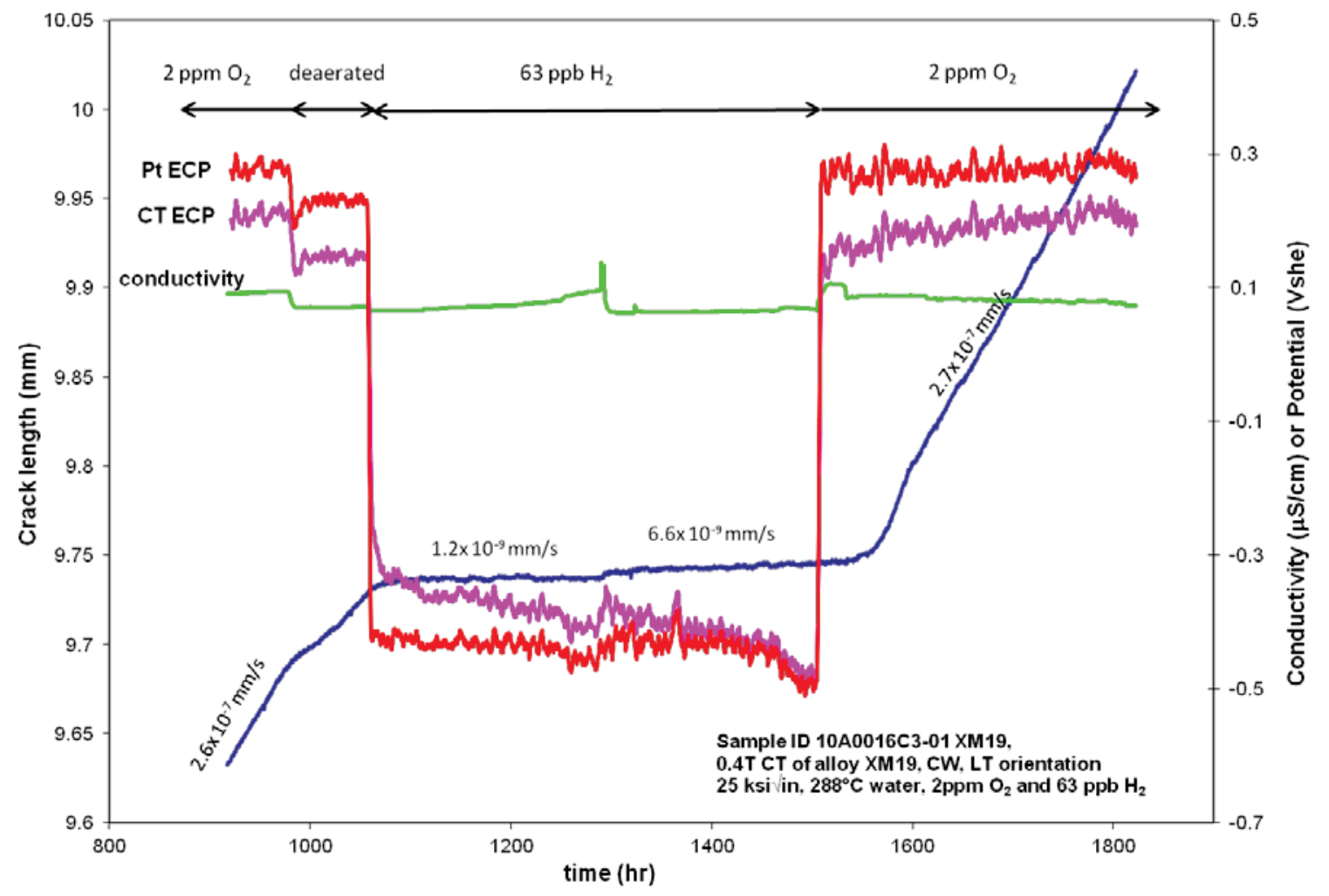

Figure 4-9: Crack length vs. time obtained with sample ID $10 \mathrm{A0016}$ C3 01, last part of the test. 


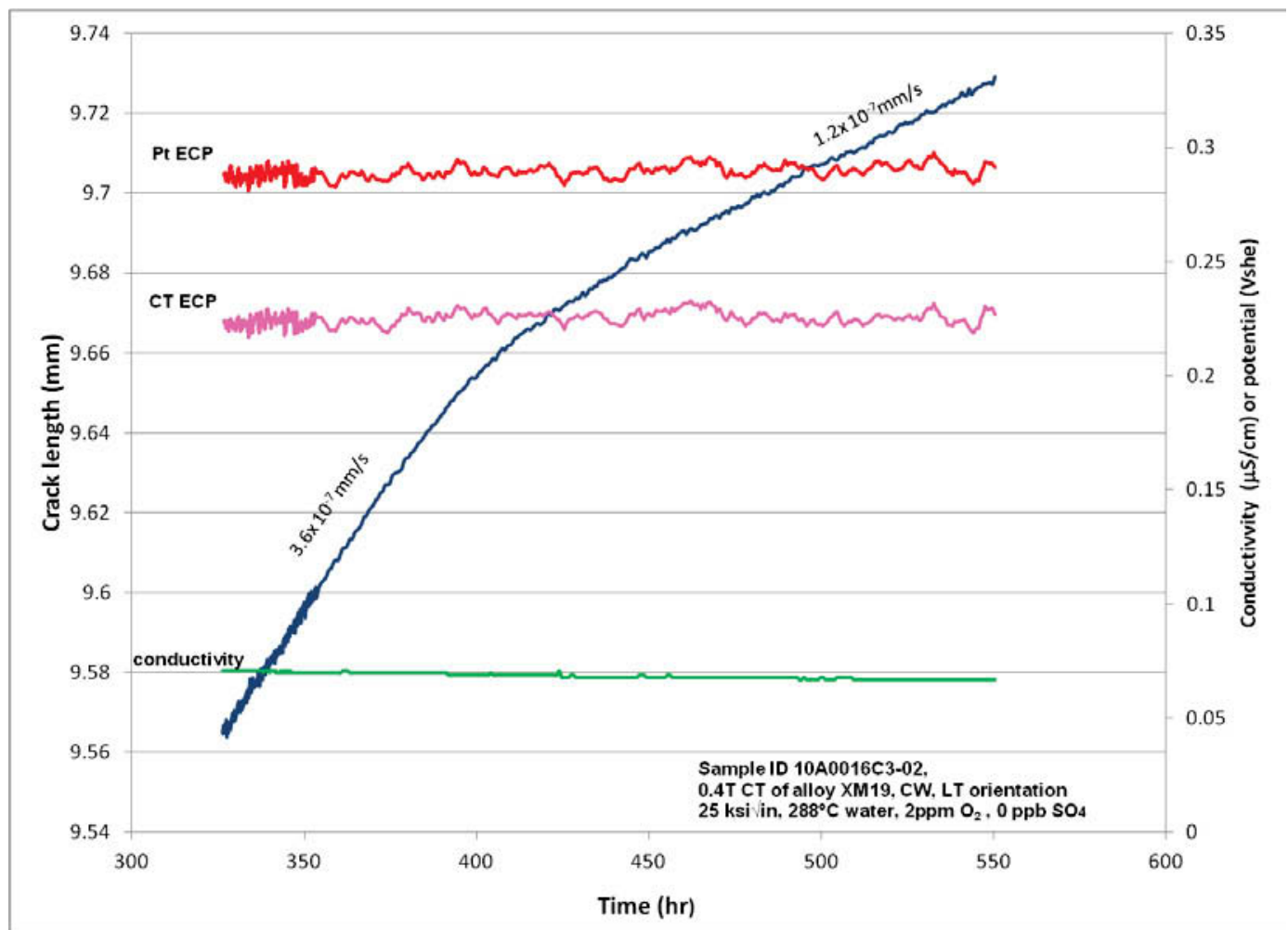

Figure 4-10: Crack length vs. time obtained with sample ID $10 \mathrm{A0016} \mathrm{C3} 02$

Post test analysis of the fracture surface of specimen (10A16 C3 01) showed that the fracture surface was reasonably straight (Figure 4-11). One will notice, however, the presence of very thin ligament of oxidized material ahead of the crack front. The SEM fractography (Figure 4-12, Figure 4-13) showed that the crack propagated in a granular mode for the duration of the SCC test with several secondary cracks.

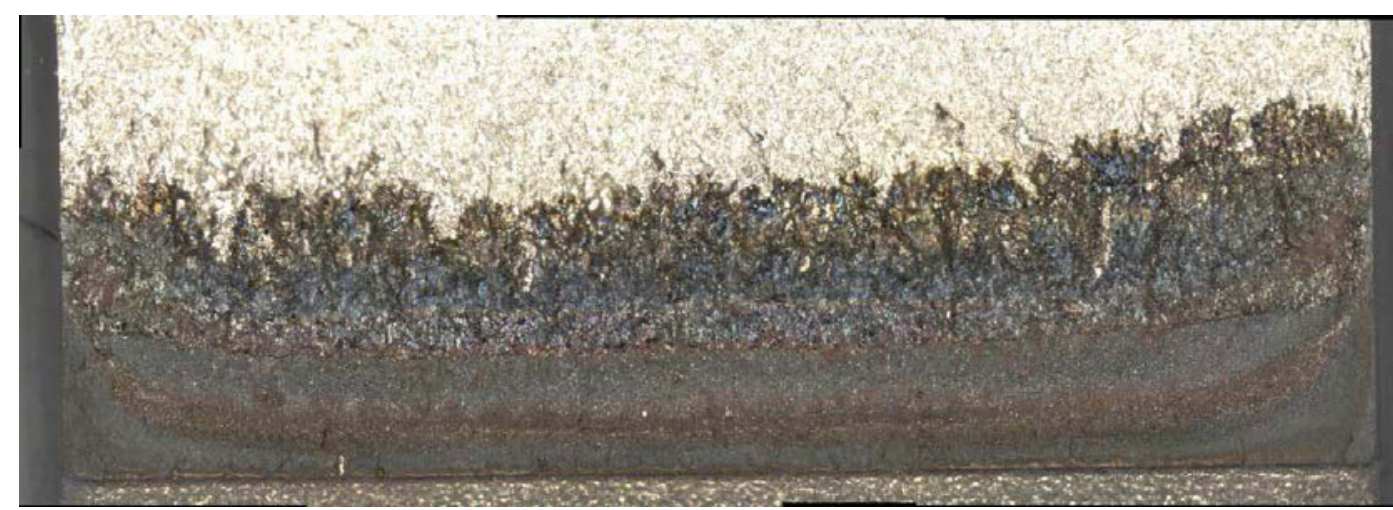

Figure 4-11: Fracture surface of sample ID 10A0016 C3 01, obtained by optical microscopy. 


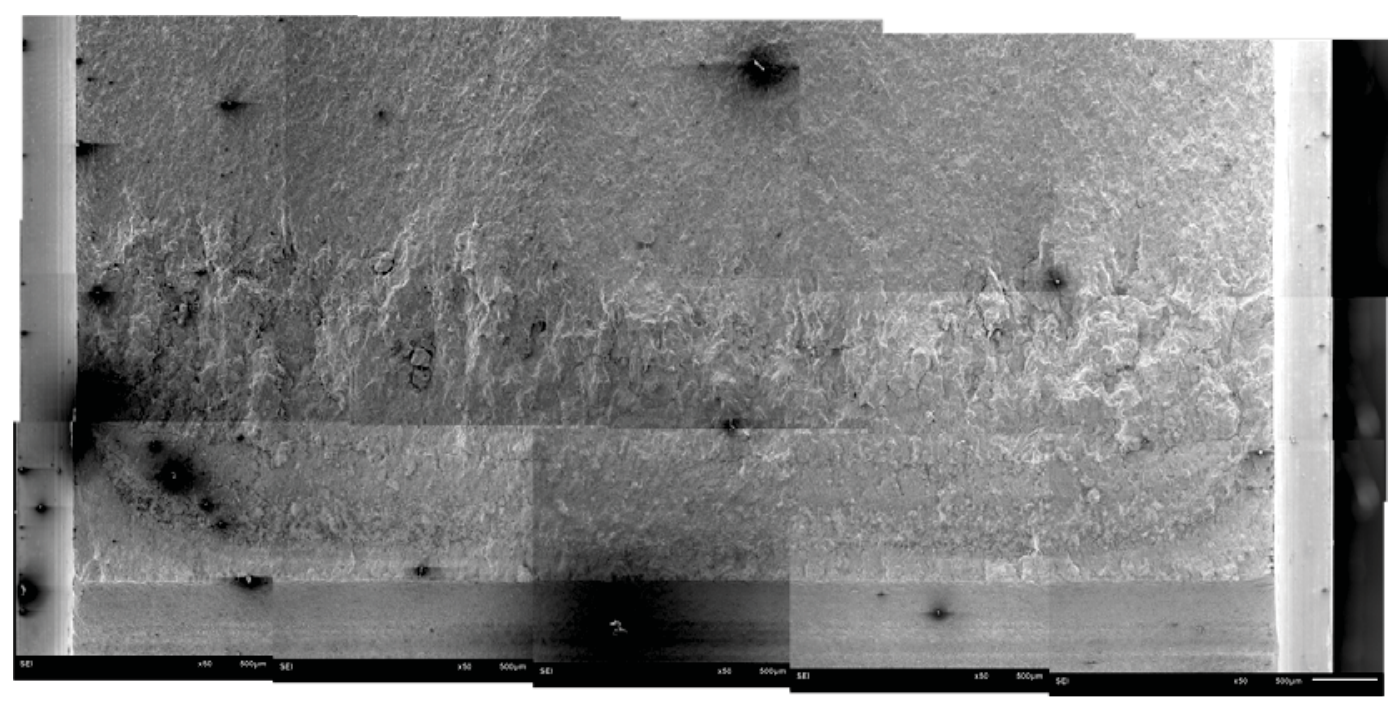

Figure 4-12: SEM micrograph of the fracture surface of sample ID 10A0016 C3 01.

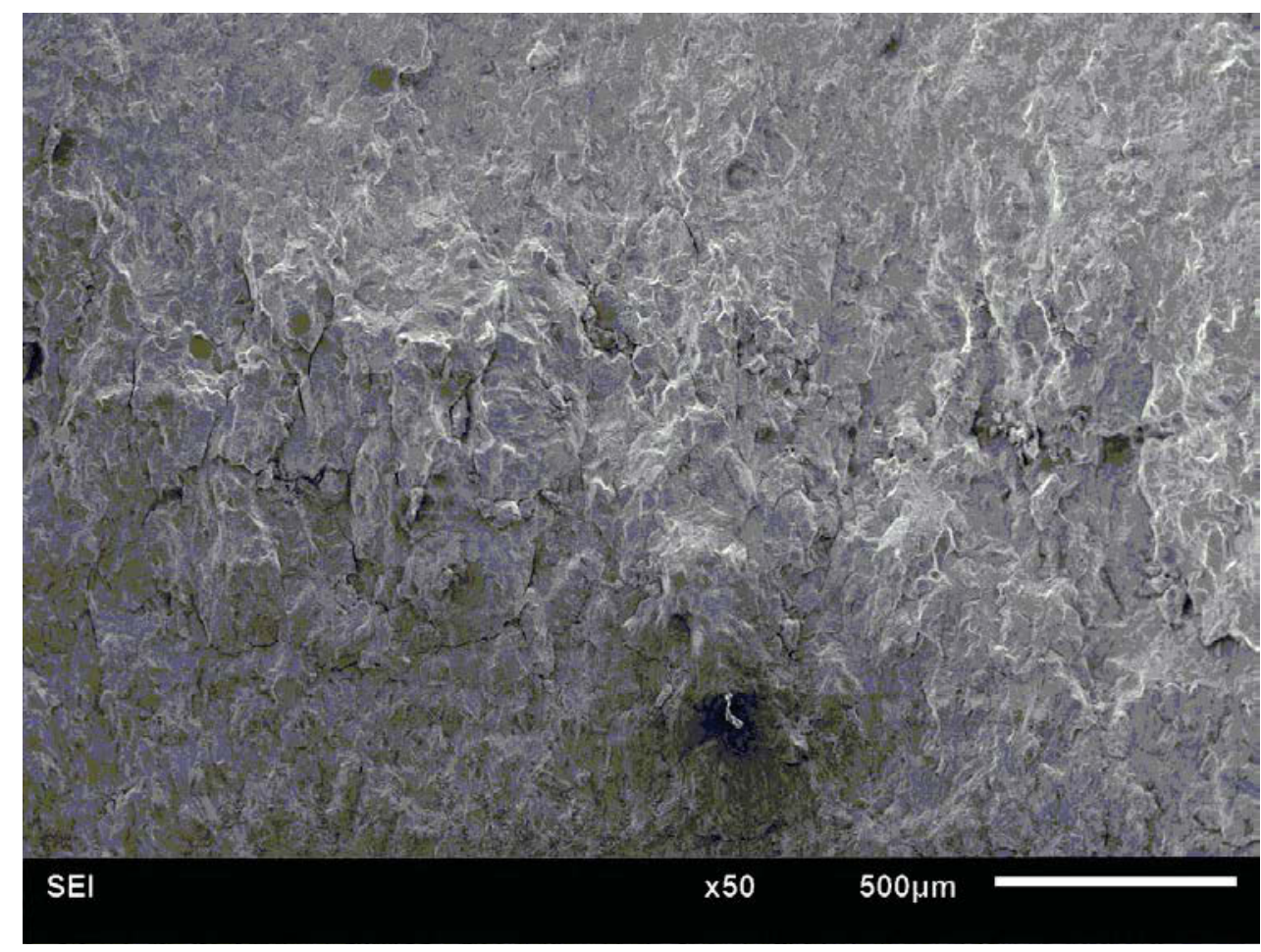

Figure 4-13: Detail of SEM micrograph of the fracture surface of sample ID 10A0016 C3 01.

\section{References}

1. Standard Test Methods for Tension Testing of Metallic Materials. ASTM E 8-04. West Conshohocken, PA : ASTM International, 2004. 
2. Standard test method for measurement of fracture toughness. ASTM E 1820-09. West Conshohocken, PA : ASTM International, 2009.

3. BWRVIP-240: BWR Vessels and Internals Project, Metallurgical Analyses and Macro and Microstructural Mapping of Alloy X-750 and Alloy XM-19 Plates. Palo Alto, CA : EPRI, 2010. 1021003. 4. Mills, W. J. Effect of Temperature on the Fracture Toughness Behavior of Inconel X-750. [ed.] L. N. Gilbertson and R. D. Zipp. Fractography and Materials Science, ASTM STP 733. : American Society for Testing and Materials, 1981, pp. 98-114.

5. Microstructure and SCC of Alloy X-750. Andresen, P. L., et al. [ed.] J. T. Busby, G. Ilevbare and P. L. Andresen. : TMS (The Minerals, Metals \& Materials Society), 2011. Proceedings of the 15th International Conference on Environmental Degradation of Materials in Nuclear Power Systems-Water Reactors.

6. Anderson, T. L. Fracture Mechanics: Fundamentals and Applications. : CRC Press, Inc., 1995. 


\section{Appendix}

\section{A. X-750 Specimen Sectioning and Machining}

Three sections of alloy X-750 that had been removed from a spare upper support bracket (heat number 2750-5-7656) provided by the Southern Co. were provided to INL by GE-GRC. These sections are shown in Figure A-1 and were labeled "A", "C", and "EP". Figure A-2 shows an overall layout of the support bracket from which these sections were cut. Based on discussions between INL and EPRI team members, section "EP" was chosen to be representative of the general microstructure and within reasonable proximity to an area that was recently cracked in service. Additionally, the size of section "EP" allows machining of all required specimens from within the same proximity.
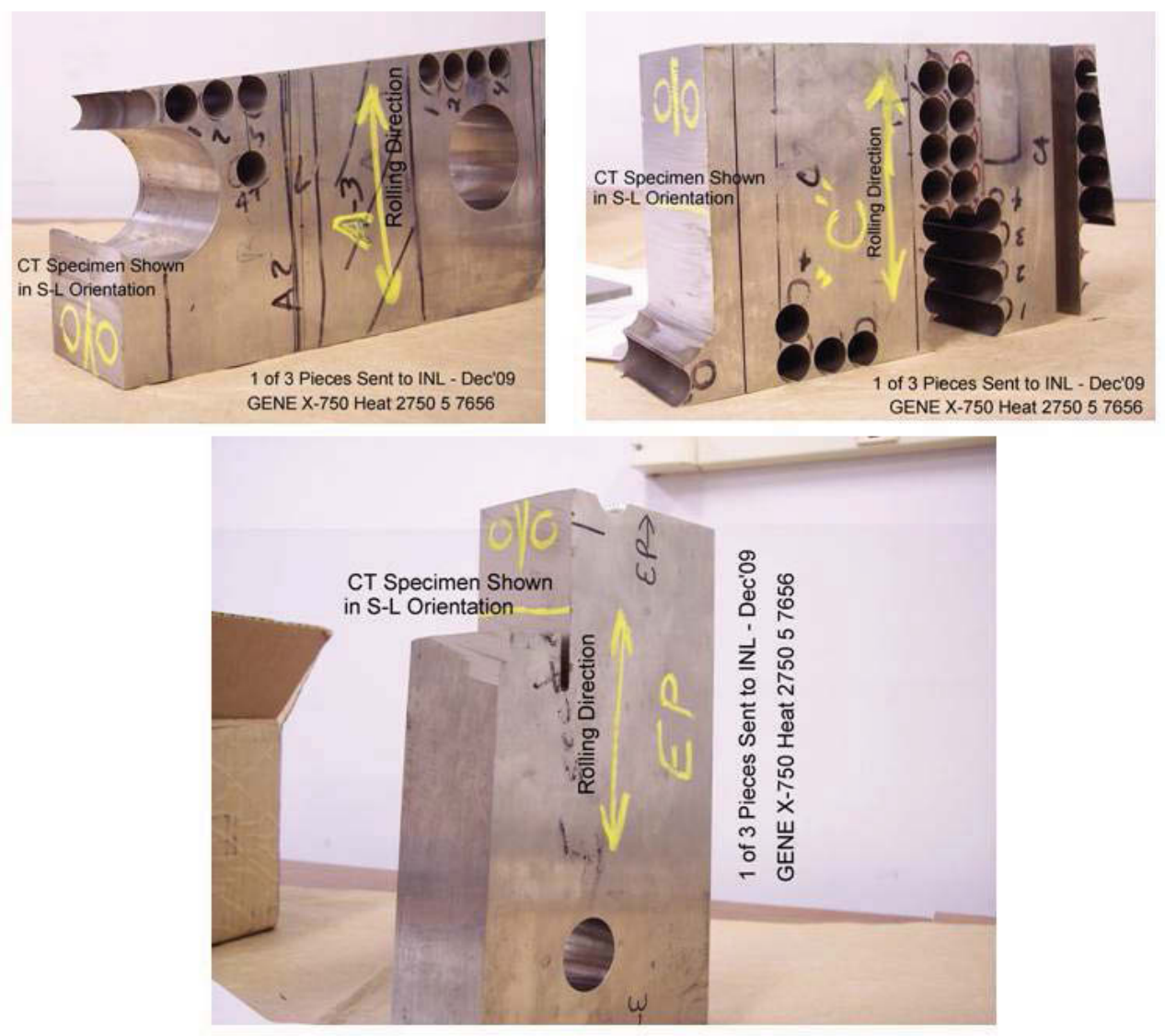

Figure A-1: X-750 sections provided to INL by GE-GRC. 


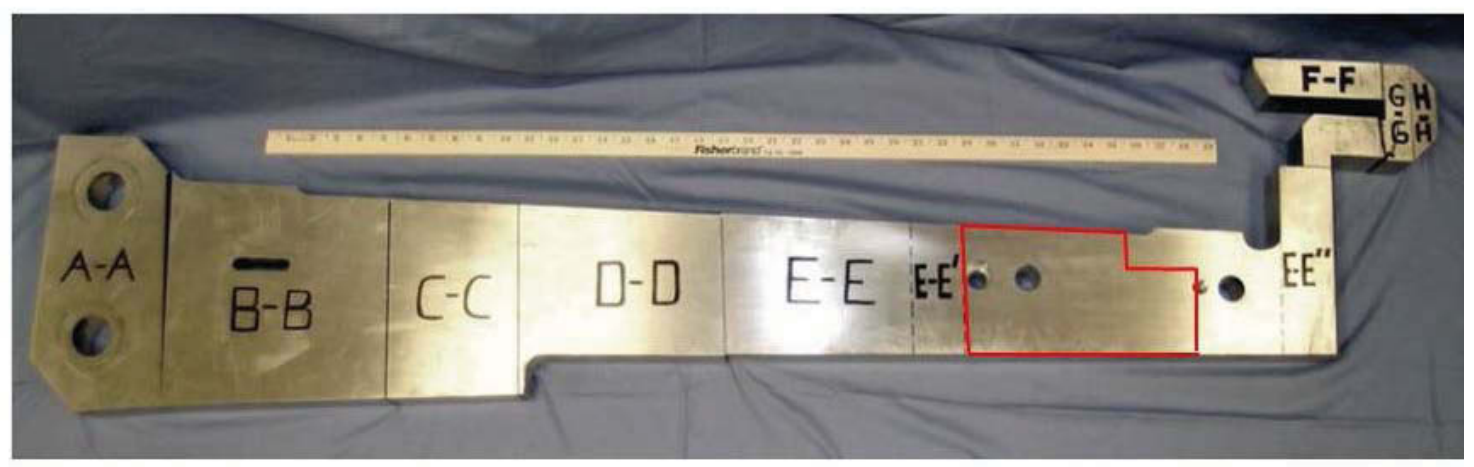

Figure A-2: Support bracket with outline of section "EP".

\section{Specimens to be Used for Alloy X-750 Baseline SCC and IASCC Testing}

In order to establish a baseline comparison between GE-GRC and INL for crack growth rate, two subsections were cut from the end of section EP in the T-L plane such that they would be side by side in the center (S direction) portion of the section. From each of these sections, one T-L orientation specimen and one L-T orientation CT specimen were cut. The GE-GRC specimens were machined by GE-GRC and were sized at 0.5T-CT (1.25 X scaled to the 0.4T-CT INL specimens shown in Figure A-3 and the INL specimens were machined by a subcontractor (Northwest Machine and Manufacturing) and sized at 0.4T-CT with the crack tips in nominally similar locations to those of the GE-GRC 0.5T-CT specimens with respect to the L-T plane. Figure A-4 shows the cutting locations of the subsections with respect to section EP and the outline of specimens as machined from one of these subsections. The two specimens retained by INL were labeled "10A0002 EP B T-L" and "10A0002 EP B L-T". A third specimen, "10A0002 EP B L-T 2" was eventually machined due to an error by the machine shop in production of specimen "10A0002 EP B L-T" in which the specimen was not clamped properly and one of the specimen loading pin holes was destroyed. This third specimen was machined from the center of the subsection from extra material. Specimens "10A0002 EP B L-T 2" and "10A0002 EP B T-L" were designated for SCC testing and specimen "10A0002 EP B L-T" was retained for potential further use. 


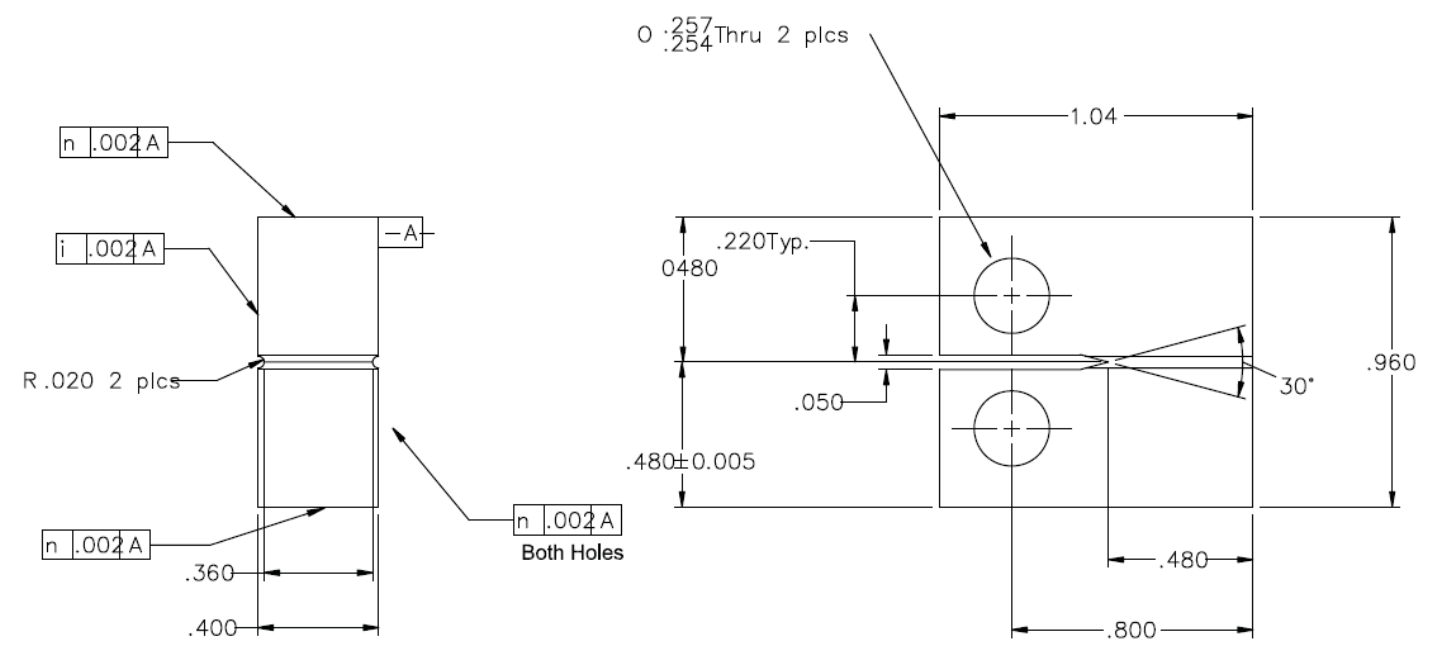

Figure A-3: 0.4T compact tension (CT) specimen used for SCC and IASCC tests (units are inches).



Figure A-4: Initial L-T and T-L orientation specimens and location of S-L specimens.

In addition to the L-T and T-L orientation specimens, two 0.4T-CT specimens were machined from section EP in the S-L orientation as shown in Figure A-4. These specimens were labeled "L", and "R" and are referred to as "10A0002 EP S-L L" and "10A0002 EP S-L R", respectively. Specimen "10A0002 EP S-L R" was used for testing, and "10A0002 EP S-L L" was retained for future use.

Specimens to be used for IASCC were removed from the bulk of section EP and were all machined in the L-T orientation. Figure A-5 shows the scheme for layout and orientation of all of these specimens. 
For the sake of brevity, the "EP" was removed from the naming convention for these specimens. As shown in Figure A-5, approximately $5 \mathrm{~mm}$ was first removed from each surface to avoid any surface processing effects and three rectangular sub-sections were cut through the thickness (S direction) of section EP that were nominally $11.5 \mathrm{~mm}$ (0.45 inches) thick and oriented in the L-T plane; specimen outlines are shown as guidelines for machining. A total of 36, 0.4T-CT specimens were machined from these three sub-sections in the orientations shown (L-T). The naming convention for these specimens is the material identifier "10A0002", followed by a letter designator "A", "B", or "C" and then a number from 1 to 12 . For example, a specimen extracted from subsection "A" at the lower left corner would be labeled "10A0002 A 01" and so on. Of these 36 specimens, 6 from subsection "C", numbered 07-12 were found to be non-conforming based on a dimensional check and were therefore set aside and not used for SCC testing. Three specimens, one from each of the subsections "A", "B", and "C" were retained for unirradiated SCC testing; these three specimens were "10A0002 A 01", "10A0002 B 01", and "10A0002 $\mathrm{C} 01$ ". The remaining 27 specimens were set aside for irradiation and subsequent IASCC and fracture toughness testing..

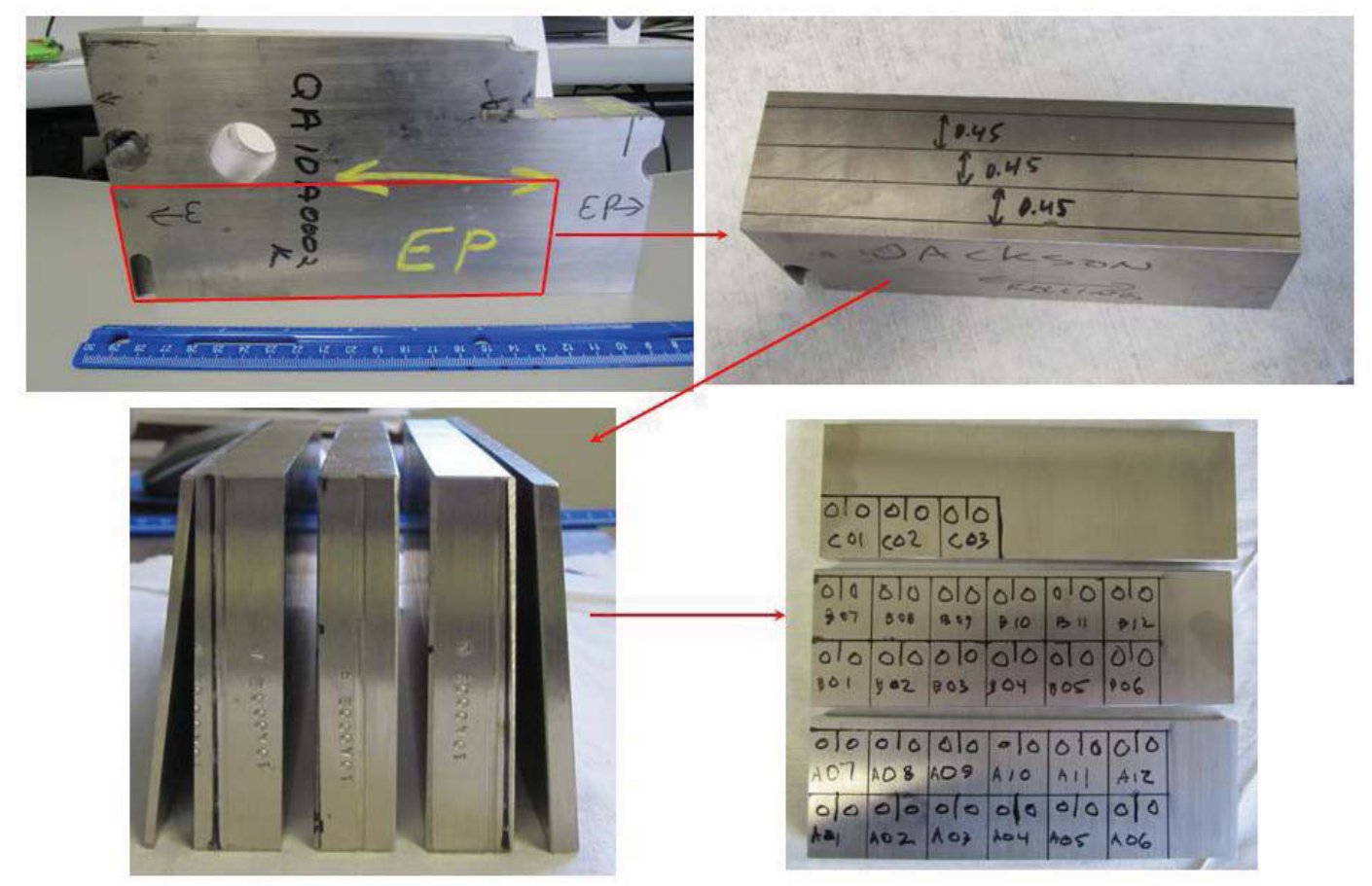

Figure A-5: L-T orientation, alloy X-750 specimens for irradiation.

Specimen "10A0002 EP B T-L" was found to be non-conforming so two additional 0.4T-CT specimens were machined in the T-L orientation for unirradiated SCC testing. Three rectangular sections were machined in the same planes and at the same thicknesses as the sections described in the preceding paragraph. Specimens "10A0002 B13", and "10A0002 B14" were machined from the portion of section $\mathrm{EP}$ as shown in Figure A-6. Sections 10A0002 A, and 10A0002 C from this area were retained for future use. 


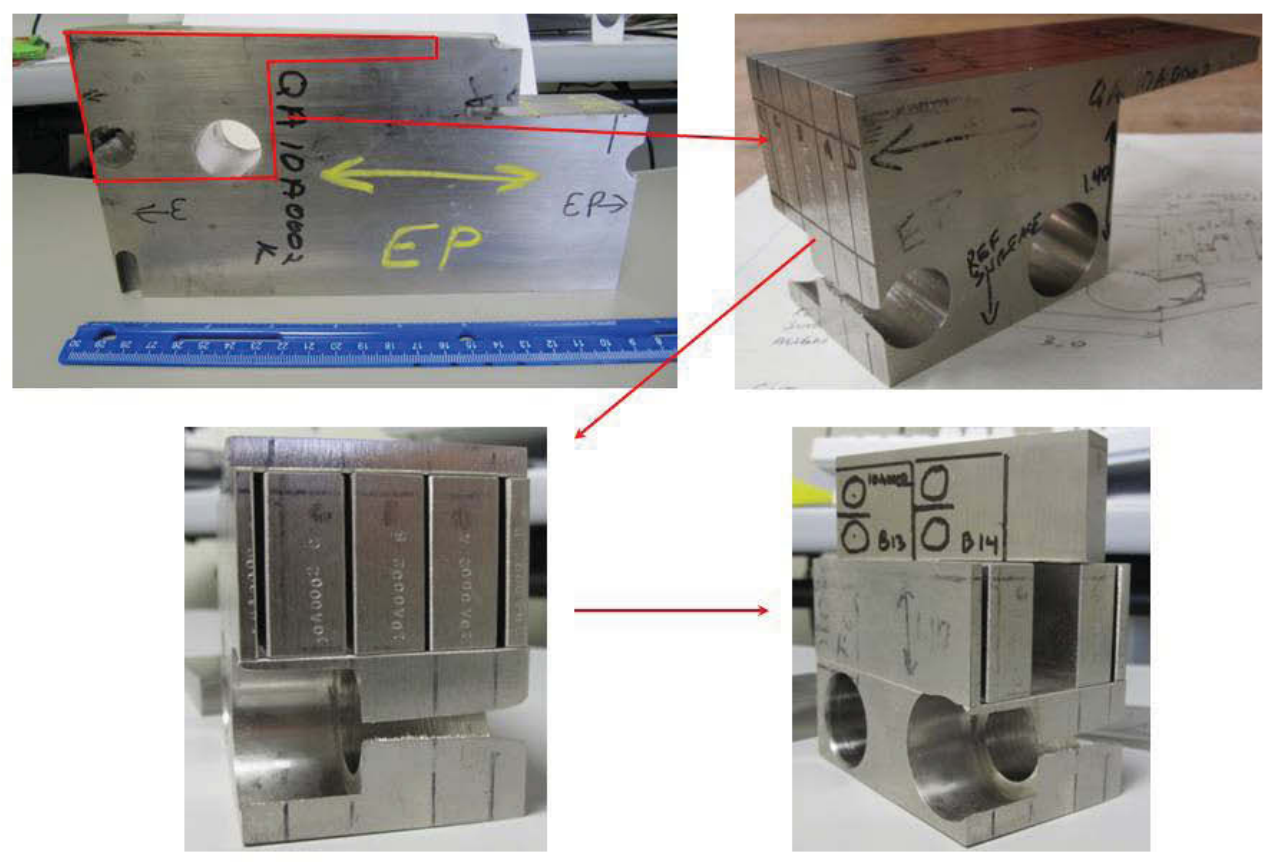

Figure A-6: Machining location for specimens 10 A0002 B13 and B14 in T-L orientation.

\section{Specimens to be Used for Baseline Alloy X-750 Fracture Toughness Testing}

Four alloy X-750 specimens were machined in the L-T orientation for baseline, unirradiated fracture toughness testing. These specimens were $0.5 \mathrm{~T}-\mathrm{CT}$ rather than $0.4 \mathrm{~T}-\mathrm{CT}$ to provide slightly more throughthickness constraint for a J-R test. At the time of machining, little fracture toughness data were available for alloy X-750 in the HTH conditions so specimen size was a bit conservative. Since $\mathrm{J}_{\mathrm{IC}}$ is not dependent on geometry if the specimens meet size standards, this is actually unnecessary and 0.4T-CT specimens would have worked just as well. The four specimens were designated "10A0002 AA 01", "10A0002 AA 02", "10A0002 BB 01", and "10A0002 BB 02". Figure A-7 illustrates the location within section "EP" from which these specimens were extracted. 


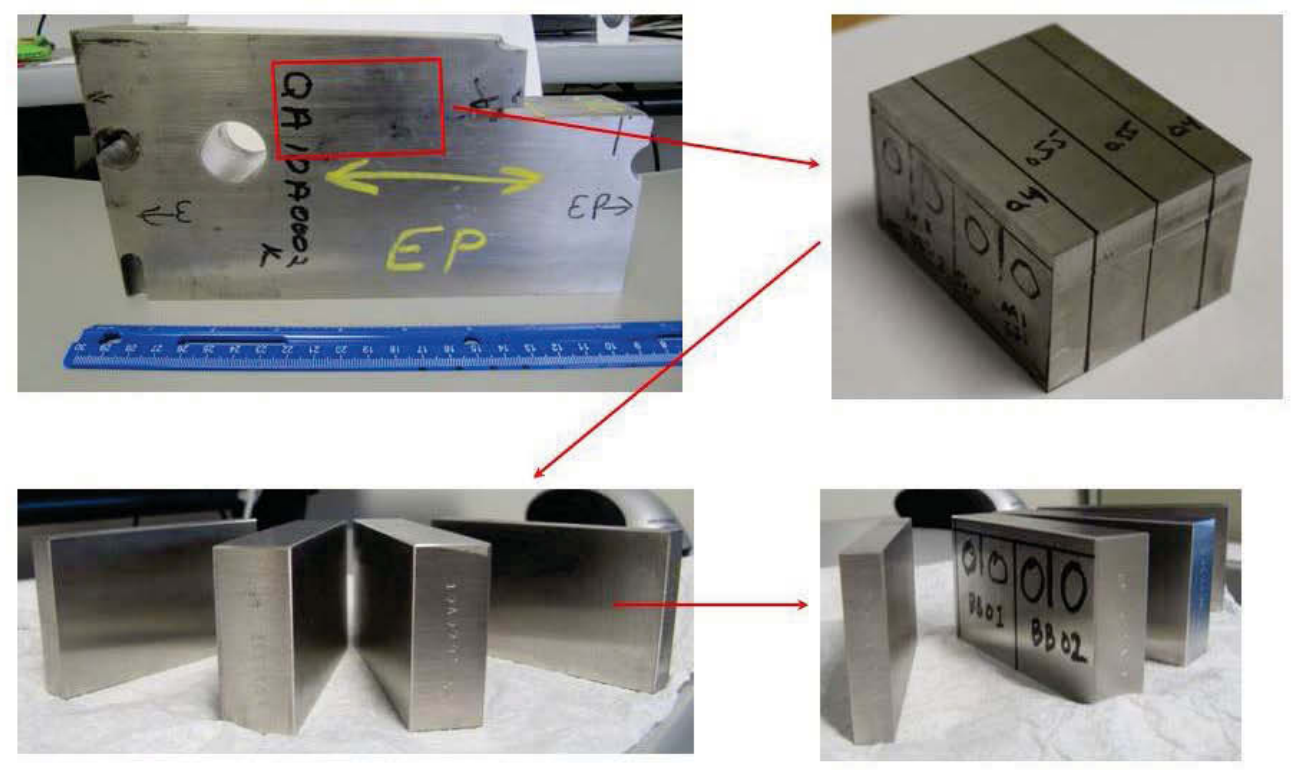

Figure A-7: Location of alloy X-750 fracture toughness specimens in section "EP".

\section{Specimens to be Used for Alloy X-750 Baseline and Irradiated Tensile Testing}

Nine alloy X-750 dogbone tensile specimens were machined with their tensile axis coincident with the L (rolling) direction. The specimen blanks were created by wire Electro Discharge Milling (EDM) cylinders from the block of material that were approximately $82 \mathrm{~mm}$ long and had a nominal diameter of $10 \mathrm{~mm}$. The dogbone tensile specimens were then machined from these cylinders to the final dimensions shown in Figure A-8. Specimen identifiers are "EP1-L3", "EP1-L4", "EP1-L5", "EP1-L6", "EP1-L7", "EP3-L3", "EP3-L4", "EP4-L3", and "EP4-L4". The location of extraction for specimens "EP1-L3", "EP1-L4", "EP3-L3", "EP3-L4", "EP4-L3", and "EP4-L4” from within "EP” is unknown since the cylinders were extracted by GE-Global Research and sent to INL, but the location of specimens "EP1L5", "EP1-L6", "EP1-L7" is shown in Figure A-9 as these three were extracted at INL.
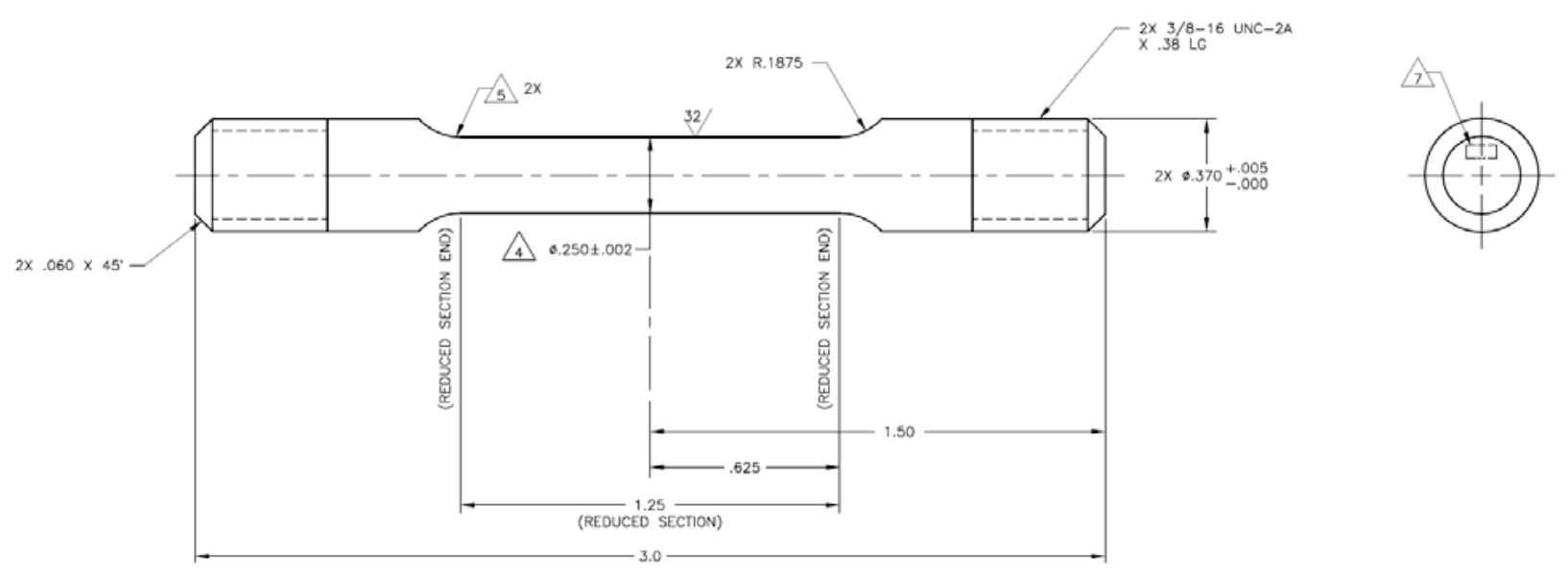

Figure A-8: Sketch of dogbone tensile specimens (units are inches). 


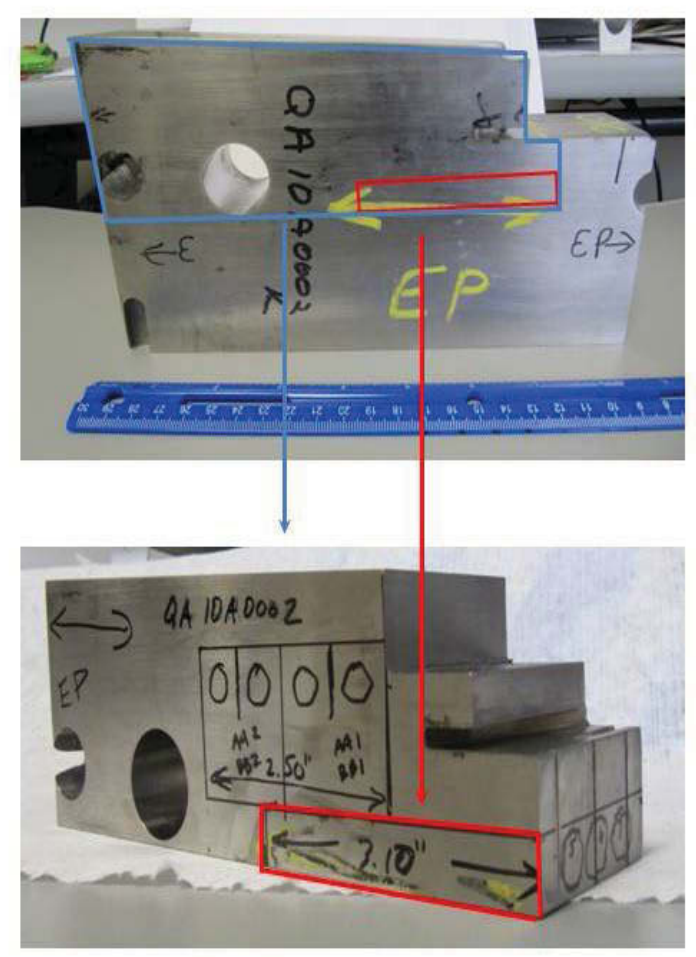

Figure A-9: Location of tensile blanks in alloy X-750 section "EP".

\section{TEM Specimens}

TEM foils were machined from the L-T plane along the edge of specimen 10A0002 C09 (a dimensionally non-conforming specimen) as shown in figure A-10. A thin sheet of material was sliced off of one edge of the specimen in the L-T plane; this sheet was thinned and polished to approximately $0.35 \mathrm{~mm}$ thickness; 14 TEM disks of $3 \mathrm{~mm}$ diameter were then punched from this foil. Twelve of these TEM disks will be placed inside a specimen blank and irradiated. The remaining foils are set aside in case they are needed for baseline studies. 


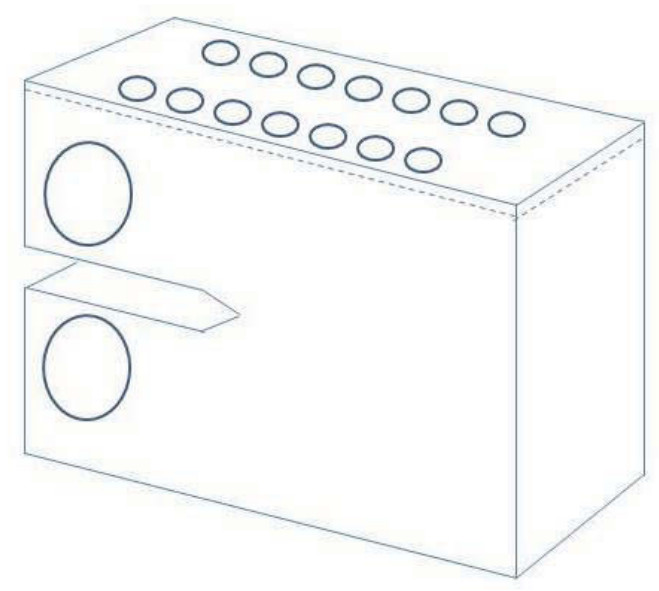

Figure A-10: Fabrication of TEM specimens from CT specimen.

\section{B. XM-19 Specimen Sectioning and Machining}

Alloy XM-19 was provided for this project as two sections from a plate form (Heat number A17509BD3) from GE Global Research who had received the original plate from GE-Hitachi Nuclear. The first section was cut from the plate that was in the "mill annealed" condition; the second section was cut from the mill annealed plate and subsequently cold rolled in the same direction as the original, as-received plate to $19.3 \%$ cold work in two passes using a Birdsboro rolling mill at GE Global Research. The approximate location of the first section, relative to the main plate is shown in figure B-1, outlined in blue. The location within the plate from which the section that was $19.3 \%$ cold worked is unknown but it is known that it was oriented in the same direction as the mill annealed section. Figure B-2 shows the initial rough sectioning of the mill annealed section, and Figure B-3 shows the initial rough sectioning of the $19.3 \%$ cold worked section. 




Figure B-1: Location of INL XM-19 section from within overall plate.
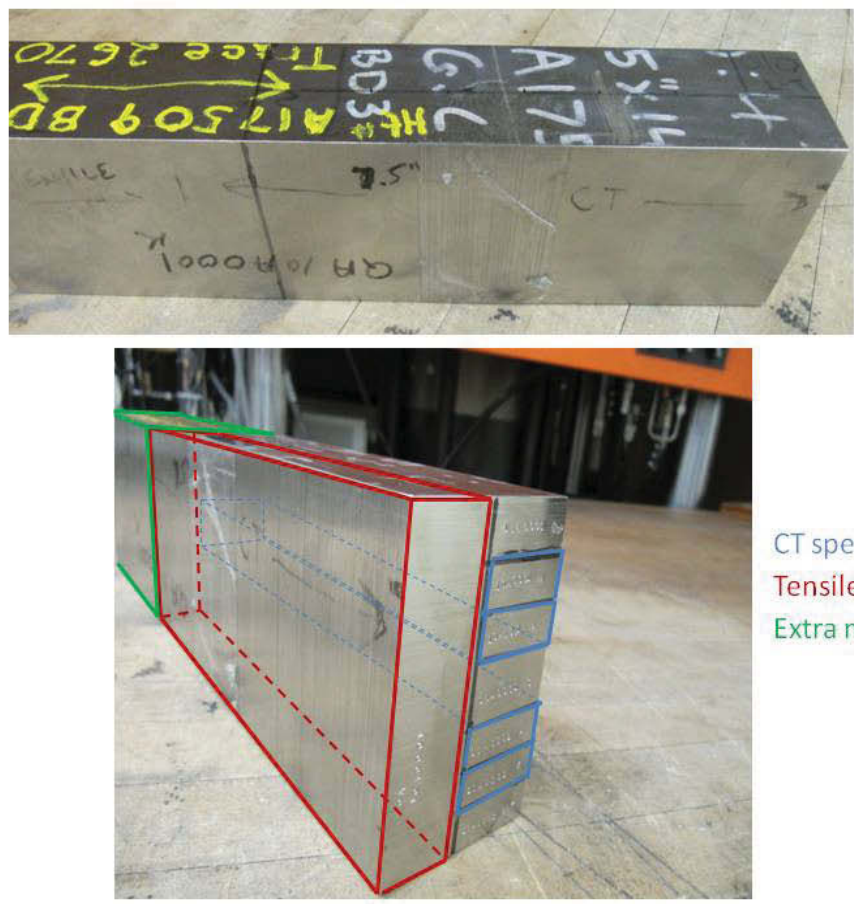

CT specimens Tensile blanks Extra material

Figure B-2: Rough sectioning of mill annealed alloy XM-19 

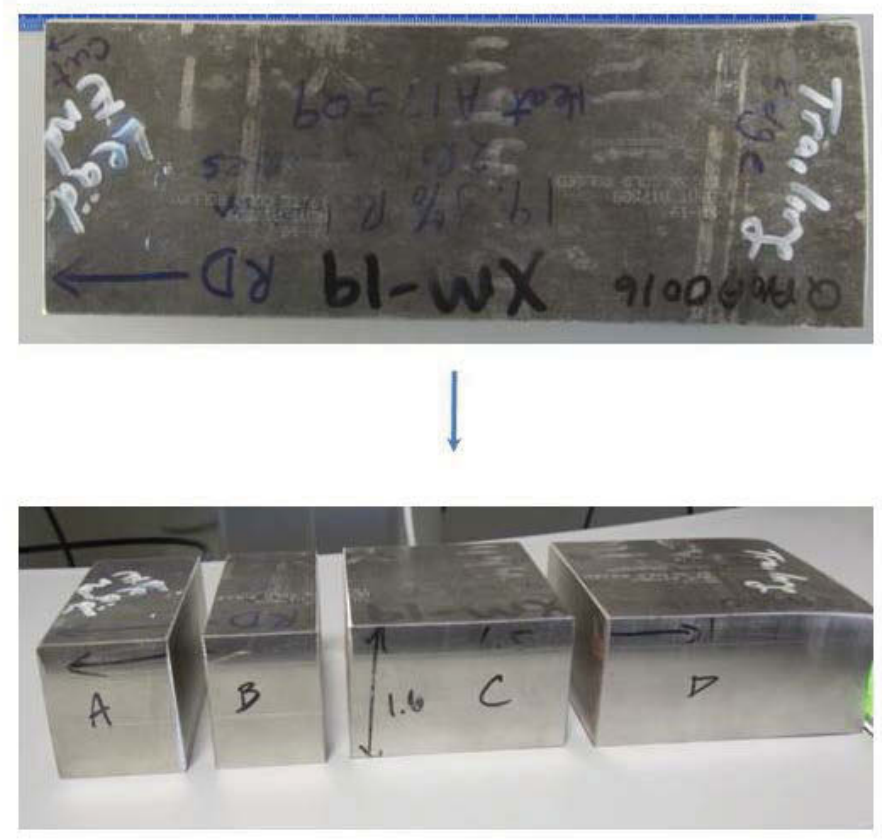

Figure B-3: Rough sectioning of $19.3 \%$ cold worked alloy XM-19

\section{Specimens to be Used for Baseline Alloy XM-19 SCC Testing}

Four, 0.4T-CT specimens (Figure A-3) were machined from the 19.3\% cold worked XM-19 in the L$\mathrm{T}$ orientation to be used for baseline (unirradiated) SCC testing. These specimens were labeled "10A0016 B1 01", "10A0016 B1 02", "10A0016 B2 01", and "10A0016 B2 02". During a receipt inspection, it was discovered that all four of these specimens were non-conforming with a notch tip approximately $0.25 \mathrm{~mm}$ off center. As a consequence, four additional 0.4T-CT specimens were machined from sections $\mathrm{C} 3$ and C4 and were labeled "10A0016 C3 01", "10A0016 C3 02", "10A0016 C4 01", and "10A0016 C4 02". These replacement specimens were used for the SCC testing of alloy XM-19 in this project. Figure B4shows the location from which these specimens were machined within the $19.3 \%$ cold worked alloy XM-19 section. The lower left hand picture depicts the sectioning of subsection " $\mathrm{B}$ " and the two lower right hand pictures depict the sectioning of subsection " $\mathrm{C}$ ". 




Figure B-4: Baseline SCC specimen extraction from 19.3\% cold worked alloy XM-19

\section{Specimens to be Used for Baseline Alloy XM-19 Fracture Toughness Testing}

Four 0.5T-CT specimens (scaled to Figure A-3) were machined from portion "A" of the 19.3\% cold worked alloy XM-19 section to be used to characterize the fracture toughness of the alloy in this condition. The specimens were machined in the L-T orientation as shown in Figure B-5. These specimens are labeled "10A0016 A1 01", "10A0016 A1 02", "10A0016 A2 01", and "10A0016 A2 02". 


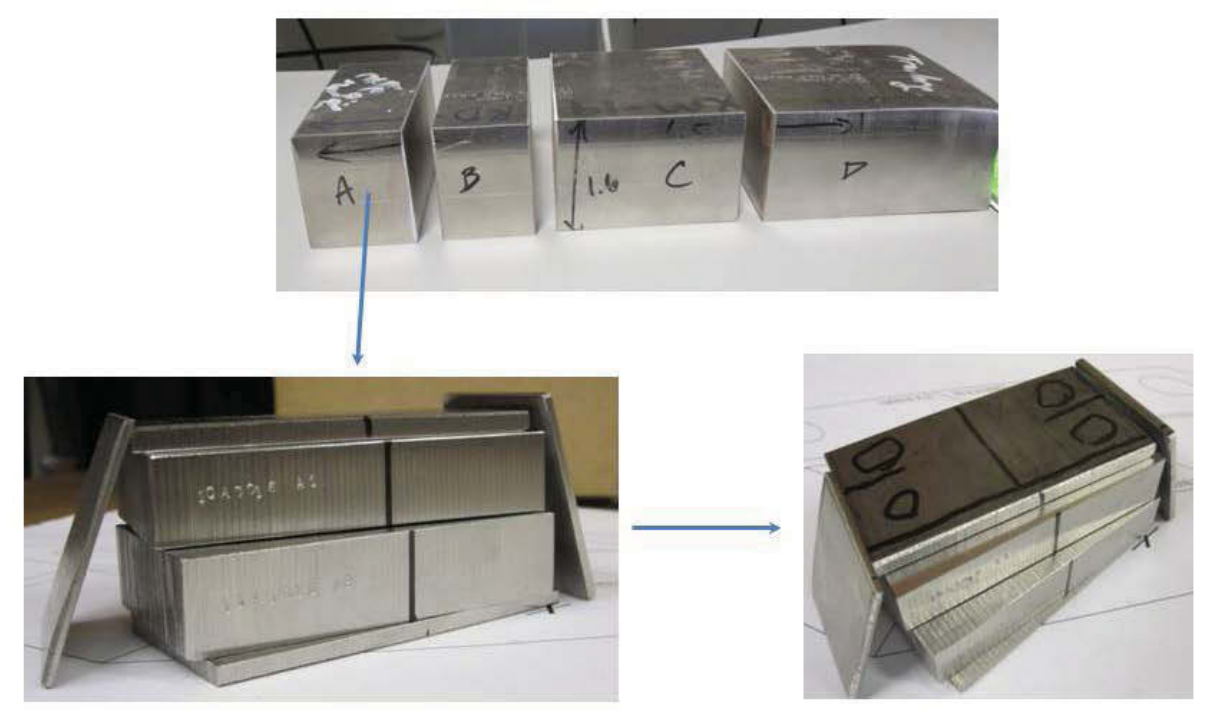

Figure B-5: Baseline fracture toughness specimen extraction for 19.3\% cold worked alloy XM-19

\section{Specimens to be Used for Baseline Alloy XM-19 Tensile Testing}

Four alloy XM-19 dogbone tensile specimens were machined from portion " $\mathrm{D}$ " of the $19.3 \%$ cold worked alloy XM-19 section with their tensile axis coincident with the L (rolling) direction. The specimen blanks were created by wire Electro Discharge Milling (EDM) cylinders from the block of material that were approximately $82 \mathrm{~mm}$ long and had a nominal diameter of $10 \mathrm{~mm}$. The dogbone tensile specimens were then machined from these cylinders to the final dimensions shown in Figure A-8. Specimen identifiers are "XM-19 CW01", "XM-19 CW02", "XM-19 CW03", and "XM-19 CW04". Figure B-6 illustrates the extraction of specimen blanks from within portion " $D$ " of the $19.3 \%$ cold worked alloy XM-19 section. 


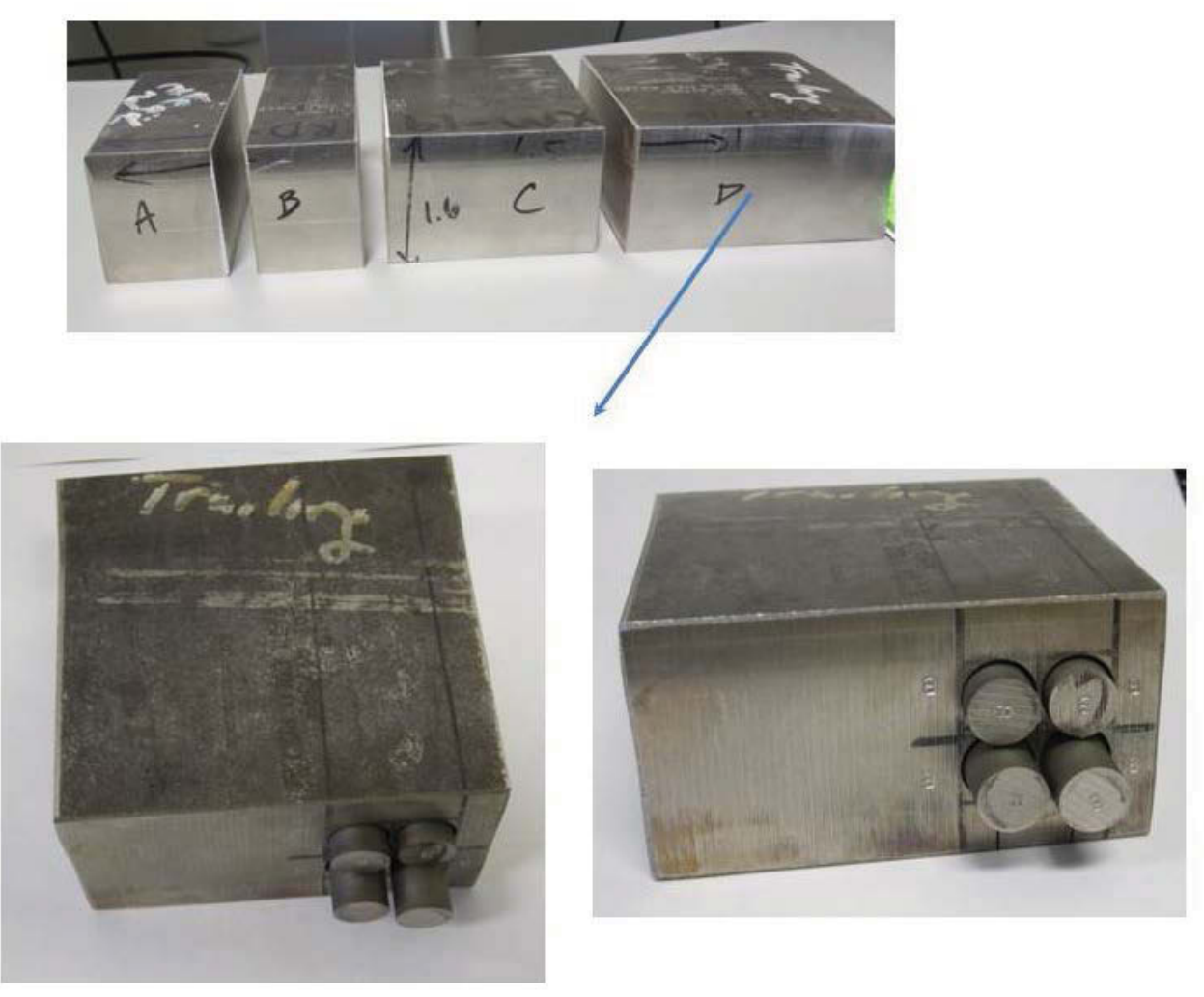

Figure B-6: Baseline tensile specimen extraction for 19.3\% cold worked alloy XM-19

\section{Specimens to be used for alloy XM-19 IASCC testing and irradiated fracture toughness}

Twenty eight $0.4 \mathrm{~T}-\mathrm{CT}$ specimens (Figure A-3) were machined from four sub-sections shown in Figure B-7 in the L-T orientation. The naming convention for these specimens is the material identifier "10A0001", followed by a letter designator "A", "B", "D", or "E" and then a number from 1 to 7 . For example, a specimen extracted from subsection "A" at the lower left corner would be labeled "10A0001 A 01" and so on. Specimen "10A0001 A 01" was set aside to be used to manufacture TEM foils for irradiation, and specimens "10A0001 E 05", "10A0001 E 06", and "10A0001 E 07" were set aside for modification to contain pre-made TEM foils for irradiation. Figure B-7 shows the layout and location of these specimens, relative to the original section received by INL. 


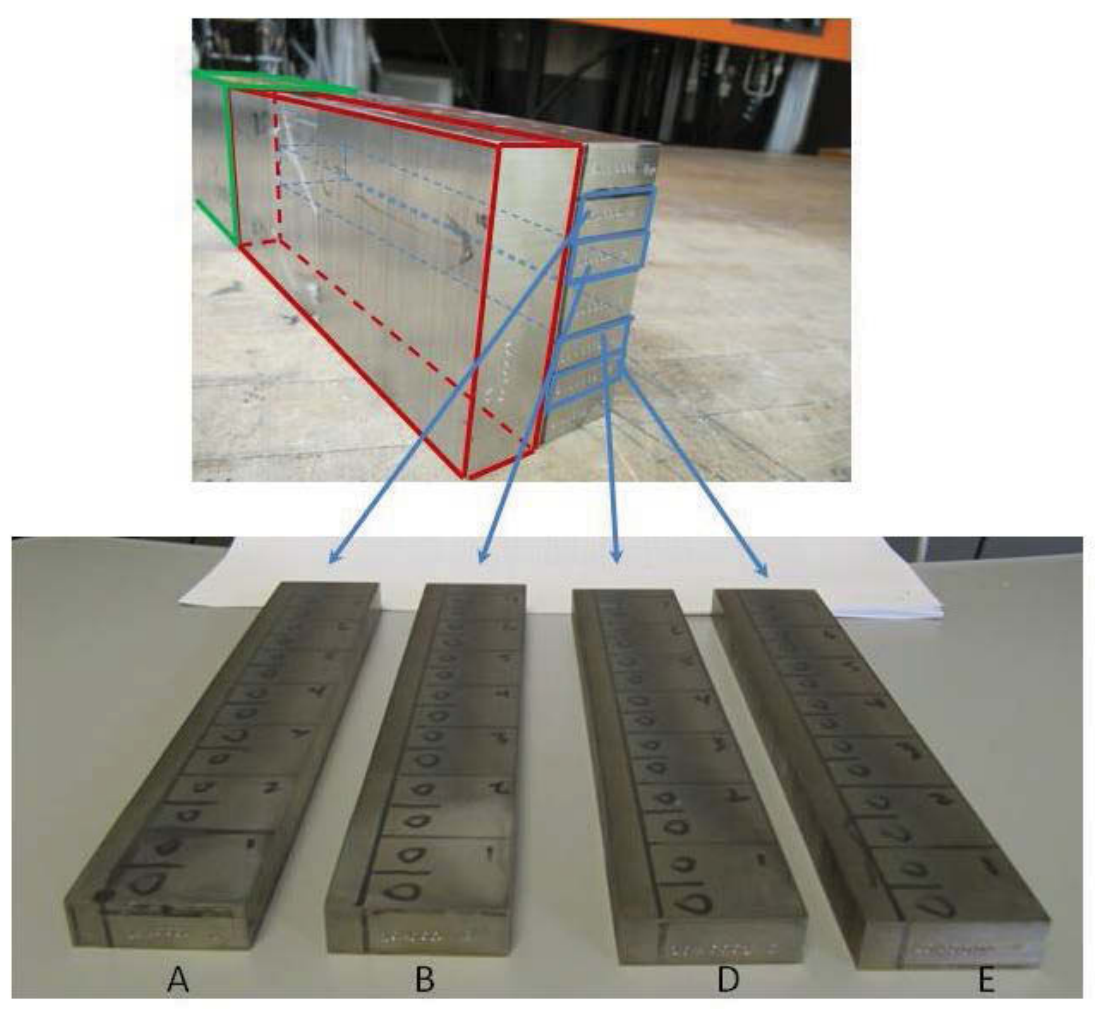

Figure B-7: Layout and location of alloy XM-19 IASCC and irradiated fracture specimens

\section{Specimens to be Used for Irradiated Alloy XM-19 Tensile Testing}

Six alloy XM-19 dogbone tensile specimens were machined from the mill annealed alloy XM-19 section with their tensile axis coincident with the L (rolling) direction. Specimen blanks were created by wire Electro Discharge Milling (EDM) cylinders from two rectangular blocks of material that were removed from the main mill annealed section as shown outlined in red ink Figure B-8. The blanks were approximately $82 \mathrm{~mm}$ long and had a nominal diameter of $10 \mathrm{~mm}$. The dogbone tensile specimens were then machined from these cylinders to the final dimensions shown in Figure A-8. Specimen identifiers are "XM-19 01", "XM-19 02", "XM-19 03", "XM-19 04", "XM-19 05" and "XM-19 CW06". Figure B8 illustrates the extraction of specimen blanks from within the mill annealed alloy XM-19 section. There are two extra specimen blanks that were not machined into dogbone tensile specimens and are retained for future use. 

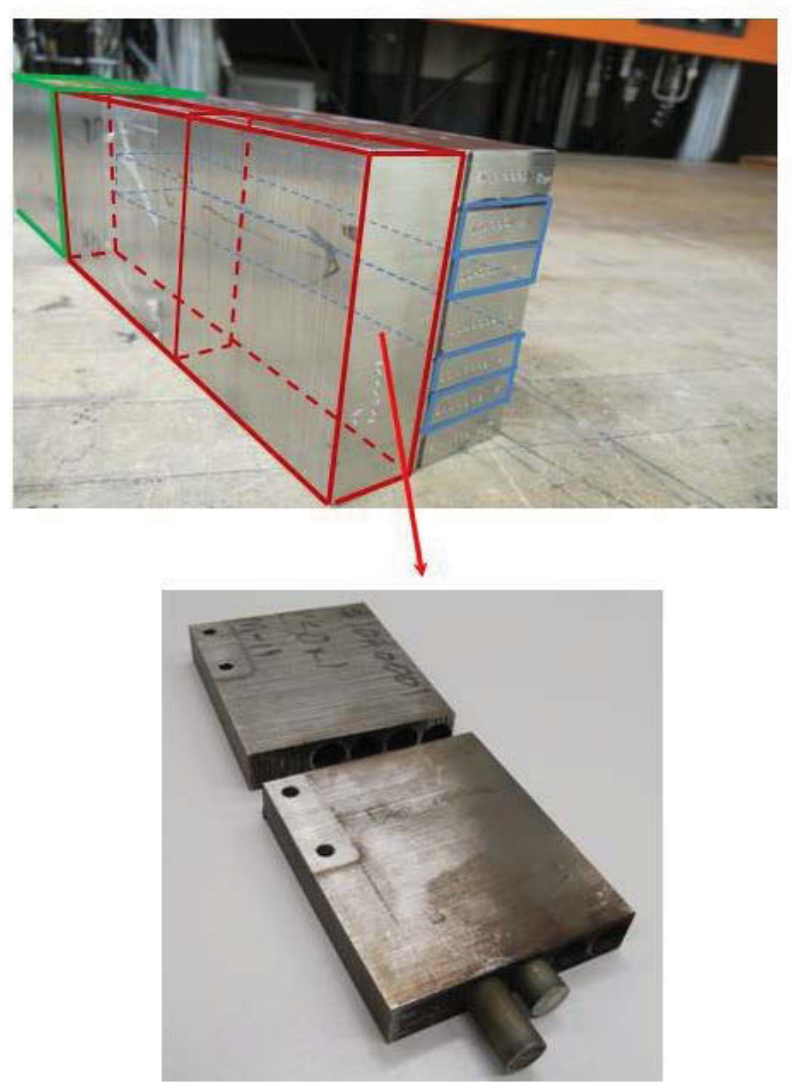

Figure B-8: Extraction of alloy XM-19 tensile blanks for irradiation

\section{Alloy XM-19 TEM Specimens for Irradiation}

TEM foils were machined from the L-T plane along the edge of specimen 10A0001 A 01 as shown in figure A-10. A thin sheet of material was sliced off of one edge of the specimen in the L-T plane; this sheet was thinned and polished to approximately $0.35 \mathrm{~mm}$ thickness; 14 TEM disks of $3 \mathrm{~mm}$ diameter were then punched from this foil. Twelve of these TEM disks will be placed inside a specimen blank and irradiated.The remaining foils are set aside in case they are needed for baseline studies. 
C. Material certifications

$\because 2005$ C0:43 FAX $8183828724 \quad$ HIGH TEMP METALS, INC. Th002
FEB 27 ,06 12:58PM

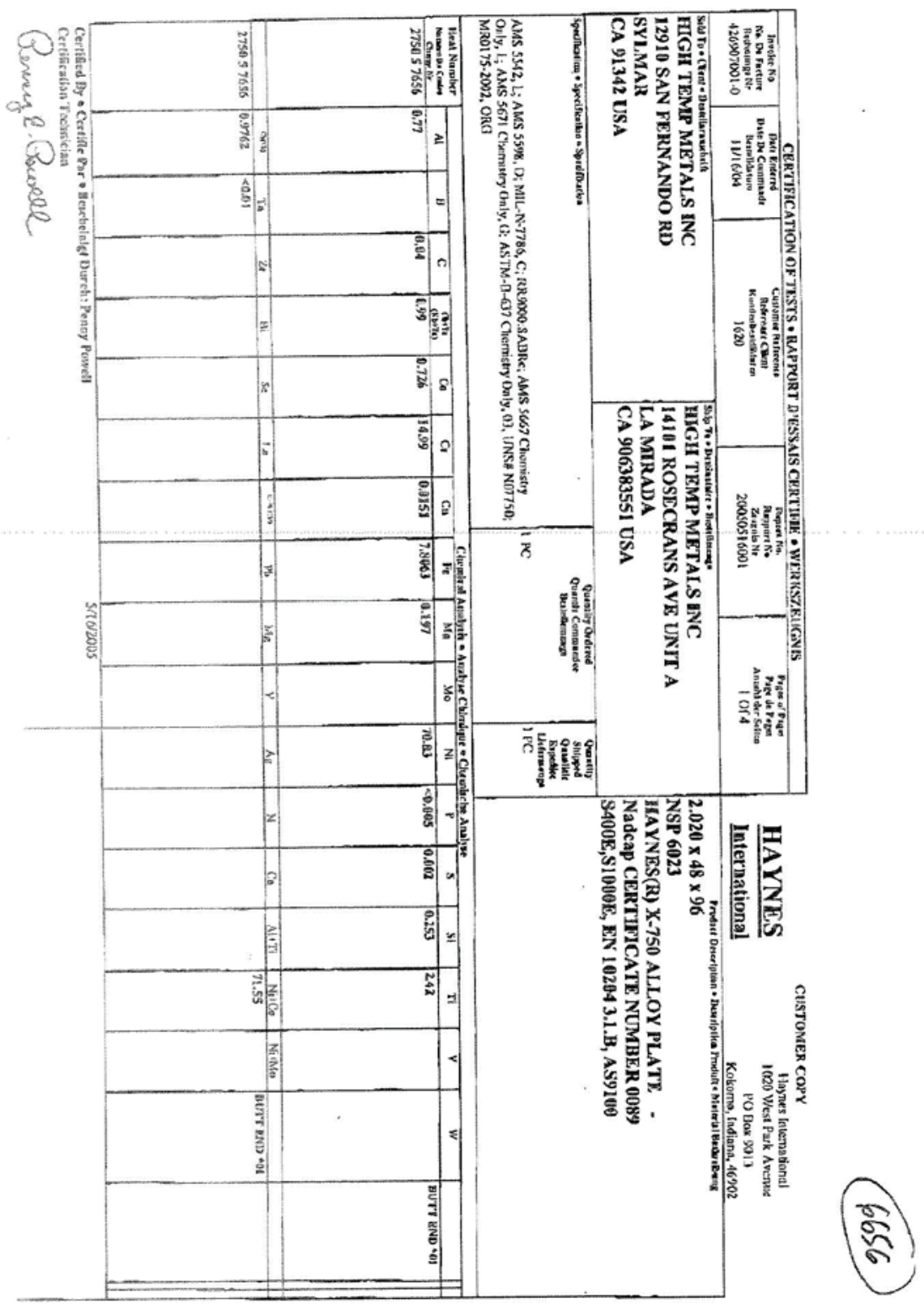

Figure C-1: Page 1 of alloy X-750 material certification report (excluding fax cover). 


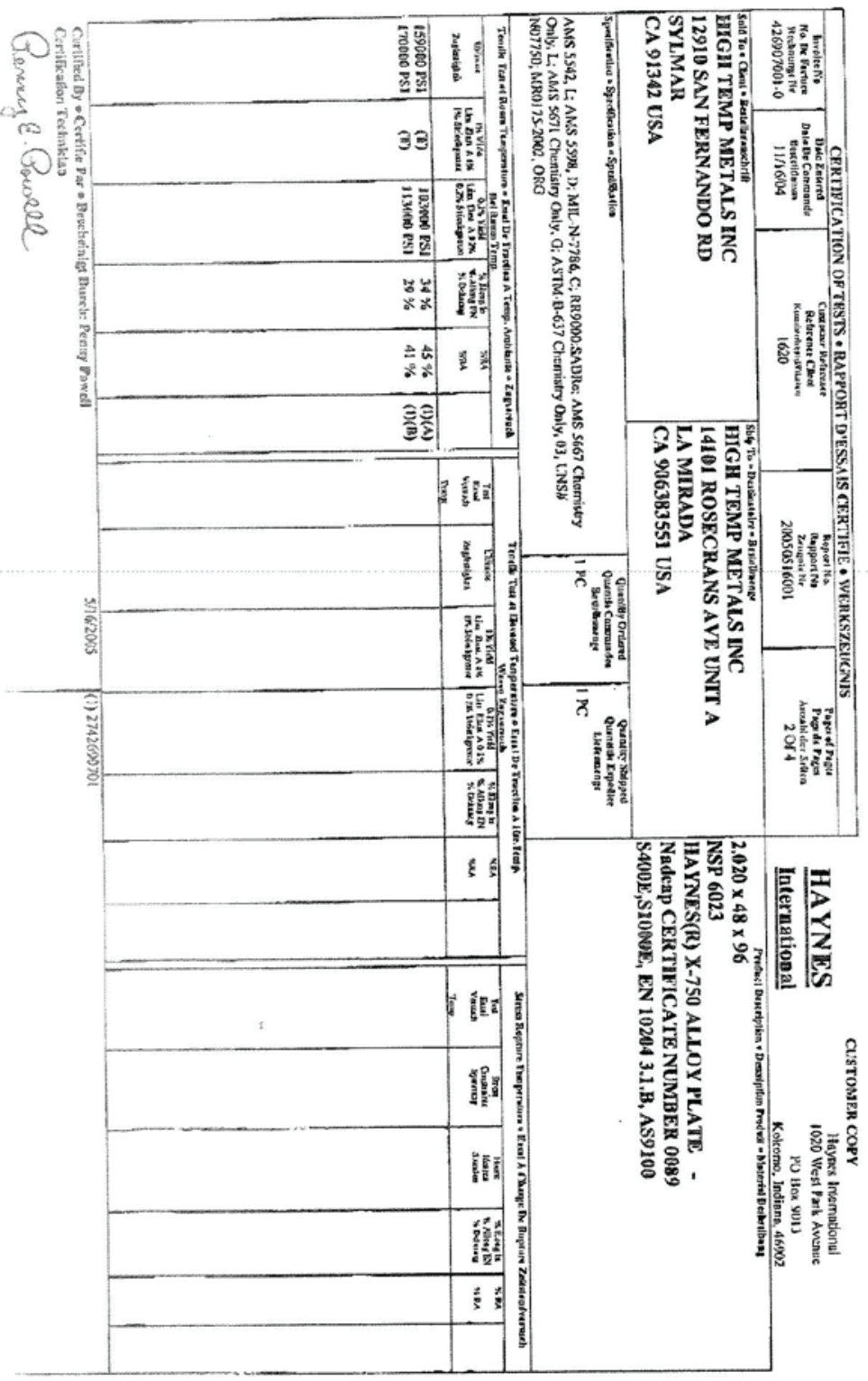

Figure C-2: Page 2 of alloy X-750 material certification report. 


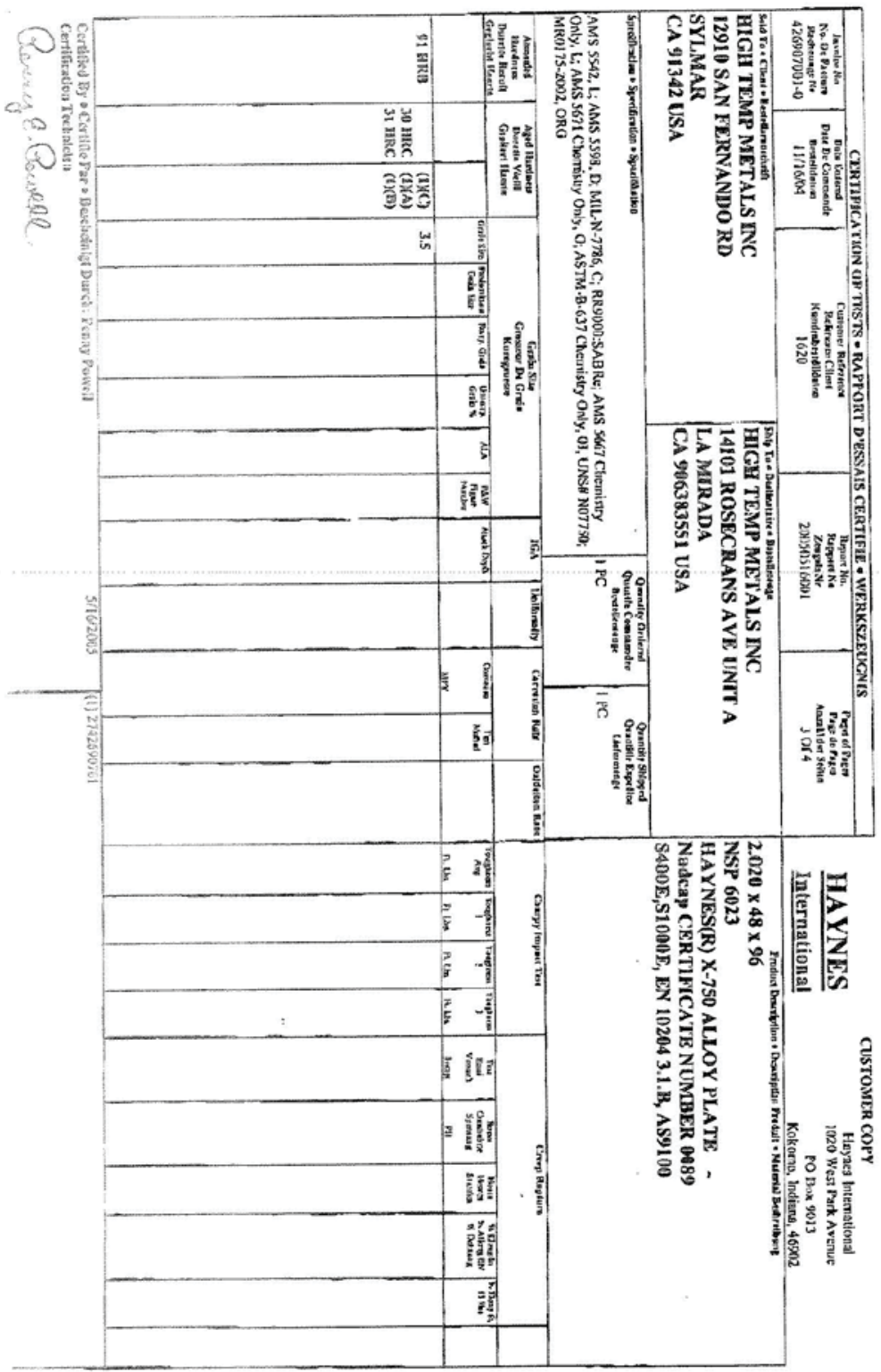

Figure C-3: Page 3 of alloy X-750 material certification report. 


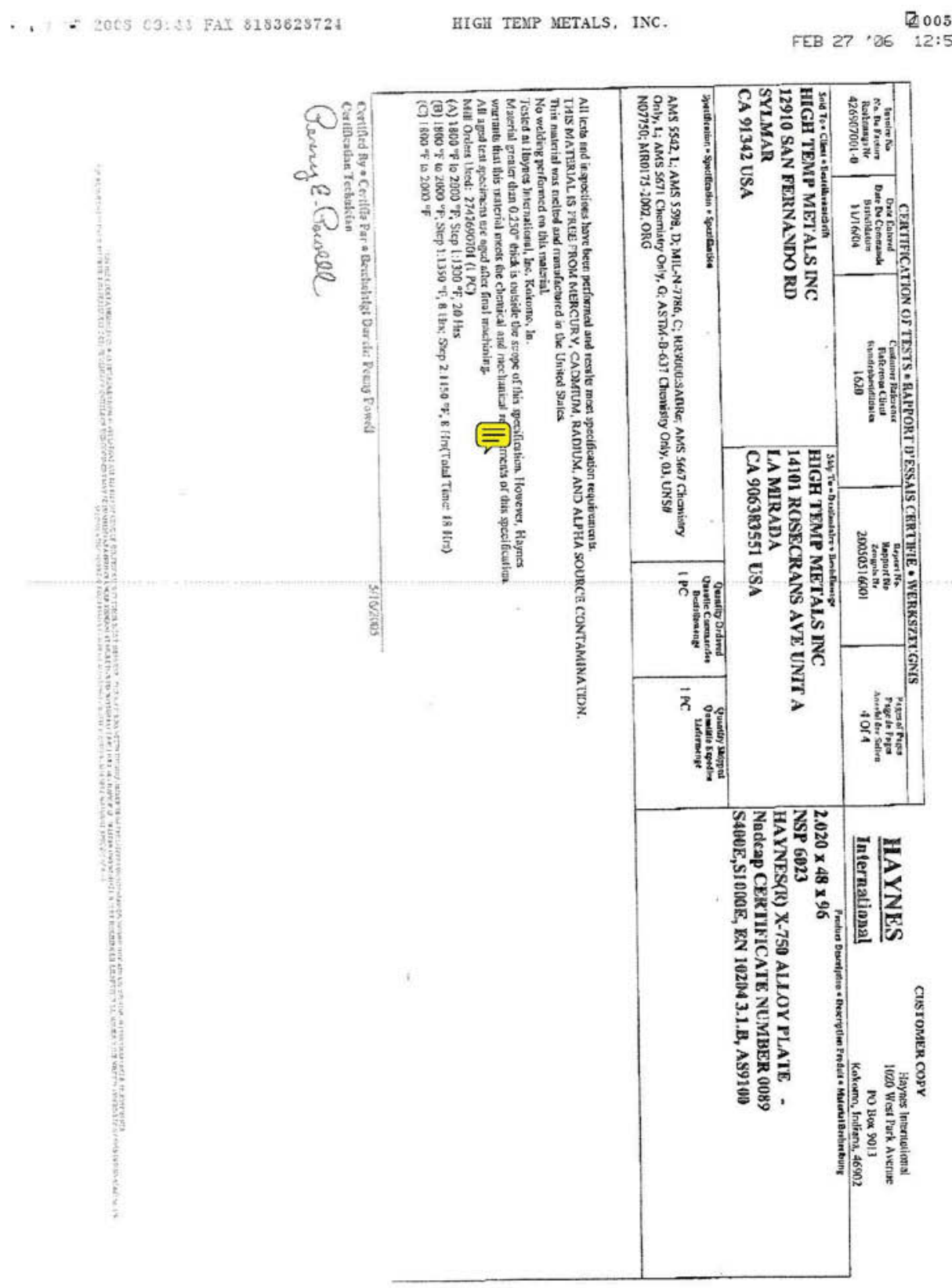

Figure C-4: Page 4 of alloy X-750 material certification report. 


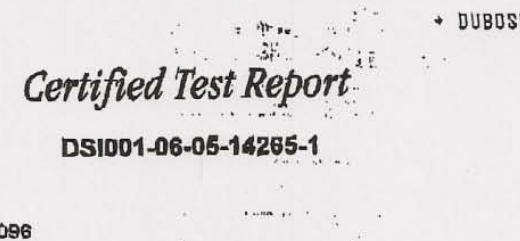

SHIP TO

Dubose National Energy Sves. 900 Industrial Drive

P.O. Box 498

Clinton; NC 28328

ATTN: Q. A.

\section{CERTIFICATION DATE \\ $5 / 3.1 / 2000$}

\section{CUSTOMER P.O.}

$61526-81$

\section{DESCRIPTIÉN}

Forged Bars, ASME Section III, Subsection NB, Class 1, 2001 Edition, 2003 Addenda, ASME SA-182, Grade FXM-19, ASME SA-479, XM-19, G.E. Spec. 26A6480, Rev, 2, Tables E-1-Z, E-2-Z, E-1-X and E-2-X,

G.E. Spec. 26A5733, Rev, 5, Tables H-Y äjd H-W, Nitronic 50:

$1 \mathrm{pe}$.

$4^{\prime \prime} \times 14^{\prime \prime}$, Heat \#A17509; BD1, Trace, \#26699.

1 pc. $\quad 5 " \times 14^{\prime \prime}$, Heat \#A17509, BD2, Trace \#26700

1 pc. $\quad 3^{\prime \prime} \times 14^{\prime \prime}$, Heat \#A17509, BD3,-Trace \#26701

Reference: Customer - General Electric. Nucl. En. PO\#GE, DC \#011111, Vendor - Press Forge, PO \#60742-65

$$
\text { at? }
$$

Three piaces of the referenced samples were submitted to chemical content evaluation and (3) pieces were found to be in conformance to ASME SA-182, Grade FXM-19, ASME SA 479, XM-19, 2001 Edition, 2003 Addenda, G.E. Spec. 26 A6480; ; Rev. 2-Tables E-1-Z, E-2-Z, E-1-X and E-2-X, and G.E. Spec. 26A5733, Rev. 5, Tables H.Y and H-W, Nitronic. 50 . with the following results:

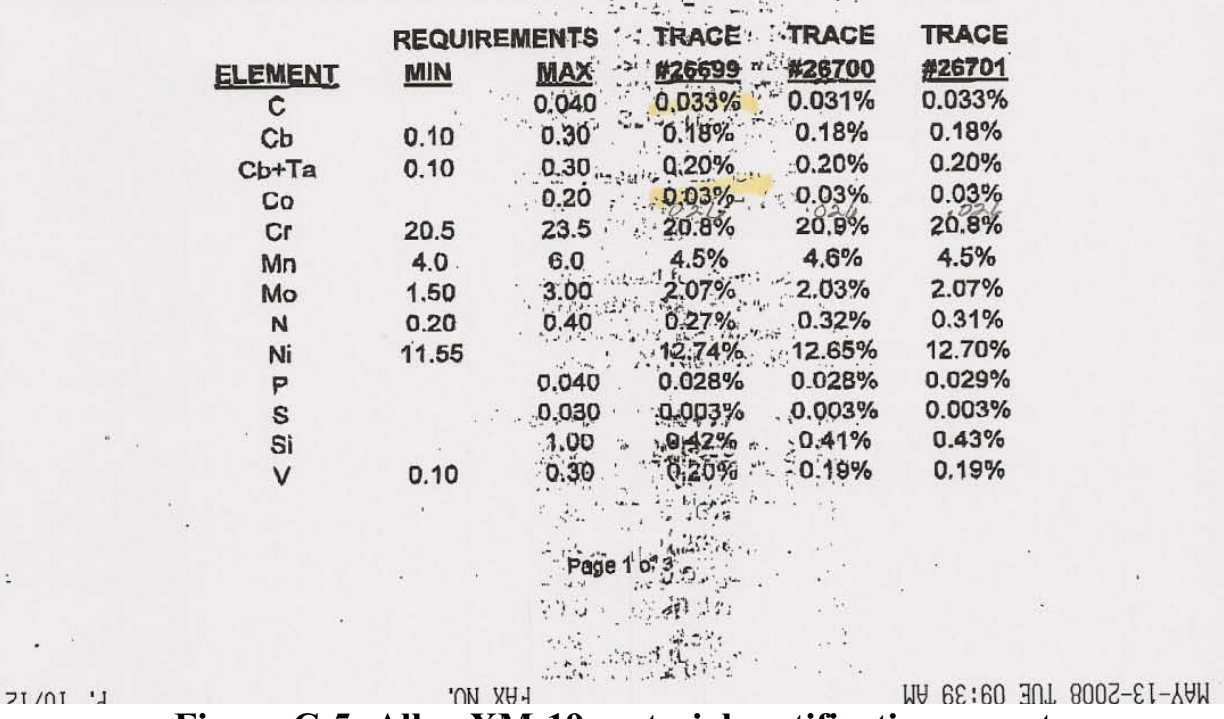

Figure C-5: Alloy XM-19 material certification report. 